\title{
SERGIO MORELLI
}

\section{GESTÃO DE CUSTOS EM PROJETOS}

UMA APLICAÇÃO PRÁTICA DO USO DO EVMS 


\section{SERGIO MORELLI}

GESTÃO DE CUSTOS EM PROJETOS

UMA APLICAÇÃO PRÁTICA DO USO DO EVMS

Dissertação apresentada à Escola

Politécnica da Universidade de São Paulo

para obtenção do Título de Mestre em

Engenharia

Área de Concentração:

Engenharia Naval e Oceânica

Orientador:

Prof. Dr. Oscar Brito Augusto 
Este exemplar foi revisado e alterado em relação à versão original, sob responsabilidade única do autor e com a anuência de seu orientador.

São Paulo, 07 de março de 2007.

Assinatura do autor

Assinatura do orientador

FICHA CATALOGRÁFICA

Morelli, Sergio

Gestão de custos em projeto, uma aplicação do uso do EVMS / S. Morelli. -- ed. rev. -- São Paulo, 2007. p.97

Dissertação (Mestrado) - Escola Politécnica da Universidade de São Paulo. Departamento de Engenharia Naval e Oceânica.

1.Administração de projetos 2.Administração de custos 3.Earned Value (EVMS) I.Universidade de São Paulo. Escola Politécnica. Departamento de Engenharia Naval e Oceânica II.t. 


\section{AGRADECIMENTOS}

Ao Coordenador do Curso de Gestão de Projetos Prof. Dr. Bernardo L.R de Andrade, pela oportunidade, sua dedicação e influência.

Ao meu orientador Prof. Dr. Oscar Brito Augusto, pelo apoio, orientações e permanente incentivo para a realização deste trabalho, compartilhando suas reflexões e idéias e possibilitando assim o aperfeiçoamento técnico-especializado.

A todos os meus amigos de trabalho, que me incentivaram e participaram deste trabalho com suas sugestões, idéias e críticas, e que sempre me apoiaram e continuam a me incentivar a atingir os meus objetivos.

À minha esposa Dumara e aos meus filhos Milena, Gilberto e Marcio e ao meu genro Marcio Monteiro que, nestes dois últimos anos tiveram a paciência e compreensão da minha pouca participação em suas vidas. 


\section{RESUMO}

O aprofundamento do processo de globalização mundial cada vez mais em evidência gera, dentre inúmeros outros fatores, o aumento da competitividade entre empresas e setores econômicos, bem como o aumento do espectro de oportunidades para as organizações de aplicação de capital nos mercados de países denominados emergentes, com mão de obra barata (Ex: China e Índia) em relação a países das Américas, Europa e atualmente o Brasil.

Tornam-se, portanto, cada vez mais competitivos os mercados para projetos de lançamentos de novos produtos, de prestação de serviços de engenharia, de sistemas informatizados, de sistemas de trabalho e novos processos. Exige-se das organizações a necessidade do uso de metodologias consistentes para o gerenciamento dos projetos, visando obter-se redução e controles mais efetivos dos custos, dos prazos de entrega e da qualidade dos projetos.

Várias são as medidas identificadas para diminuir os custos, bem como, novas metodologias são utilizadas cada vez mais pelos Gerentes de Projetos para gerenciar principalmente os custos dos projetos durante todo o seu ciclo de vida.

A maioria dos projetos é realizada sem que haja um adequado uso de metodologias e ou modelos de gerenciamento, e isto tem causado inúmeras e significativas perdas financeiras aos projetos.

A partir desta realidade, este trabalho se propõe analisar uma das áreas de conhecimento do Gerenciamento de Projetos, a de Gerenciamento dos Custos, identificando e criando um novo modelo de medição do Avanço Físico do Projeto. Este novo modelo, juntamente com as demais informações do orçamento inicial do projeto e dos custos incorridos, irá disponibilizar ao Gerente de Projeto, informações mais precisas de avaliação do progresso real do projeto em função dos prazos e custos, para tomada de decisão.

A metodologia do EVMS (Earned Value Management System) e do método de Percentual Completo (método que atribui um determinado percentual completo, entre 0 e 100\%, a cada ciclo de controle), foi aplicada na implementação desse novo modelo de medição do Avanço Físico do Projeto em um projeto industrial. Os resultados obtidos demonstraram a viabilidade do modelo utilizado na medição do 
Avanço Físico do Projeto, tanto no nível de cada um dos pacotes de trabalho como do projeto como um todo. 


\begin{abstract}
The deepening of the world globalization processes ever more in evidence generates, amoung countless other factors, the rise in competitiveness among companies and economic sectors, as well as the growth in the opportunity spectrum for the capital investment companies at so called "Emerging Countries Market", offering low-cost labor, (e.g. China and India), in relation to the countries in the Central and South America, Europe and nowadays, Brazil.

Market segments such as New Product Launching Projects, Engineering Outsourcing Services, Information Technology Systems, Work Systems and New Processes become more and more competitive. The use of consistent methodologies is demanded from companies when managing such projects, focusing on reducing and more effectively controlling costs, delivery dates as well as the quality of the project itself.
\end{abstract}

We can identify several actions taken to reduce costs, and new tools are used evermore by Project Managers, to mainly manage different project costs, along their life cycle.

Most projects are managed without the use of suitable methodologies and or managing models to follow. This has caused many and significant financial losses to such projects.

From this perspective, this study analyzes one of the areas of knowledge in Project Management, which is Cost Management, and identify as well as creating a new measuring model, which will make it possible to physically measure the progress of each project. This new model, together with relevant information from the initial forecasted budget and incurred costs, will make it available to the Project Manager, more accurate and vital information when it comes to deadlines and costs, which will help in the decision making process.

The EVMS, (Earned Value Management System) methodology and the Percentage Completion Method, (a method that attributes a determined percentage of Project completion (between 0 and 100\%), at each control cycle), were applied at the implementation of this new measuring model of Physical Project Advance, at an industrial project. The results have proved the viability of this new model, when 
measuring Physical Project Advance, not only at each work package level, but also as a Project as a whole. 


\section{SUMÁRIO}

\section{LISTA DE FIGURAS}

LISTA DE TABELAS

LISTA DE ABREVIATURAS E SIGLAS

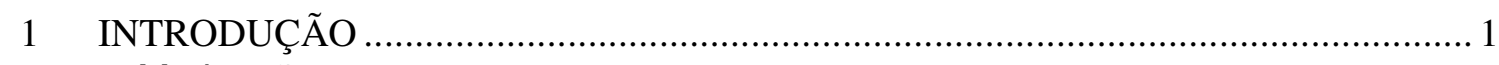

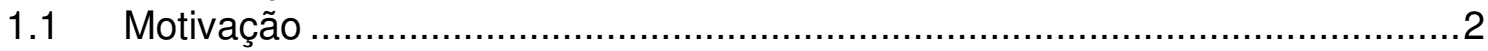

1.2 Objetivos e Contribuições Esperadas ..........................................................

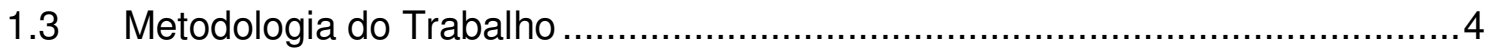

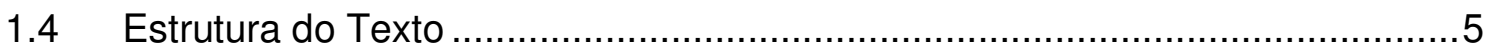

2 CONCEITOS SOBRE GERENCIAMENTO DE PROJETOS ........................................ 6

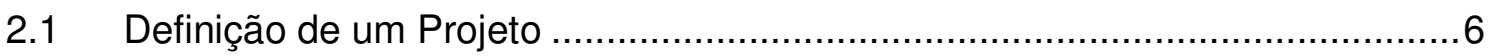

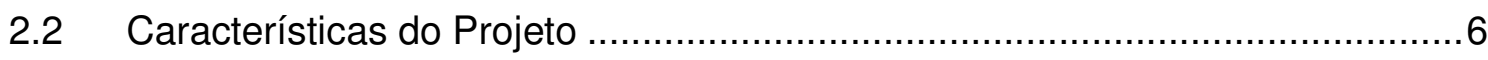

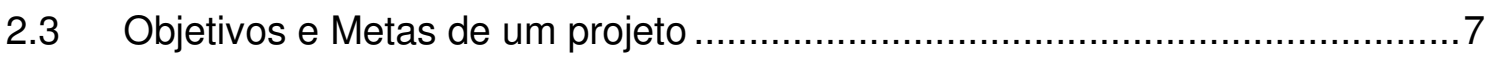

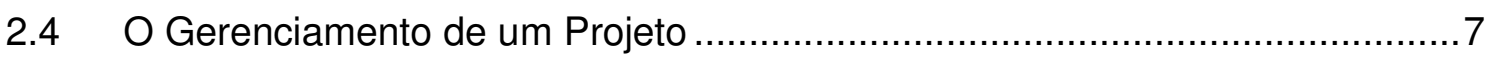

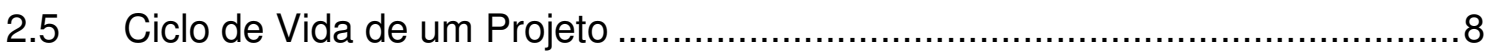

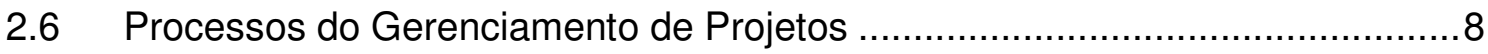

2.7 As áreas de conhecimento em Gerenciamento de Projetos.............................

3 CONCEITOS SOBRE O GERENCIAMENTO DE CUSTOS DO PROJETO ................ 11

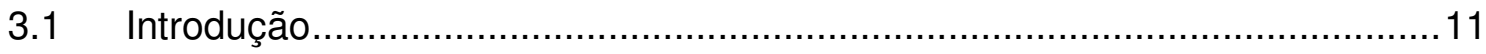

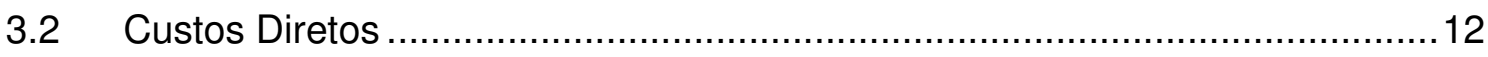

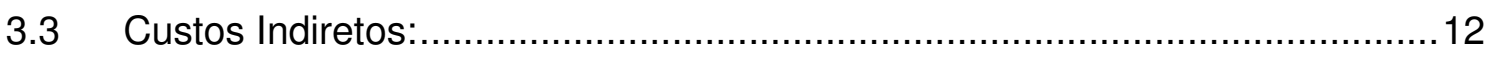

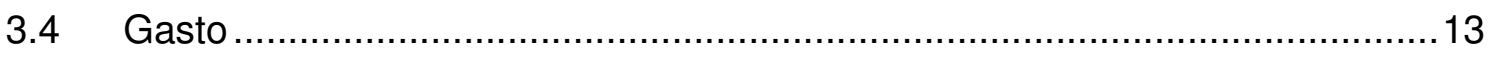

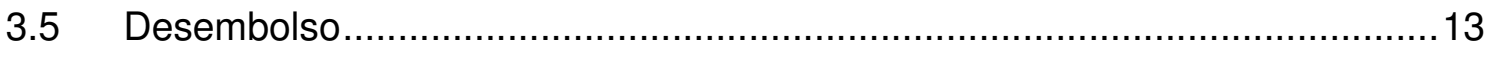

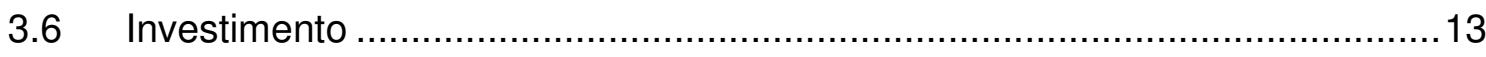

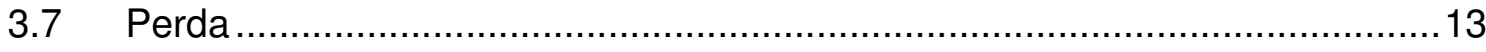

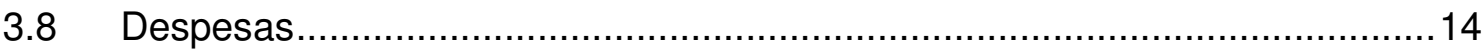

3.8.1 Despesas Administrativas Gerais.....................................................14

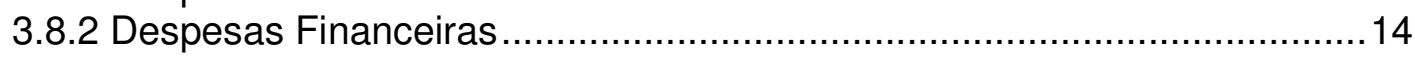

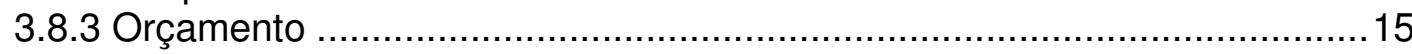

3.9 Gerenciamento de Custos do Projeto ................................................... 15

3.9.1 Estimativas dos Custos ................................................................... 16

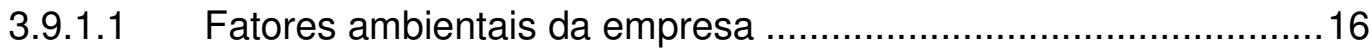

3.9.1.1.1 Condições de mercado .......................................................16

3.9.1.1.2 Bancos de dados comerciais ................................................. 16 
3.9.1.2 Ativos de processos organizacionais ........................................16

3.9.1.2.1 Políticas de estimativas de custo.......................................... 17

3.9.1.2.2 Modelos de estimativas de custo .......................................... 17

3.9.1.2.3 Informações históricas ......................................................... 17

3.9.1.2.4 Arquivos do projeto..................................................... 17

3.9.1.2.5 Conhecimento da equipe do projeto ...................................... 17

3.9.1.2.6 Lições aprendidas ............................................................ 17

3.9.1.3 Declaração do escopo do projeto .............................................17

3.9.1.3.1 Estrutura analítica do projeto (EAP) ………......................... 17

3.9.1.3.2 Dicionário da EAP ......................................................... 18

3.9.1.3.3 Plano de Gerenciamento do projeto ..................................... 18

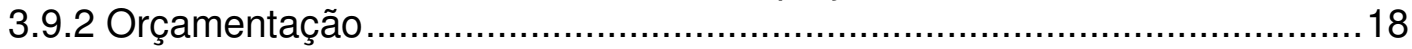

3.9.2.1 Declaração do escopo do projeto ………………………….....18

3.9.2.2 Estrutura analítica do projeto (EAP) .......................................... 18

3.9.2.3 Dicionário da EAP........................................................... 18

3.9.2.4 Estimativa de custos da atividade............................................ 18

3.9.2.5 Detalhes que dão suporte à estimativa de custos da atividade ....18

3.9.2.6 Cronograma do projeto .......................................................... 19

3.9.2.7 Calendário de recursos........................................................... 19

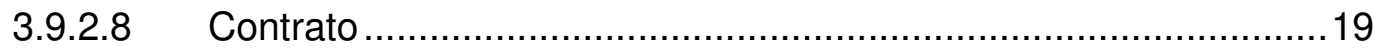

3.9.2.9 Plano de gerenciamento de custos...........................................19

3.9.3 Controle de Custos............................................................................. 19

3.9.3.1 Linha de base dos custos ...................................................... 19

3.9.3.2 Necessidade de financiamento do projeto …..............................20

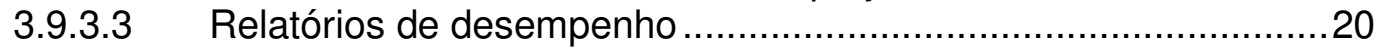

3.9.3.4 Informações sobre o desempenho do trabalho..............................20

3.9.3.5 Solicitações de mudança aprovadas ..........................................20

3.9.3.6 Plano de gerenciamento do projeto ……......................................20

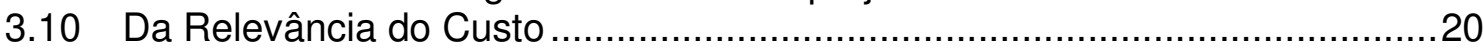

3.11 Componentes de Formação de Custo de Produtos e Serviços ......................22

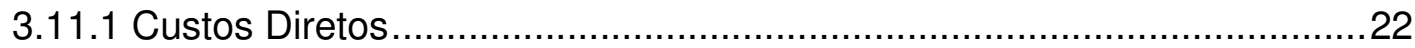

3.11.2 Custos Indiretos: ....................................................................23

3.11.3 Metodologias de Estimativa de Custeio de Produtos e Serviços .............23

3.11.3.1 Custeio por Absorção ...............................................................23

3.11.3.2 Método do Custeio Direto ou Marginal ........................................24

3.11.3.3 Sistema de Custeio baseado em Atividades..............................24

4 AVALIAÇÃO DOS ÍNDICES DE DESENPENHO DOS PROJETOS ATRAVÉS DO

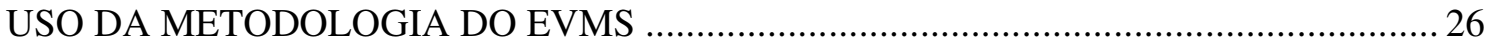

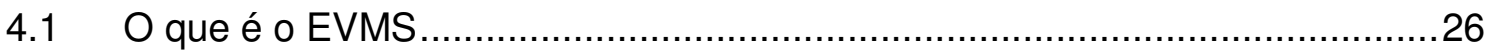

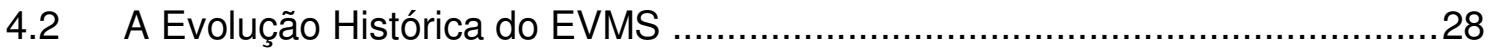

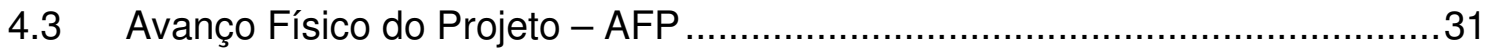

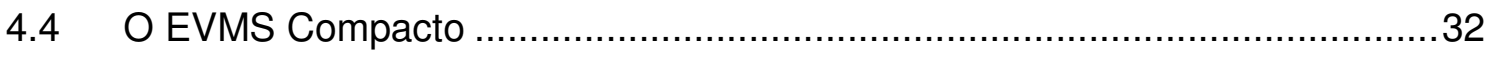

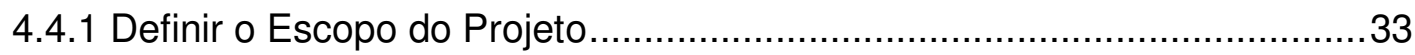

4.4.2 Criação de um Plano Analítico Integrado ................................................34

4.4.3 Existência de um Sistema de Controle Formal de Planejamento................35

4.4.4 Designar cada CAP individual a um responsável pelo monitoramento ......36

4.4.5 Estabelecer uma Linha Base de Custo - CAP's......................................36 
4.4.6 Efetuar medições do desempenho do Planejamento ...............................37

4.4.7 Efetuar medições do desempenho do Custo .......................................... 39

4.4.8 Re-estimar o Desempenho Final de Custos - EAC ...............................40

4.4.9 Conhecer qual o desempenho de custo e de prazo necessário para a obtenção das metas de custo e de prazo do projeto........................................40

4.4.10 Manter o Controle das Mudanças de Escopo do Projeto .........................41

4.5 Medição e Cálculo do Avanço Físico.......................................................41

4.5.1 Marcos com valores ponderados ............................................................ 41

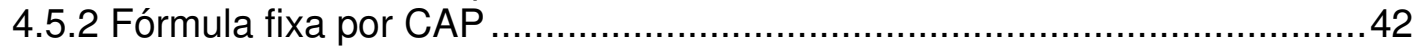

4.5.3 Percentual Completo............................................................................ 42

4.5.4 Percentual Completo com marcos de controle .......................................... 43

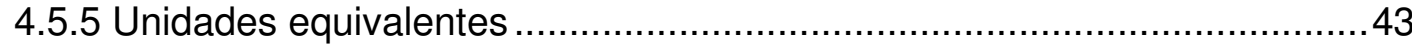

4.5.6 CAPs com Características compartilhadas ............................................. 44

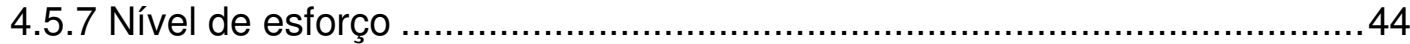

5 PROCESSO ATUAL DE GERENCIAMENTO DE PROJETOS E CONTROLE DO

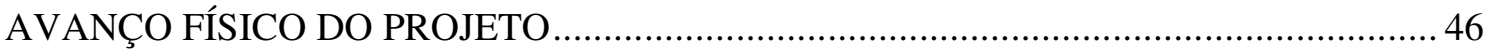

5.1 Processo atual de Gerenciamento de Projetos .......................................46

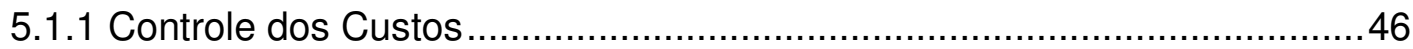

5.1.2 Atualização do planejamento do projeto ..........................................46

5.1.3 Disponibilidade dos relatórios de custos e recursos mensais ..................47

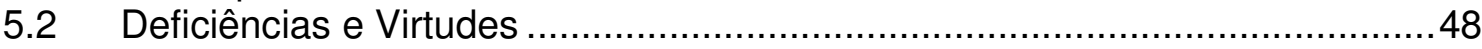

5.3 Proposição de Nova Metodologia de medição do trabalho realizado - Avanço

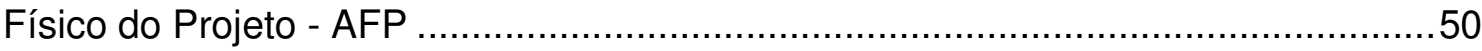

5.3.1 Proposta de uma nova metodologia para cálculo do Avanço Físico .........51 5.3.1.1 Cálculo da porcentagem do avanço físico mensal de cada atividade 52

5.3.1.2 Cálculo da porcentagem do avanço físico mensal por pacotes de trabalho 54

5.3.1.3 Cálculo da porcentagem do avanço físico mensal do projeto.......55

5.3.2 Alterações a serem implementadas nos sistemas existentes ...................56

5.3.2.1 Complementação no Sistema de apontamento de horas ..............56

5.3.2.2 Complementação no Sistema SAP ..............................................56

5.3.2.3 Alterações no sistema de planejamento Primavera.......................56

5.3.2.4 Geração de Relatório Consolidado ...........................................56

6 APLICAÇÃO DA NOVA METODOLOGIA EM UM SISTEMA DE CONTROLE

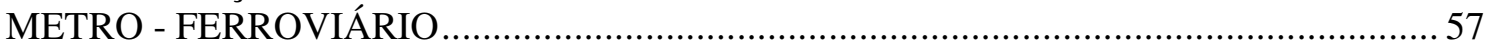

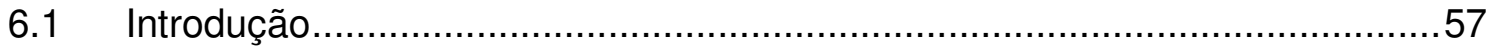

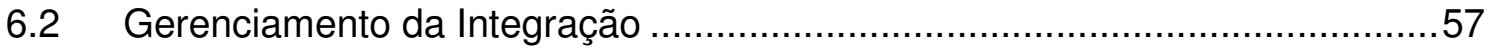

6.2.1 Reunião de transferência do projeto "Transfer Meeting". ..........................58

6.2.2 Elaboração do Plano de Gerenciamento do Projeto (PGP) ......................58

6.2.3 Reunião de Abertura do Projeto ("Launch Meeting")................................58

6.2.3.1 Definição dos responsáveis pela elaboração e aprovação de cada

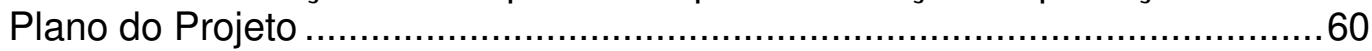

6.2.3.2 Estrutura Organizacional do Projeto ......................................61

6.3 Gerenciamento do escopo do projeto .............................................. 62

6.3.1 Termo de abertura ou Project Charter............................................... 62 


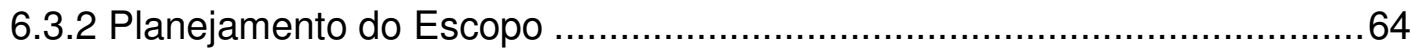

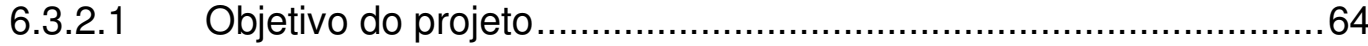

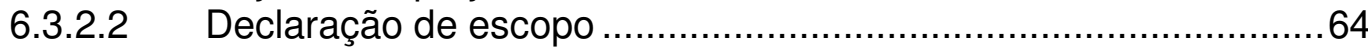

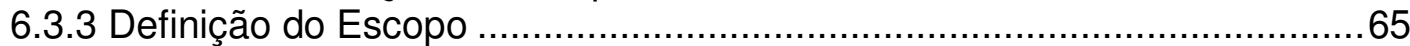

6.3.3.1 Estrutura Analítica do Projeto (EAP), (Work Breakdown Structure WBS) 65

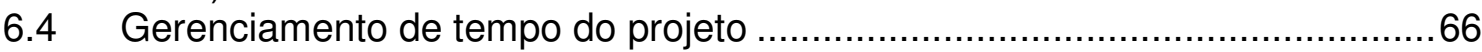

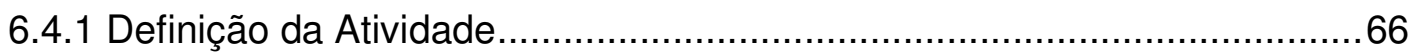

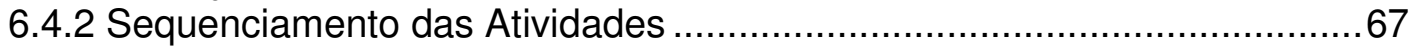

6.4.3 Estimativa de recursos das atividades ..............................................67

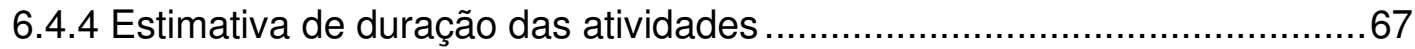

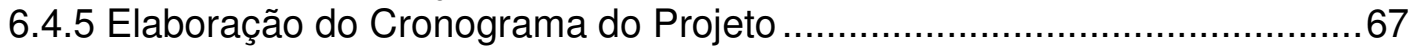

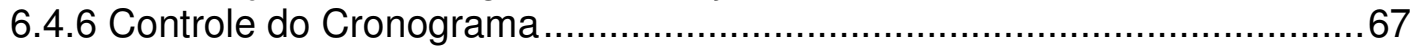

6.5 Gerenciamento de custos do projeto .......................................................

6.5.1 Relatório de Custos das Atividades................................................... 71

6.5.2 Custos de Aquisição de Materiais, Equipamentos e Contratação de

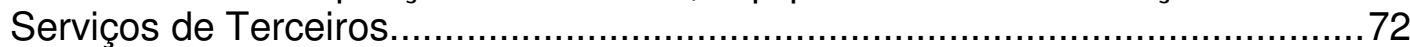

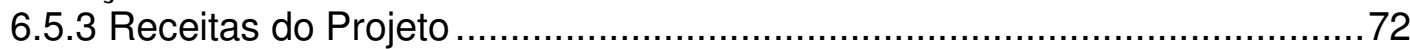

6.6 Implementação da Nova Metodologia em um projeto em desenvolvimento...73

6.6.1 Cálculo do Avanço Físico do Projeto......................................................74

6.6.2 Divisão do planejamento em Pacote de Trabalho ...................................77

6.6.3 Atualização do Avanço Físico do Projeto em cada Pacote de Trabalho ...81

6.7 Demonstração dos cálculos do EVMS através de Tabelas e de Gráficos do

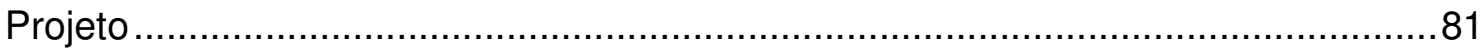

6.7.1 Etapa de Planejamento do Projeto ……................................................. 82

6.7.1.1 Planejamento dos recursos iniciais de mão de obra do projeto (PV) 82

6.7.1.1.1 Curva do planejamento dos recursos de mão de obra de engenharia .....

6.7.1.2 Planejamento dos custos iniciais de Aquisição de Materiais,

Equipamentos e Serviços de Terceiros do projeto (PV)....

6.7.1.2.1 Curva do planejamento da Aquisição de Materiais e

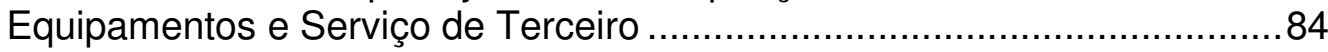

6.7.1.3 Curva do Planejamento Inicial do Projeto (BAC) …………..........84

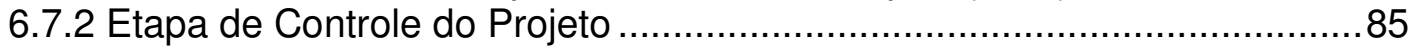

6.7.2.1 Planilha do Cálculo do Avanço Físico do Projeto (EV) …...............85

6.7.2.2 Curvas dos cálculos do Avanço Físico do Projeto (EV) .................86

6.7.2.2.1 Curva do Avanço Físico da mão de obra realizada no Projeto.. 86

6.7.2.2.2 Curva do Avanço Físico do Projeto relacionado à Aquisição de

Materiais e Serviços e contratação de Serviços de Terceiros........................86

6.7.2.2.3 Cálculo do Avanço Físico total do Projeto .................................87

6.7.2.3 Planilha do cálculo dos custos efetivamente incorridos no projeto

(AC) $\quad 88$

6.7.2.4 Curvas dos cálculos dos custos reais incorridos do projeto (AC) 88

6.7.2.4.1 Custos incorridos da mão de obra realizada no Projeto ..............88

6.7.2.4.2 Custos incorridos da aquisição de materiais, equipamentos e contratação de serviços externos............................................................ 89

6.7.2.4.3 Curva do Cálculo dos custos incorridos total do Projeto ............90 
6.7.2.5 Fluxo de Caixa do Projeto...........................................................90

6.7.2.6 Resumo Geral do Projeto ..................................................... 91

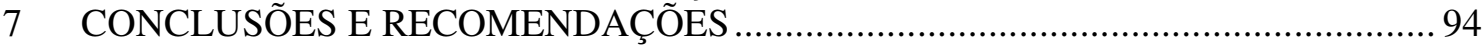

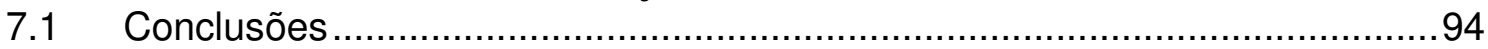

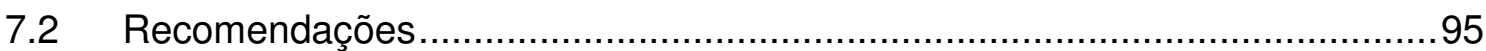




\section{LISTA DE FIGURAS}

Figura 2.6 - Mapeamento entre os grupos de processos de Gerenciamento de Projetos e o ciclo PDCA

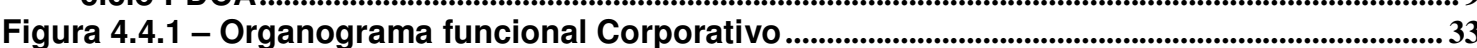

Figura 4.4.2 - Planejamento de Pacotes de Trabalho ....................................................................34

Figura 4.4.3 - Sistema de Controle Formal de Planejamento .........................................................................35

Figura 4.4.5 - Estrutura do orçamento do projeto.............................................................................................37

Figura 4.4.6 - Indicadores das variações de Prazos e Custos (SV e CV) .............................................38

Figura 6.2.3.2 - Estrutura Organizacional do Projeto ........................................................................................61

Figura 6.3.3.1 - Estrutura Analítica do Projeto -EAP .....................................................................................65

Figura 6.4.3 - Cronograma das atividades do projeto (Gráfico de Gantt) ............................................ 70

Figura 6.7.1.1.1 - Gráfico dos recursos de mão de obra de engenharia ..............................................83

Figura 6.7.1.2.1 - Gráfico dos recursos da Aquisição de Materiais,Equipamentos e Serviço de Terceiros

Figura 6.7.1.3 - Gráfico do Orçamento inicial do projeto (BAC)

Figura 6.7.2.2.1 - Gráfico do Avanço Físico da mão de obra realizada ..................................................86

Figura 6.7.2.2.2 - Gráfico do Avanço Físico na aquisição de materiais, equipamentos e serviços

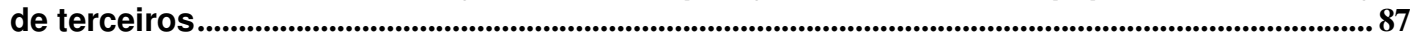

Figura 6.7.2.2.3 - Gráfico do Avanço Físico Total do Projeto (EV) ......................................................87

Figura 6.7.2.4.1 - Gráfico dos Custos incorridos da mão de obra realizada ........................................ 89

Figura 6.7.2.4.2 - Gráfico dos Custos incorridos da aquisição de materiais, equipamentos e contratação de serviços de terceiros ....................................................................................................... 89

Figura 6.7.2.4.3 - Gráfico dos Custos incorridos total do projeto........................................................90

Figura 6.7.2.5 - Gráfico do Fluxo de Caixa do Projeto .............................................................................90 


\section{LISTA DE TABELAS}

Tabela 4.2 - Acontecimentos ocorridos nas últimas décadas entre a Gestão de Projetos e o EVMS

Tabela 4.5.1 - Medição do Avanço Físico do Projeto através de marcos com valores ponderados.

Tabela 4.5.2 - Medição do Avanço Físico do Projeto através de fórmula fixa 25/75........................42

Tabela 4.5.3 - Medição do Avanço Físico do Projeto através do percentual completo ................. 43

Tabela 4.5.4 - Medição do Avanço Físico do Projeto através do percentual completo com marcos de controle no final de cada mês

Tabela 4.5.5 - Medição do Avanço Físico do Projeto através de unidades equivalentes para uma célula de controle CAP.

Tabela 4.5.6 - Medição do Avanço Físico do Projeto através de CAPs com características compartilhadas

Tabela 5.2 - Cálculo atual do Avanço Físico do Projeto.

Tabela 5.3.1 - Porcentagem da atividade dentro do projeto

Tabela 5.3.1.2 - Conjunto de atividades e dias previstos pertencentes a um pacote de trabalho (pacote de trabalho da área PC_ATS)

Tabela 5.3.1.3 - Cálculo do avanço físico mensal do projeto...............................................................55

Tabela 6.2.2 - Plano de Gerenciamento do Projeto ..................................................................................58

Tabela 6.2.3 - Definição dos Planos do Projeto a serem elaborados ..................................................59

Tabela 6.2.3.1 - Definição das Responsabilidades dos Planos do Projeto a serem elaborados60

Tabela 6.3.1 - Termo de Abertura do Projeto ou Project Charter do Projeto ...................................... 63

Tabela 6.4.1 - Definição e estimativa de duração de cada atividade....................................................66

Tabela 6.4.2 - Descrição e os prazos de execução de cada atividade .....................................................68

Tabela 6.5.1 - Relatório dos custos das atividades distribuídos mensalmente................................ 71

Tabela 6.5.2 - Custos de aquisição de Materiais e Equipamentos e Serviços de Terceiros....... 72

Tabela 6.5.3 - Receitas previstas do Projeto ....................................................................................73

Tabela 6.6.1 - Percentual do Avanço físico das atividades e do projeto .............................................75

Tabela 6.6.2.1 - Atividades relacionadas ao Gerenciamento do Projeto.............................................. 77

Tabela 6.6.2.2 - Atividades relacionadas a área de Engenharia de Sistemas....................................78

Tabela 6.6.2.3 - Atividades relacionadas a área de Aplicação ...........................................................78

Tabela 6.6.2.4 - Atividades relacionadas a área de Configuração ......................................................... 79

Tabela 6.6.2.5 - Atividades relacionadas a área de Eng. de Produtos................................................. 79

Tabela 6.6.2.6 - Atividades relacionadas a área de Suprimentos .......................................................79

Tabela 6.6.2.7 - Atividades relacionadas a área de Engenharia de Testes de Integração em

Fábrica e Comissionamento em Campo

Tabela 6.6.2.8 - Atividades relacionadas a área de Documentação e Treinamento ........................80

Tabela 6.7.1.1 - Planejamento dos custos mensais das Atividades........................................................82

Tabela 6.7.1.2 - Custos mensais para Aquisição de Materiais, Equipamentos e Serviço de terceiros.

Tabela 6.7.2.1 - Planilha do Cálculo do Avanço Físico do Projeto .......................................................85

Tabela 6.7.2.3 - Cálculo dos custos incorridos no projeto ......................................................................88

Tabela 6.7.2.6 - Resumo dos indicadores do andamento mensal do projeto ....................................91 


\section{LISTA DE ABREVIATURAS E SIGLAS}

AC - Actual Cost of Work Performed $=$ ACWP - Custo real incorrido pago pelo trabalho realizado até a presente data

AFP - Avanço Físico do Projeto $=E V=B C W P$

APM - Association for Project Management - Associação para Gerenciamento de Projeto

CBB - Contract Budget Base - É o valor total contratado entre contratada e contratante, o qual inclui além das reservas, contingências ou incertezas do projeto, os respectivos honorários, ou margem de rentabilidade, mudanças negociadas e autorizadas de escopo (aditivos de Contrato)

CAP - Cost Accounting Plan - Mapas de Centro de Custo

CA - Control Accounting - Custos Indiretos de Fabricação

CMM - Capability Maturity Model

CPI - Cost Performance Index - Índice de desempenho de custo do projeto

CPM - Critical Patch Method

CR - Critical Ratio - Índice que determina a ponderação entre o Custo e o Prazo do projeto

C/SCSC - Cost Schedule Control Systems Criteria - Critério de Controle dos Sistemas de Custo e Prazo

CV - Cost Variation - Índice que determina a variação de custo

DOD - Department of Defense - Departamento de Defesa dos Estados Unidos

EAC - Estimate at Completion - indica os gastos já efetivamente realizados até o presente momento, mais o valor atual revisado que é necessário para o término do projeto, constituindo, portanto, o valor final do projeto quando concluído

EAP - Estrutura Analítica do Projeto - (= WBS)

EIA - Eletronic Industries Association - Associação das Indústrias Eletrônicas ERP - Enterprise Resource Planning 
ETC - Estimate to Completion - indica os custos revisados do planejamento do Projeto ainda necessários para terminar o Projeto; ou seja, os custos que ainda temos previsto a gastar para terminar o projeto

EV - Earned Value $=$ BCWP $=$ Avanço Físico do Projeto (AFP) - Budget Cost of Work Performed - Representa a medida do trabalho realizado até a data atual

EVMS - Earned Value Management System - Metodologia utilizada para o Gerenciamento de Projetos através de índices de desempenho de prazo e custos IOS - International Organization for Standardization

NDIA - National Security Industrial Association - Associação Nacional de Segurança Industrial

NSIA - National Defense Industrial Association - Associação Nacional de Defesa Industrial

OBS - Organizational Breakdown Structure - OBS - Organograma funcional corporativo

PMB - Performance Measurement Baseline - Linha de Base Orçamentária, a qual será objeto de medida de seu desempenho

PV - Planned Value $=$ BCWS - Budget Cost of Work Scheduled - É a integração dos custos do trabalho previsto e do tempo necessário de execução das atividades

RAMS - Reliability, Availability, Maintainability, Safety

SOW - Statement of Work - Descrição do trabalho a realizar

SPI - Schedule Performance Index - Índice de desempenho de prazo do projeto

SV - Schedule Variance - Variação do prazo de execução do Projeto

TCPI - Work Remaining / Cost Remaining - Indicador da relação entre o Trabalho que ainda falta a ser realizado e do Custo necessário para sua realização

WBS - Work Breakdown Sctruture - ( = EAP)

WP - Work package - Pacote de Trabalho 


\section{INTRODUÇÃO}

A Gestão de Projetos no Brasil começou a ser encarada com profissionalismo há aproximadamente 10 anos, quando o Brasil passou por uma crise sem precedentes, ocasionada também pela turbulência internacional devido às condições econômicas vigentes em vários paises de vários continentes, principalmente devido às duas recessões econômicas nos Estados Unidos em meados da década de 90.

Naquela oportunidade, as organizações tiveram que reavaliar os seus processos de produção, de custos e de planejamento, para que seus produtos agregassem qualidade, custos reduzidos e entrega dentro dos prazos estabelecidos pelos compradores, visando a competitividade internacional. Para que esses objetivos pudessem ser alcançados, as empresas que já haviam anteriormente investido em alguns cursos de treinamento em planejamento e programação, começaram a aplicar os processos de Gerenciamento de Projetos, até então pouco difundidos nas organizações.

Com a aplicação dessas práticas, cada vez mais utilizadas pelas organizações, verificou-se nos últimos 20 anos, que os resultados alcançados com a metodologia foram e continuam sendo considerados excelentes. Segundo (KERZNER, 2002), "o mundo está finalmente reconhecendo a importância da Gerência de Projetos e seu impacto na lucratividade da empresa".

Atualmente, com a valorização da moeda Real frente às demais moedas, principalmente ao US\$ e do Euro (que em abril de 2005 era de 3,272 Reais, e em abril de 2006 era de 2,6 Reais), tendo, portanto o Real uma valorização de $25,8 \%$ no período de um ano, as organizações estão enfrentando sérias dificuldades em exportar seus produtos e serviços para todos os continentes, pois os custos, principalmente os de mão de obra em diversos países da Europa e Ásia, tais como: Bélgica, Índia e China, tornaram-se mais competitivos do que os praticados no Brasil.

Diante dessa realidade do mercado, novas ações estão sendo tomadas nas empresas para tornarem-se cada vez mais competitivas, principalmente nas de engenharia de sistemas, projetos de engenharia e de software, buscando-se uma padronização nos seus processos e principalmente o reuso de documentação, 
módulos de software, projetos similares anteriores, e da utilização de metodologias de gerenciamento de projetos.

Portanto, para a sobrevivência de qualquer empresa em qualquer tipo de atividade, torna-se necessário buscar continuamente novas estratégias e contínuo aperfeiçoamento das técnicas de produção, um rígido controle dos prazos, dos custos e da qualidade do produto ou do projeto, de forma a colocar produtos e serviços nos mercados nacionais e internacionais com preços competitivos que venham a atender as necessidades exigidas pelos clientes.

Uma das metodologias mais utilizada pelos Gerentes de Projetos para avaliar o desempenho de um projeto é o EVMS, que consiste em avaliar, por meio de indicadores, se o projeto está cumprindo as atividades do planejamento no prazo estabelecido, dentro do orçamento aprovado, na qualidade especificada e se não há nenhum desvio de escopo. Destaca-se entre estes indicadores, o índice EV Earned Value, ou AFP - Avanço Físico do Projeto, que consiste da medição do trabalho efetivamente realizado durante um determinado período de tempo considerado. Neste trabalho, a partir deste instante, será utilizado a sigla AFP ou o próprio texto quando nos referenciarmos a Avanço Físico do Projeto.

\subsection{Motivação}

Primeiramente, o estudo crescente na área de Gerenciamento de Projetos mostra que as pesquisas estão evoluindo e os métodos aplicados nesta área vêm melhorando a cada ano.

Percebeu-se que nas últimas duas décadas estavam ocorrendo estudos para definir e implantar processos de gestão de projetos, além de questionamentos sobre a sua utilização, vantagens e desvantagens.

A partir da década de 90, observa-se uma tendência dos artigos em tratarem de assuntos relacionados à aplicabilidade dos processos de gestão de projetos, estudos de casos e indicadores de desempenho dos processos de Gerenciamento de Projetos. Neste momento fica claro que depois das definições e métodos de implantação, muitas organizações e instituições aplicaram processos de Gerenciamento de Projetos e começaram a divulgar estes resultados. 
Em 2003, (OLIVEIRA, 2003) apresentou tese de mestrado, que retrata o Gerenciamento de Projetos e a Aplicação da Análise de Valor Agregado em Grandes Projetos, que é uma referência importante na área. Oliveira utilizou diversos autores de diversos livros, artigos, publicações, e sua experiência profissional em uma grande empresa, para descrever o processo de gerenciamento de projetos e, principalmente sobre a Análise do Valor Agregado (AVA). Ao final de seu trabalho, ele apresenta um caso de aplicação da AVA em um projeto de engenharia metroferroviário, recomendando novos estudos especificamente quanto à precisão das estimativas e prazos através da AVA.

Nos últimos anos ocorreu um aumento significativo na divulgação de artigos relacionados a abordagens de melhoria de processos de gestão de projetos, através do PMI - Project Management Institute e de diversas revistas especializadas, denotando o amadurecimento dos conceitos e dos processos aplicados, o que foi uma das causas da escolha do tema deste trabalho. Mas em contrapartida, percebeu-se que os trabalhos específicos voltados ao Avanço Físico do Projeto (AFP) são escassos, o que reforçou ainda mais a decisão de prosseguir com as pesquisas.

Outro ponto importante que motivou a escolha do tema foi à experiência profissional e prática do autor em uma empresa que atua na área de sistemas de Supervisão e Controle de Transporte Metro-Ferroviário, na qual se verifica que alguns profissionais ainda têm dificuldades na aplicação de processos de Avanço Físico do Projeto aos projetos.

Portanto, depois de detectado o problema real e após estudos realizados na área, decidiu-se desenvolver o presente trabalho.

\subsection{Objetivos e Contribuições Esperadas}

O objetivo do presente trabalho é analisar os conceitos associados voltados a uma das áreas de Gerenciamento de Projetos, Gerenciamento de Custos, e da metodologia do EVMS voltada ao AFP, com o auxílio de livros, dissertações de mestrado e teses de doutorado, artigos publicados em seminários, conferências, revistas especializadas e periódicas, identificar as vantagens e/ou desvantagens em utilizar a metodologia do EVMS, propor ações de melhoria, e aplicar a metodologia em um projeto na área Metro-Ferroviária. 
Foram analisadas as diversas metodologias existentes que podem ser utilizadas com auxílio da metodologia do EVMS, e definido o método de Percentual Completo, como o método que melhor atende os processos da empresa.

A metodologia definida neste trabalho, de Percentual Completo, foi aplicada em um projeto de engenharia de Sinalização e Controle na área de Transportes Metro-Ferroviária. Com a aplicação desse método nas atividades componentes de cada pacote de trabalho, tem-se: uma melhor precisão no cálculo do andamento do AFP, um melhor monitoramento e controle dos índices de desempenho do projeto, associados aos prazos, custos e qualidade, e a possibilidade de analisar, através dos indicadores e dos gráficos gerados, os resultados obtidos.

Além disso, integram-se diferentes métodos e técnicas relacionadas à gestão de projetos com enfoque principal em EVMS. Espera-se com este trabalho contribuir nos seguintes aspectos: Definição de um processo de aplicação mais precisa da metodologia do EVMS que possa auxiliar através da análise dos índices de desempenho apresentados num determinado tempo, 0 estágio atual de desenvolvimento do projeto; utilização do EVMS para representação gráfica dos indicadores do nível de desempenho do projeto, baseados em seus prazos e custos; integração de diversas abordagens relacionadas ao EVMS; avaliação detalhada do AFP através de um estudo de caso.

Uma das maiores contribuições deste trabalho, além das citadas anteriormente, será o novo foco dado à linha de pesquisa da análise do AFP, realizada através das atividades contidas em cada um dos pacotes de trabalho.

Assim, é possível integrar aspectos de gerenciamento de projetos, o que dá ao presente trabalho uma característica de interdisciplinaridade.

\subsection{Metodologia do Trabalho}

O tema da dissertação foi estruturado com base em três etapas fundamentais: a definição detalhada do problema, a pesquisa bibliográfica e o desenvolvimento da pesquisa.

A definição do tema iniciou-se durante o curso das disciplinas de pósgraduação, realizados pelo autor, de Gerenciamento de Empreendimentos (2002) da Fundação Getúlio Vargas de São Paulo - FGV, Gerenciamento de Projetos (2002 - 
2003) da Fundação Carlos Alberto Vanzolini - USP, e do mestrado (2003 - 2004) na Engenharia Naval e Oceânica da Universidade de São Paulo - USP.

Além da contribuição das disciplinas, aliada à experiência prática vivida em diversos projetos de engenharia, detectou-se que a preocupação na definição e formalização de um processo de Avanço Físico do Projeto (AFP) era realmente relevante. Percebeu-se essa necessidade, tanto no meio acadêmico quanto na área de engenharia de projetos, motivando o seu estudo de forma mais aprofundada.

O próximo passo foi o início de uma pesquisa bibliográfica na área de Gerenciamento dos Custos, principalmente do EVMS, dentro do processo de Gerenciamento de Projetos. Nesta etapa foram analisados e apresentados todos os conceitos relacionados à gestão dos diversos custos incidentes em qualquer tipo de projeto e, posteriormente, o do EVMS e outros tópicos que auxiliaram o desenvolvimento da dissertação, descritos nos capítulos 2 a 4.

\subsection{Estrutura do Texto}

No capítulo 2 são tratados os conceitos sobre o Gerenciamento de Projetos. No capítulo 3, os conceitos sobre o Gerenciamento de Custos em projeto. No capítulo 4, a Avaliação dos índices de desempenho dos projetos através do uso da metodologia do EVMS. No capítulo 5, apresenta-se o processo atual de gerenciamento de projetos e do controle do Avanço Físico em projetos na empresa. No capítulo 6, descreve-se a Aplicação da nova metodologia em um Sistema de Controle MetroFerroviário. No capítulo 7, são apresentadas as conclusões e recomendações sobre a metodologia implementada, e finalmente no capítulo 8, as Referências Bibliográficas. 


\section{CONCEITOS SOBRE GERENCIAMENTO DE PROJETOS}

\subsection{Definição de um Projeto}

Um projeto é um empreendimento singular e temporário com o objetivo de desenvolver um produto ou serviço. Ele ser Temporário, significa que cada projeto tem início e fim bem definidos; ser Singular (único) significa que o produto ou serviço produzido é de alguma forma, diferente de todos os outros produtos ou serviços semelhantes já realizados. Não deve ser confundido com atividades continuadas e repetitivas; encerra-se quando os objetivos propostos são atingidos.

O conceito de projeto foi pioneiramente difundido por (GADDIS, 1959): "um projeto é uma unidade da empresa dedicada a atingir uma meta - geralmente a conclusão bem sucedida do desenvolvimento de um produto no prazo, dentro do orçamento e em conformidade com especificações de desempenho predeterminadas".

Para (MEREDITH, 1985): "um projeto é uma atividade específica e finita a ser empreendida" (...) "um projeto é usualmente uma atividade única com um bem definido conjunto de resultados finais esperados".

O Project Management Institute - (PMI, 2001) principal associação mundial de gerenciadores de projetos, os define como "empenhos temporários empreendidos para criar produtos e serviços únicos".

\subsection{Características do Projeto}

Todo projeto caracteriza-se por certo grau de incerteza em relação ao resultado final ou o caminho a ser perseguido para atingi-lo.

Todo projeto caracteriza-se também por certo grau de complexidade, dependendo do número de variáveis que afetam sua execução, entre as quais, a multidisciplinariedade, o número de pessoas envolvidas, a dispersão geográfica da equipe, a diversidade e volume de informações a serem analisadas, a duração do projeto e o número de organizações envolvidas. Envolve também o desejo e vontade empreendedora, é ambicioso e desafiador, embora viável, é temporário, tem ciclo de vida pré-determinado, é marcado por objetivos, é único, não se confunde com a rotina, e sempre apresenta riscos e incertezas. 


\subsection{Objetivos e Metas de um projeto}

Pode-se enunciar que os Objetivos e Metas de um projeto são os de alcançar o controle adequado do projeto, de modo a assegurar sua conclusão no prazo e no orçamento determinado (custos), obtendo a qualidade estipulada.

Todo projeto requer o estabelecimento de um orçamento de referência. Orçamento é uma estimativa de custo transformada em compromisso para a execução; tem um prazo limite ou diversos prazos, para cada etapa de execução. Estes prazos são chamados de marcos de entrega ("milestones" no inglês), pois se tornam balizas para a execução. O fator qualidade é sempre um objetivo. Compõem-se de qualidade do produto do projeto e qualidade da implantação e gestão. No primeiro caso, trata-se da conformidade às especificações. No segundo caso, compreende as execuções harmônicas, sinérgicas, econômicas e promotoras de aprendizado.

(MENEZES, 2003), define que o seguinte tríduo deve caminhar junto num projeto: prazo, custo e qualidade. Isto significa que, ao variarmos um desses parâmetros, estaremos afetando um ou os outros dois, também.

Além do tríduo, há objetivos ligados ao desempenho da execução do projeto, sejam eles produtividade ou efetividade da gestão, como também objetivos ligados ao desempenho do produto, depois de concluído o projeto. Se voltado para o lucro, os benefícios esperados de um projeto podem ser a rentabilidades esperada ou 0 aproveitamento de oportunidade mercadológica. Se voltado para o atendimento a demandas sociais, daí decorrem seus objetivos esperados. Em todos os casos, há objetivos ligados à aprendizagem e à evolução da metodologia de gestão.

\subsection{O Gerenciamento de um Projeto}

O Gerenciamento do Projeto é a aplicação de conhecimentos, habilidades e técnicas para projetar atividades que visem atingir ou exceder as necessidades e expectativas dos financiadores do projeto (Stakeholders), com relação ao projeto. Envolve invariavelmente o equilíbrio entre demandas concorrentes. Entre eles podem-se citar: Cuidar da concepção, execução e testes do projeto; Definir o Escopo; Aperfeiçoar e racionalizar o conjunto dos objetivos de prazos, custo e qualidade; Desempenho e benefícios esperados; Diferentes necessidades e expectativas; Harmonizar financiadores ou partes interessadas do projeto, visando atender suas necessidades e expectativas e influenciando-os em benefício do 
projeto; Enfrentar pró - ativamente a incerteza e os riscos visando ampliar o controle sobre a execução.

Segundo a norma (ISO10006, 1997) (IOS - International Organization for Standardization): "O Gerenciamento do Projeto inclui o planejamento, organização, supervisão e controle de todos os aspectos do projeto em um processo contínuo, para alcançar seus objetivos".

\subsection{Ciclo de Vida de um Projeto}

O Ciclo de Vida de um Projeto define o início e o fim do projeto, bem como, divide o projeto em fases ou processos para facilitar o seu controle. Nele encontram-se as respostas para questões do tipo: que trabalho técnico deve ser feito em cada fase, e quem deve estar envolvido em cada fase.

Para cada fase espera-se um conjunto de resultados, que auxilia a decisão sobre a continuidade e/ou correção de desvios do projeto.

\subsection{Processos do Gerenciamento de Projetos}

Os cinco grupos de processos de gerenciamento de projetos organizam e descrevem o trabalho do projeto. São executados por pessoas e, como as fases do projeto, estão inter-relacionados e dependem uns dos outros. Entre eles podem-se citar: Grupos de processos de iniciação: autorização do projeto ou da fase. Indica qual é o conteúdo do projeto, a justificativa para a sua execução e os responsáveis pela gestão. Grupos de processos de planejamento: definição e refinamento dos objetivos e seleção da melhor alternativa de ação para alcançar os objetivos. Envolvem não só o planejamento físico e financeiro (tempos e custos), como também os planos da qualidade, de escopos, de comunicações, de suprimentos, de riscos e de alocação de pessoal. Grupos de processos de execução: Integrar e coordenar pessoas e outros recursos para realizar o plano de gerenciamento do projeto para o projeto. Grupos de processos de monitoramento e controle: assegurar que os objetivos do projeto estão sendo atingidos, através da monitoração regular de seu progresso, para verificar variações dos planos, projetarem tendências, avaliar impactos e, portanto, tomar ações corretivas quando necessário para atender aos objetivos do projeto; Grupo de processos de encerramento: formalizar a aceitação do produto, serviço ou uma fase do projeto e encerrá-lo (a) de forma organizada. 


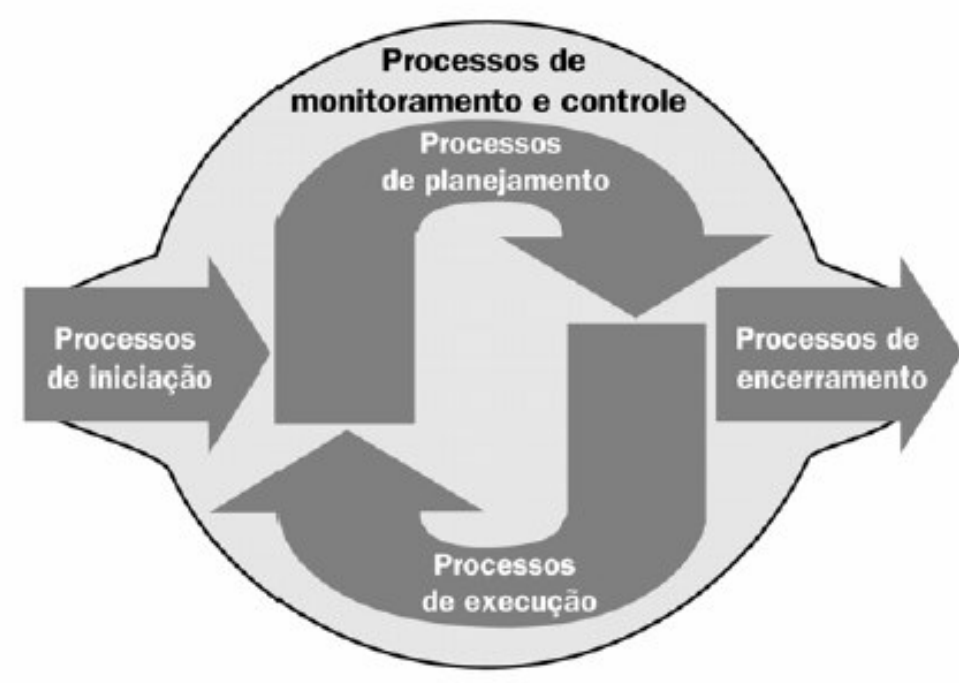

Figura 2.6 - Mapeamento entre os grupos de processos de Gerenciamento de Projetos e o ciclo PDCA

\subsection{As áreas de conhecimento em Gerenciamento de Projetos}

As nove áreas de conhecimento em Gerenciamento de Projetos definidas no (PMBOK, 2004), descrevem o gerenciamento de projetos em termos de seus processos componentes. Estes processos são definidos em nove grupos integrados. Cada um desses processos tem um detalhamento específico e uma abrangência própria, porém está integrado com os demais processos, formando um todo único e organizado. O Gerenciamento de Integração do projeto descreve os processos e as atividades que integram os diversos elementos do gerenciamento do projeto, que são identificados, definidos, combinados, unificados e coordenados dentro dos grupos de processos de gerenciamento de projetos. O Gerenciamento do Escopo do projeto descreve os processos envolvidos na verificação de que o projeto inclui todo o trabalho necessário, e apenas o trabalho necessário, para que seja concluído com sucesso. O Gerenciamento de Tempo do projeto descreve os processos relativos ao término do projeto no prazo correto. O Gerenciamento de Custos do projeto descreve os processos envolvidos em planejamento, estimativa, orçamentação e controle de custos, de modo que o projeto termine dentro do orçamento aprovado. O Gerenciamento da Qualidade do projeto descreve os processos envolvidos na garantia de que o projeto irá satisfazer os objetivos para os quais foi realizado $O$ Gerenciamento de Recursos Humanos do projeto descreve os processos que organizam e gerenciam a equipe do projeto. O Gerenciamento das Comunicações do projeto descreve os processos relativos à geração, coleta, 
disseminação, armazenamento e destinação final das informações do projeto de forma oportuna e adequada. O Gerenciamento de Riscos do projeto descreve os processos relativos à realização do gerenciamento de riscos em um projeto. $O$ Gerenciamento de Aquisições do projeto descreve os processos que compram ou adquirem produtos, serviços ou resultados, além dos processos de gerenciamento de contratos. 


\section{CONCEITOS SOBRE O GERENCIAMENTO DE CUSTOS DO PROJETO}

\subsection{Introdução}

O funcionamento de qualquer empreendimento no mercado exige a aquisição (ou aplicação) de recursos dos mais variados, pelos quais se devem pagar em troca de sua utilização produtiva. Os pagamentos pela utilização destes recursos, dentro de condições determinadas que seja distinta conforme o tipo de recurso de que se trata, configuram-se como os custos da empresa.

(ELISEU, 2003) define custos como sendo o gasto relativo ao bem ou serviço utilizado na produção de outros bens ou serviços. Ex. matéria prima, energia elétrica, máquinas.

Assim, para colocar em movimento certo processo de produção, são necessários, por exemplo, o local onde serão produzidos os produtos, edifícios, infra-estrutura (luz, água, telefone, escritório), máquinas e equipamentos, o trabalho humano e os insumos necessários para a produção dos produtos.

Além desses recursos produtivos, são necessários recursos relacionados à estrutura administrativa (de produção, da administração geral, de vendas, de marketing, etc).

A utilização de máquinas e equipamentos, edificações e instalações geram os chamados custos de depreciação, um tipo especial de pagamentos que, ao longo de um determinado período (a vida útil ou econômica da máquina, ou o ciclo do padrão tecnológico, por exemplo) deve servir para acumular um montante de dinheiro que seja suficiente para a reposição ou renovação total ou parcial destes recursos produtivos.

Pela aquisição e utilização do material a ser transformado, a empresa gera os custos dos insumos materiais, e através da venda do seu produto, ela tem condições de repor estes materiais, mantendo em funcionamento a sua atividade produtiva.

A utilização do trabalho humano origina os custos dos salários e dos encargos sociais cujo pagamento corresponde à necessidade de reposição da força de trabalho no processo produtivo. 
Os recursos aplicados na montagem e utilização da estrutura administrativa da empresa geram diversos conjuntos de gastos (denominados, genericamente, de cargas estruturais de custos, "overheads" (custos e despesas indiretos fixos)), que vão desde as remunerações dos diretores e gerentes, até a depreciação de máquinas e equipamentos de escritório, incluindo gastos gerais com materiais, etc.

Pela utilização do trabalho de vendedores são gerados os gastos com comissões; o esforço de vendas gera um conjunto variado de gastos, incluindo treinamento da equipe de vendas, de representantes, realização de convenções, etc; as ações de marketing geram gastos também variados, que abrangem desde a propaganda até a assistência pós-venda.

O conceito de custos, então, relaciona-se com a aquisição, utilização e reposição contínua (com maior ou menor freqüência) de recursos produtivos por parte de uma empresa. Os custos, portanto, são gastos efetuados pela empresa ao longo de todo o ciclo de suas atividades (compra, transformação, vendas e distribuição) e que devem ser recuperados, na medida exata, no momento do recebimento do valor referente às vendas de seus produtos ou serviços.

A recuperação dos custos se faz através da formulação do preço de venda para cada produto ou serviço, preço este que, além de cobrir os custos, deve conter uma margem de lucro cuja determinação, embora tenha como referência os custos, depende em grande parte do tipo de mercado e da particular forma de inserção da empresa neste mercado.

\subsection{Custos Diretos}

(CLELAND; IRELAND, 2002), definem custos diretos como sendo cobranças ocorridas no projeto que têm uma relação direta com o volume de serviços ou bens recebidos, os quais estão associados ou cuja aquisição é específica para o projeto.

\subsection{Custos Indiretos:}

São os custos relacionados à Administração geral da Empresa ou de mão de obra, materiais, equipamentos, etc, os quais são compartilhados entre diversos projetos; ou seja; cada projeto paga pelo serviço, consumo de material ou equipamento utilizado durante o tempo necessário para produzir a encomenda. 


\subsection{Gasto}

É todo o dispêndio com a finalidade econômica específica, visando gerar outro produto ou serviço, com finalidade econômica ao nível de empreendimento, gerando valor de uso e não valor de mercado (em termos econômicos);

Segundo (ELISEU, 2003), gasto é a compra de um produto ou serviço qualquer, que gera sacrifício financeiro para a entidade (desembolso), sacrifício esse representado por entrega ou promessa de entrega de ativos (normalmente dinheiro).

(WERNKE, 2004), define como sendo as transações financeiras nas quais a empresa utiliza recursos ou assume uma dívida, em troca de obtenção de algum bem e serviço.

\subsection{Desembolso}

Pagamento resultante da aquisição do bem ou serviço. Pode ocorrer antes, durante ou após a entrada da utilidade comprada, portanto defasada ou não do momento do gasto.

\subsection{Investimento}

Gasto ativado em função de sua vida útil ou de benefícios atribuíveis a futuro(s) período(s). Todos os sacrifícios havidos pela aquisição de bens e serviços (gastos) que são "estocados" nos Ativos da empresa para baixa ou amortização quando de sua venda, de seu consumo, de seu desaparecimento ou de sua desvalorização são especificamente chamados de investimentos.

Segundo (WERNKE, 2004), investimento são os gastos que irão beneficiar a empresa em períodos futuros. Enquadram-se nessa categoria, por exemplo, as aquisições de ativos como estoques e máquinas.

\subsection{Perda}

(ELISEU, 2003), define perda como bem ou serviço consumidos de forma anormal e involuntária. Não se confunde com a despesa (muito menos com o custo), exatamente por sua característica de anormalidade e involuntariedade; não é um sacrifício feito com a intenção de obtenção de receita.

Segundo (WERNKE, 2004), perda são os fatos ocorridos em situações excepcionais que fogem à normalidade das operações das empresas. 


\subsection{Despesas}

É todo gasto efetuado na fase pós-custo, ou seja, todos os gastos associados que são incorridos após a produção do bem ou serviço e no momento em que se pretende disponibilizar o produto ou serviço para a venda.

(ELISEU, 2003), define despesas como sendo, bem ou serviço consumido direta ou indiretamente para a obtenção de receitas. São itens que reduzem o Patrimônio Líquido e que têm essa característica de representar sacrifícios no processo de obtenção de receitas. Ex: A comissão de vendedor, por exemplo, é um gasto que se torna imediatamente uma despesa.

Segundo (WERNKE, 2004), despesas expressam o valor dos bens ou serviços consumidos direta ou indiretamente para obtenção de receitas, de forma voluntária.

Existem além de custos variáveis diretos, custos indiretos de fabricação rateados, outros componentes de custo (como as despesas) que oneram o produto, tais como: Despesas de Armazenagem e Estocagem; Despesas Variáveis de Venda, Comissões; Seguros; Fretes e Embalagens Adicionais; Taxas de Cobrança e descontos comerciais, dentre outros itens; Impostos diretamente incidentes sobre o faturamento: Imposto de Circulação de Materiais e Serviços (ICMS - 18\%, variável por região fiscal), Planos de Integração Social (PIS), Contribuição para Fins Sociais COFINS (3,65\%); Imposto sobre Produtos Industrializados (IPI - Alíquota Variável por tipo de classificação fiscal) e Imposto sobre Serviços (ISS - variável por região).

\subsubsection{Despesas Administrativas Gerais}

Existem ainda as denominadas despesas administrativas gerais, geralmente despesas funcionais fixas de estrutura relativa aos departamentos administrativos (Recursos Humanos, Marketing, Finanças, Centro Corporativo, Desenvolvimento de Produtos, Apoio, etc.) que são atribuídas aos produtos em função de quotas de fração ideal. Por exemplo, se a despesa fixa do departamento de marketing é de $\mathrm{R} \$$. $556.777,00$ por mês então se divide o total das despesas pela previsão de vendas do mês e aí se tem à estimativa das despesas fixas de venda.

\subsubsection{Despesas Financeiras}

As despesas financeiras diretamente associadas ao descasamento de prazos decorrentes do ciclo operacional e ciclo de caixa da empresa poderão ser imputadas 
ao preço do produto, pois representam o custo do capital de giro e as despesas decorrentes de financiamentos próprios também comporão o índice multiplicador ou divisor que aplicado ao custo do produto ou serviço, fornece o preço de venda (mark-up) do produto ou serviço.

\subsubsection{Orçamento}

(CLELAND; IRELAND, 2002), definem que um orçamento representa o plano de gastos em períodos de tempo para o projeto por item de despesa. O orçamento é o agregado de todos os custos do projeto, diretos e indiretos, podendo incluir o lucro do projeto. É dividido em fases de tempo para mostrar o perfil do fluxo de caixa em termos do índice de gastos e categorias.

Orçamentos constituem o acúmulo de todas as despesas, sendo inseridos em uma categoria de despesas. Trata-se de um mecanismo de controle que autoriza gastos no projeto apenas nas categorias identificadas e financiadas. Despesas que excedem o orçamento ou que estejam inseridas em uma categoria não identificada devem receber aprovação da alta administração.

O desenvolvimento do orçamento deve estar coerente com o custo. As categorias de custos que devem ser incluídas no orçamento são as seguintes:

Custo não processado: são os custos que constituirão o custo real dos bens ou serviços; Custos de encargos ou indiretos (também chamado de despesas gerais ou administrativas), é a porcentagem do custo não processado que é distribuído pela empresa como a parte ajustada para o projeto; Custo de encargo são os custos que incluem os custos indiretos como uma porcentagem do custo não processado; Custo total, são os custos por categoria para o projeto; Lucro, em geral, é uma porcentagem do custo total do projeto; Preço total é o preço do projeto para o cliente, incluindo todos os custos e lucros.

\subsection{Gerenciamento de Custos do Projeto}

O processo de Gerenciamento de Custos do projeto envolve o planejamento dos recursos do projeto com base para a estimativa dos valores dos custos analíticos dos recursos, do estabelecimento da linha base do orçamento, a qual será à base de mensuração da eficiência no uso dos recursos do projeto, e o respectivo fluxo de caixa. 
O Gerenciamento de Custos tem por objetivo principal a estimativa dos recursos de atividades desmembradas em pacotes de trabalho expressos em horas ou dias/homem/atividades, o custo dos recursos de equipamentos, estrutura e materiais necessários ao desenvolvimento das atividades previstas na lista de atividades.

Segundo o (PMBOK, 2004), o Gerenciamento dos Custos é subdividido em três processos, Estimativa de Custos, Orçamentação e Controle de Custos.

\subsubsection{Estimativas dos Custos}

É o processo através do qual são estimados os custos (quanto vai ser gasto?) relacionados a cada recurso (humano, material ou equipamentos) a ser empregado durante 0 projeto. Nesta fase, serão analisadas e identificadas as alternativas e estratégias possíveis para se definir mais precisamente a melhor estimativa de custo a ser adotada para cada item da EAP. Os insumos básicos para este processo são:

\subsubsection{Fatores ambientais da empresa}

O processo de estimativa de custos considera:

\subsection{Condições de mercado}

Quais produtos, serviços e resultados estão disponíveis no mercado, de quem, e sob que termos e condições.

\subsection{Bancos de dados comerciais}

Informações sobre valores de custo de recursos frequentemente estão disponíveis a partir de bancos de dados comerciais que acompanham custos de recursos humanos e habilidades e fornecem custos padrão para materiais e equipamentos. Outra fonte são as listas de preços de fornecedores publicadas.

\subsubsection{Ativos de processos organizacionais}

As políticas, os procedimentos e diretrizes relacionadas às estimativas de custos formais e informais existentes são considerados no desenvolvimento do plano de gerenciamento de custos, na seleção de ferramentas de estimativa de custos e nos métodos de monitoramento e distribuição de informações a serem usados. 


\subsection{Políticas de estimativas de custo}

Algumas organizações predefiniram abordagens para a estimativa de custos. Quando eles existirem, o projeto irá operar dentro dos limites definidos por essas políticas.

\subsection{Modelos de estimativas de custo}

Algumas organizações desenvolveram modelos (um padrão genérico) para serem usados pela equipe de projeto. A organização pode aprimorar o modelo continuamente com base em sua aplicação e utilidade em projetos anteriores.

\subsection{Informações históricas}

Informações que pertencem ao produto ou serviço do projeto e são obtidas de várias fontes dentro da organização podem influenciar o custo do projeto

\subsection{Arquivos do projeto}

Uma ou mais organizações envolvidas no projeto irão manter registros de desempenho de projetos anteriores suficientemente detalhados para auxiliar no desenvolvimento de estimativas de custos. Em algumas áreas de aplicação, membros individuais da equipe podem manter esses registros.

\subsection{Conhecimento da equipe do projeto}

É possível que membros da equipe do projeto se lembrem de custos reais ou estimativas de custos anteriores. Embora essas recordações possam ser úteis, em geral elas são menos confiáveis que o desempenho documentado.

\subsection{Lições aprendidas}

Lições aprendidas poderiam incluir estimativas de custos obtidas de projetos anteriores que são semelhantes em escopo e tamanho.

\subsubsection{Declaração do escopo do projeto}

Descreve as necessidades de negócios, a justificativa, os requisitos e os limites atuais do projeto

\subsection{Estrutura analítica do projeto (EAP)}

Fornece a relação entre todos os componentes do projeto e as entregas previstas do projeto. 


\subsection{Dicionário da EAP}

O dicionário da EAP e as declarações do trabalho detalhadas relacionadas fornecem uma identificação das entregas e uma descrição do trabalho em cada componente da EAP necessário para produzir cada entrega.

\subsection{Plano de Gerenciamento do projeto}

Fornece o plano geral para execução, monitoramento e controle do projeto e incluí planos auxiliares que fornecem diretrizes e orientação para planejamento e controle do gerenciamento de custos.

\subsubsection{Orçamentação}

Envolve a agregação dos custos estimados de atividades do cronograma individuais ou pacotes de trabalho para estabelecer uma linha de base dos custos totais para a medição do empenho do projeto.

\subsubsection{Declaração do escopo do projeto}

Descreve as necessidades de negócios, a justificativa, os requisitos e os limites atuais do projeto.

\subsubsection{Estrutura analítica do projeto (EAP)}

Fornece a relação entre todos os componentes do projeto e as entregas previstas do projeto.

\subsubsection{Dicionário da EAP}

O dicionário da EAP e as declarações do trabalho detalhadas relacionadas fornecem uma identificação das entregas e uma descrição do trabalho em cada componente da EAP necessário para produzir cada entrega.

\subsubsection{Estimativa de custos da atividade}

As estimativas de custos de cada atividade do cronograma dentro de um pacote de trabalho são agregadas para que seja obtida uma estimativa de custos para cada pacote de trabalho.

\subsubsection{Detalhes que dão suporte à estimativa de custos da atividade}

A qualidade e o tipo de detalhes adicionais que dão suporte à estimativa de custos da atividade do cronograma variam de acordo com a área de aplicação. 


\subsubsection{Cronograma do projeto}

Inclui todas as datas de início e de término planejadas de todas as atividades do cronograma, marcos de entrega do cronograma, pacotes de trabalho, pacotes de planejamento e contas de controle do projeto.

\subsubsection{Calendário de recursos}

Documenta os dias trabalhados que determinam as datas nas quais um recurso específico, uma pessoa ou material, pode estar ativo ou ocioso.

\subsubsection{Contrato}

São informações relacionadas a quais produtos, serviços ou resultados foram comprados, e seus custos são usados no desenvolvimento do orçamento.

\subsubsection{Plano de gerenciamento de custos}

O componente plano de gerenciamento de custos do plano de gerenciamento do projeto e outros planos auxiliares são considerados durante a orçamentação.

\subsubsection{Controle de Custos}

O controle de custos inclui: Controlar os fatores que criam as mudanças na linha de base dos custos; Garantir que houve um acordo em relação às mudanças solicitadas; Monitorar as mudanças reais quando e conforme ocorrem; Garantir que os possíveis estouros nos custos não ultrapassam o financiamento autorizado periodicamente e no total para o projeto; Monitorar o desempenho de custos para detectar e compreender as variações em relação à linha base dos custos; Registrar exatamente todas as mudanças adequadas em relação à linha de base dos custos; Evitar que mudanças incorretas, inadequadas ou não aprovadas sejam incluídas nos custos relatados ou na utilização de recursos; Informar as partes interessadas adequadas sobre as mudanças aprovadas; Agir para manter os estouros nos custos esperados dentro dos limites aceitáveis.

\subsubsection{Linha de base dos custos}

É um orçamento dividido em fases usa-se como base em relação à qual será medido, monitorado e controlado o desempenho de custos geral no projeto. 


\subsubsection{Necessidade de financiamento do projeto}

A necessidade de financiamento, total e periódica (por exemplo, anual ou trimestral), é derivada da linha de base dos custos e pode-se definir que ela tenha um excesso, geralmente uma margem, para prever um início mais acelerado ou estouros nos custos.

\subsubsection{Relatórios de desempenho}

Fornecem as informações sobre desempenho de custos e de recursos como resultado do progresso do trabalho real.

\subsubsection{Informações sobre o desempenho do trabalho}

São coletadas as informações sobre o desempenho do trabalho relativas ao andamento e aos custos das atividades do projeto que estão sendo realizadas.

\subsubsection{Solicitações de mudança aprovadas}

Do processo Controle Integrado de Mudanças podem incluir modificações nas cláusulas relativas a custos do contrato, no escopo do projeto, na linha de base dos custos ou no plano de gerenciamento de custos.

\subsubsection{Plano de gerenciamento do projeto}

O plano de gerenciamento do projeto e seu componente plano de gerenciamento de custos, além de outros planos auxiliares, são considerados durante a execução do processo Controle de custos.

\subsection{Da Relevância do Custo}

Muitos gerentes de projetos acreditam que o gerenciamento dos custos e orçamentos do projeto pode ser executado pelos respectivos especialistas da área financeira da empresa. Isto pode se constituir em um grande erro pelo qual o gerente de projeto poderá pagar um alto preço!

Segundo (SCHULTE, 2001), as falhas no planejamento dos custos, são responsáveis pelo insucesso da quase totalidade dos projetos com problemas de descontrole marginal dos custos.

Muitos também erram ao avaliarem de forma isolada somente os custos e não custos e prazos através da metodologia do Earned Value Management System (EVMS). 
O controle dos custos do orçamento, e do prazo, é essencial e absolutamente indispensável para a tomada de decisões em tempo hábil, de monitorar o projeto e efetuar as mudanças necessárias para a sua conclusão eficaz, dentro do prazo e, principalmente, do custo.

Todavia existe uma carência muito grande de conhecimentos sobre a disciplina custo para muitos GP's. A estrutura de conhecimento de custos e orçamentos pressupõe os seguintes itens de conhecimento, imprescindíveis para processo de formação gerencial dos GP's: Dos componentes de Formação de Custo de Produtos e Serviços; Das metodologias de estimativa de Custeio de Produtos e Serviços; Das técnicas de elaboração de orçamento de Projetos; e das Metodologias de controle de desempenho de projetos;

A estrutura metodológica do (PMBOK, 2004) é em si bastante útil como referência básica, todavia não fornece os métodos e metodologias de custeio e orçamento.

Deve-se, portanto, apresentar de forma sucinta as principais metodologias de custeio indispensáveis à estrutura de conhecimentos, para capacitar os gerentes de projeto, no processo decisório, desde a negociação de um contrato com um cliente e a obtenção de um custo inicial do projeto, até a mensuração do desempenho do contrato, passando pela abertura dos Mapas de Centro de Custo e também pelo conhecimento do Fluxo de Caixa e seus riscos associados.

A estrutura metodológica de referência do (PMBOK, 2004) é bastante precisa em seu escopo. Deve-se, a partir da EAP, definir os recursos, profissionais necessários, de materiais e equipamentos, de suporte e apoio, da estrutura organizacional e administrativa e outros recursos necessários à execução do projeto.

O conhecimento das reais necessidades de Recursos Humanos do Projeto ensejará importantes elementos de decisão para o Gerente de Projeto, o qual deverá decidir se utiliza profissionais dos quadros da própria empresa ou se contrata profissionais terceirizados para compor a equipe de prestadores de serviços do projeto. Necessitará também saber quais são os custos e os riscos envolvidos em adquirir parte ou todos os equipamentos do projeto, no mercado ou por encomenda, ou se a empresa poderá, ela mesma, fabricar parte ou a totalidade dos equipamentos. 
Para tanto ele necessita elaborar uma Estimativa dos Custos dos Recursos Humanos, das Contratações de Profissionais Terceirizados e dos Materiais e Equipamentos necessários durante o transcorrer do projeto. De posse destas informações, inicia-se o processo de elaboração dos orçamentos, que consiste no agrupamento dos itens de custos e em sua transformação num Fluxo de Caixa estruturado em forma de preços e prazos, bem como, das receitas previstas durante o transcorrer do projeto, associadas aos marcos de entrega de cada etapa do projeto.

Tanto as receitas quanto os custos estimados e os orçamentos detalhados deverão ser controlados quanto a sua realização e desempenho, sendo os mesmos controlados utilizando-se da metodologia do EVMS, descrita no capítulo 4.

A parte do controle da aquisição, armazenamento e distribuição dos materiais e equipamentos é feita pela sistemática tradicional de cotações, orçamentação, etc, e nesta dissertação, o controle dos custos (previstos $x$ realizados) dos materiais e equipamentos também é realizado utilizando-se da metodologia do EVMS.

É muito oportuno lembrar que a metodologia do EVMS pressupõe uma estrutura de controle em separado, com Mapas de Centro de Custo distintos para cada atividade ou grupo de atividades e, sobretudo, para a distinção entre o trabalho executado, o próprio EVMS.

\subsection{Componentes de Formação de Custo de Produtos e Serviços}

Os itens de custo de um produto são compostos pelos Custos Variáveis Diretos e Indiretos, assim denominados, pois, variam em relação ao volume de produção e também por serem totalmente identificáveis com relação à sua aplicação no produto.

\subsubsection{Custos Diretos}

Como custos diretos pode-se associar: Os Custos de Recursos Humanos, que são os preços da mão de obra para desempenhar as atividades no projeto e quaisquer despesas relativas ao projeto, como supervisão; Os Custos de Materiais que são os preços de bens e serviços à consumir no projeto e tornar-se-ão partes do produto final; Os Contratos de trabalho terceirizado para uma parte do projeto (pode ser uma parte do trabalho do projeto ou apoio do projeto) como a análise independente de determinada área; Os Custos de Suporte, que são os custos como viagens, entretenimento e outras despesas pequenas. 


\subsubsection{Custos Indiretos:}

Como custos indiretos podem-se associar: Custos e despesas indiretos fixos, Custos fixos de estrutura e funcionamento da fábrica que se repetem mensalmente, a depreciação das máquinas e equipamentos, os salários dos Supervisores, Gerentes, Chefes, Encarregados, Pessoal dos Departamentos de Apoio, benefícios, dos Aluguéis, Luz, Telefones, Água, dos Prêmios de seguro, tributos e taxas, dos Custos de manutenção corretiva e preventiva, e dos serviços terceirizados de conservação, limpeza, vigilância, refeitório, etc.

É importante lembrar que todos os gastos efetivamente incorridos até o momento da disponibilidade para a venda são custos e, a partir do momento que o produto estiver armazenado e pronto para ser vendido, todos os gastos daí decorrentes serão classificados como despesas.

Esta distinção não é meramente conceitual, e sim importante elemento definidor que, se não for devidamente observado produzirá distorções na apuração do resultado da empresa, causando erro na composição do preço final de venda do produto ou serviço.

\subsubsection{Metodologias de Estimativa de Custeio de Produtos e Serviços}

Após o conhecimento dos itens de custo resta-nos compreender a estrutura de cálculo das metodologias de custeio (significa Apropriação de Custos) mais utilizadas, a de Custeio por Absorção, Custeio Direto ou Marginal e a de Custeio Baseado em Atividade.

\subsubsection{Custeio por Absorção}

Segundo (ELISEU, 2003), o custeio por absorção é o método derivado da aplicação dos princípios de contabilidade geralmente aceitos, nascido da situação histórica mencionada, sendo o mais utilizado pelas empresas, por ser o único aceito pelas autoridades fiscais. Consiste na apropriação de todos os custos de produção aos bens elaborados, e só os de produção; todos os gastos relativos ao esforço de produção são distribuídos para todos os produtos ou serviços feitos.

As principais vantagens do custeio por absorção segundo (WERNKE, 2004), são: atende à legislação fiscal e deve ser usado quando a empresa busca o uso do sistema de custos integrados à contabilidade, permite a apuração do custo por centro de custos, visto que sua aplicação exige a empresa contábil nesse sentido, 
ao absorver todos os custos de produção, permite a apuração do custo total de cada produto.

A principal desvantagem do custeio por absorção segundo (WERNKE, 2004), consiste na utilização dos rateios para distribuir os custos entre os departamentos e/ou produtos.

Segundo (ELISEU, 2003), existe também uma condição particular do Custeio por Absorção que é o processo de departamentalização que pode ser bastante útil para a eliminação das arbitrariedades das chaves de rateio (são geralmente os volumes de mão de obra consumida proporcionalmente por cada produto). "A departamentalização constitui-se numa grande solução para a eliminação dos critérios arbitrários das chaves de rateio".

\subsubsection{Método do Custeio Direto ou Marginal}

O custeio Marginal surgiu na década de 30 com o objetivo de tornar mais flexível o processo decisório associado a preços e custos e decisões de fabricação. O método do custeio marginal elimina as arbitrariedades das chaves de rateio tranformando os custos indiretos de fabricação em Despesas Fixas de Fabricação, alocando os Custos Indiretos de Fabricação (CIF) não individualmente aos produtos objetos de custeio, mas diretamente à Demonstração de Resultados da Empresa.

\subsubsection{Sistema de Custeio baseado em Atividades}

O sistema de custeio ABC (Activity Based Costing) é um método de análise de custos cujo objetivo está associado ao gerenciamento por projetos e ou por processos. Basicamente suas principais funções estão associadas a mensuração dos custos fixos das atividades e a identificação das atividades que mais agregam valor e a eliminação daquelas atividades que não agregam valor.

(NAKAGAWA, 1995) considera que o custeio ABC é um método de análise de custos que busca "rastrear" os gastos de uma empresa para analisar e monitorar as diversas rotas de consumo dos recursos diretamente identificáveis com suas atividades mais relevantes e destas para os produtos ou serviços.

Segundo os Profs. Robert Kaplan e Robin Cooper, da Harvard Business School, (KAPLAN; COOPER, 1998), para saber-se o que é o ABC é necessário responder 4 questões básicas: Que atividades estão sendo executadas pelos 
recursos organizacionais?; Quanto custa executar estas atividades organizacionais nos processos de negócios?; Porque a empresa precisa executar estas atividades e processos de negócios?; Quanto de cada atividade é necessário para os produtos, serviços e clientes do meu negócio?.

No Custeio por Absorção os CIFs são apropriados aos produtos por meio das chaves de rateio, o que contém certa arbitrariedade. No Custeio Direto os CIFs são considerados como Despesas Fixas de Produção e alocados diretamente aos resultados globais da empresa. No $A B C$ os $\mathrm{ClFs}$ são rastreados e alocados às atividades e, estas últimas, aos clientes e produtos. 


\section{AVALIAÇÃO DOS ÍNDICES DE DESENPENHO DOS PROJETOS ATRAVÉS DO USO DA METODOLOGIA DO EVMS}

\subsection{O que é o EVMS}

O EVMS é uma das principais metodologias da Gestão de Projetos, que disponibiliza uma série de indicadores de desempenho, permitindo ao gerente do projeto ter uma visão global do projeto. Os dois principais indicadores apresentados ao gerente de projeto são os indicadores de custos e o de prazos. Com estas informações, os gerentes poderão analisar o estado atual do projeto como inicialmente planejado, para a tomada de ações preventivas e corretivas necessárias.

Segundo (SCHULTE, 2001), em um estudo de projetos de software para o "Standish Group", tanto em corporações privadas, como públicas, aproximadamente $90 \%$ dos projetos objetos da pesquisa falharam, tanto por estarem acima do custo previsto, como abaixo do prazo previsto no planejamento. De forma análoga $33 \%$ foram cancelados antes de sua conclusão, por estarem muito acima do custo previsto e bem abaixo do prazo previsto no planejamento e, em muitos casos, totalmente fora do escopo! Aproximadamente, mais de 1/3 do total das corporações estudadas, corporações de variada tipologia, pequenas, médias e grandes, experimentaram o crescimento desproporcional dos custos do projeto entre 150 a $200 \%$ (sendo $189 \%$ a média). Calcula-se que nos EUA são perdidos anualmente, 1,45 bilhão de dólares com o crescimento desproporcional dos custos, e 1/3 dos casos estudados apresentaram o não cumprimento de prazo previsto no planejamento entre 200 a 300\%, (sendo 222\% a média). Estes percentuais revelam que as metodologias e técnicas não estão sendo usadas adequadamente ou têm sido ineficientes.

O EVMS, é controlado com o auxílio de três curvas adimensionalizadas, as quais são definidas por (BURKE, 2003) como sendo:

PV $($ Planned Value $)=$ BCWS $-($ Budget Cost of Work Scheduled $)$. É a integração dos custos do trabalho previsto e do tempo necessário de execução das atividades ou dos homen/hora e do tempo, os quais são utilizados para elaborar a curva $\mathrm{S}$, a qual é definida como a cuva "Baseline" do projeto. 
EV $($ Earned Value $)=$ BCWP $-($ Budget Cost of Work Performed $)$. Também chamada de "earned value", é a curva que representa a medida do trabalho efetivamente realizado, até a data atual.

AC (Actual Cost) $=$ ACWP - (Actual Cost of Work Performed). É o custo real incorrido pago pelo trabalho realizado até a presente data.

Os principais objetivos ao se utilizar o EVMS são: Medir o desempenho através de critérios técnicos consistentes, previamente estabelecidos; Analisar o planejamento, verificando o estado atual do andamento do projeto e projeções futuras, analisando o caminho crítico (Rede Pert CPM, Gráfico de Gantt); Analisar o consumo dos recursos do trabalho efetivamente realizado (não apenas o trabalho previsto no planejamento); Quantificar problemas técnicos por meio de indicadores associados ao escopo, prazo e custo; Não modificar o planejamento inicial do projeto sem o controle das mudanças do Escopo; Realizar previsões no planejamento inicial de custo e prazo no início e durante o projeto, por meio da re-estimativa em função do desempenho de custo e prazo; data de término e custo final; Apresentação dos indicadores de desempenho, necessários, para a tomada de ações preventivas e corretivas; Manter a verdade e a disciplina de escopo, prazo e custo, e do planejamento inicial.

\section{Para um gerenciamento eficiente de um projeto necessita-se no mínimo de três}

indicadores: Do orçamento do projeto (Recursos Humanos, Materiais, Equipamentos, etc); Do Avanço físico do projeto - AFP (no final do período a ser considerado); Dos custos efetivamente gastos no período para a realização das atividades (custos incorridos do trabalho realizado).

O EV é a soma dos valores dos trabalhos concluídos. Então, para as atividades concluídas o EV é igual aos valores orçados. Para as atividades não iniciadas o EV é igual à zero. Para as atividades em progresso, precisamos de um sistema de medição que utilize um critério objetivo e apresente métodos alternativos para estas medições.

Um dos métodos utilizados consiste em multiplicar o orçamento pela porcentagem de trabalho realizado para se obter o EV. Algumas atividades são imensuráveis, por exemplo, o trabalho do Gerente de Projetos ou de um inspetor de 
qualidade. Este tipo de atividade é denominado grau de esforço. Seu EV é assumido como sendo igual ao valor orçado, quando a tarefa é realizada, ela se torna um EV.

\subsection{A Evolução Histórica do EVMS}

O EVMS foi introduzido na indústria em 22 de dezembro de 1967 pelo Departamento de Defesa Americano DOD (Department of Defense). Foi inicialmente denominado de Sistema de Controle de Critérios de Custo e Cronograma (C/SCSC). Desde o princípio, o DOD definiu consistentemente os requisitos para uso do EVMS através de uma série de critérios a serem atendidos pelas companhias que desejassem fazer negócios com o DOD. Estes critérios foram originalmente especificados dentro da DOD. Com a emissão da Instrução 7000.2, denominada Medição de Desempenho para Aquisições Selecionadas, foram estabelecidos 35 critérios para a indústria privada em qualquer tempo que ela desejasse fornecer ou adquirir um novo sistema para o DOD. No decorrer dos anos outras agências do governo Americano e muitos governos estrangeiros (mais notoriamente Austrália, Canadá, Nova Zelândia e Suécia) adaptaram critérios idênticos ou similares para companhias do setor privado.

Em 18 de abril de 1995 num encontro formal do sub comitê de gerenciamento de sistemas NDIA (National Defense Industrial Association), em Fênix - Arizona, o sub-comitê NDIA insistiu fortemente no sentido de criar tarefas de revisão dos critérios estabelecidos pelo DOD. O objetivo estabelecido foi bastante claro: tornar os critérios mais inteligíveis e transparentes e de maior aplicabilidade ao mundo dos negócios, abandonando a postura do hermetismo contábil e tornando-os mais compatíveis com as necessidades da indústria privada. Poucos meses depois o NDIA, reuniu-se formalmente através de um amplo Congresso, discutiu de forma abrangente e por fim reformulou a versão original dos 35 critérios do "Cost/Schedule Control Systems Criteria" (C/SCSC). Quando efetivamente liberou a versão para a indústria, esta passou a ser chamada de EVMS, contendo, então 32 critérios, três a menos que o original C/SCSC, muito mais enxutos e de maior viabilidade de aplicação, pois estavam mais atualizados e compatíveis à linguagem da Gestão de Projetos.

Em 14 de dezembro de 1996, o então Secretário de Defesa para Aquisição e Tecnologia - Dr. Paul Kaminski - aceitou textualmente os 32 critérios do EVMS. Os 
critérios EVMS para indústria foram então incorporados ao DOD MANUAL 5000.2R em 1997.

O significado dessas mudanças não foi nas palavras ou simplesmente na quantidade de critérios, mas na atitude em relação ao processo EVMS. Durante 1997 houve transferência da posse dos requisitos do EVMS do governo americano para a indústria privada, ou seja, a partir de 1997 o EVMS passou a ser institucionalizado e assim todas as empresas de projetos que forneçam ou adquiram quaisquer equipamentos, serviços ou tecnologias estão obrigadas a serem certificadas e a utilizarem, portanto, os 32 critérios do EVMS.

A indústria privada adotou as técnicas do EVMS, não por ordem do governo, mas porque o EVMS representava a melhor metodologia disponível para gestão de projetos no setor privado. O NDIA continuou seu trabalho para tornar o EVMS, em bases internacionais, como sendo a melhor prática e também requisitou que o EVMS fosse formalmente normatizado no NSIA (National Security Industrial Association) e na EIA (Electronic Industries Association).

Em julho de 1998, a norma NSIA / EIA Standard 748 foi formalmente liberada. E em 17 de agosto de 1999, Dr. Jacques S. Gansler - o novo Secretário de Defesa para Aquisição e Tecnologia - aceitou que a referida norma fosse aplicada em todos os projetos do DOD, e institucionalizou o EVMS Standard (padrão) substituindo formalmente o C/SCSC. O EVMS passou a ser formalmente de uso obrigatório para todas as empresas envolvidas direta ou indiretamente na gestão dos projetos relacionados a quaisquer órgãos do governo dos EUA.

O Departamento de Defesa dos EUA utiliza desde 1959 o C/SCSC e o EVMS por força das intensas pressões do Congresso dos EUA, quanto à liberação de recursos para o Departamento de Defesa, então envolvido em polêmicas quanto aos excessivos preços praticados pelos seus fornecedores, que quando se tratava de fornecer para o Pentágono e demais órgãos do Departamento de Defesa, praticamente duplicava seus preços, tornando-o um simples parafuso de US\$ 0,15 custar na fuselagem de um avião da Força Aérea, muitas vezes mais de US\$20,00. Não só se tratava de um problema de custos adicionais, mas também e, principalmente, de escopo de produto, qualidade, risco, custo e prazos. 
Das necessidades do Departamento de Defesa dos EUA, quanto ao gerenciamento de seus projetos relativamente ao escopo, prazo, risco, qualidade e custo surge o C/SCSC e depois o EVMS e o EVMS Standard, que como veremos a seguir constitui-se numa estrutura metodológica formalmente eficaz para 0 planejamento dos recursos, estimativa dos custos, orçamento e controle de recursos e gerenciamento do valor do trabalho efetivamente realizado.

Tabela 4.2 - Acontecimentos ocorridos nas últimas décadas entre a Gestão de Projetos e o EVMS

\begin{tabular}{|c|c|}
\hline Data & Acontecimento \\
\hline $\begin{array}{l}\text { Década } \\
\text { de } 50\end{array}$ & $\begin{array}{l}\text { Criação do método CPM (Critical Path Method) } \\
\text { A Marinha americana adota o CPM } \\
\text { Criação do método PERT (Program Evaluation and Review Technique) }\end{array}$ \\
\hline $\begin{array}{l}\text { Década } \\
\text { de } 60\end{array}$ & $\begin{array}{l}\text { DoD (Department of Defense) americano apresenta o critério C/SCSC } \\
\text { (Cost/Schedule Control System Criteria) para seus projetos } \\
\text { O Project Management Institute (PMI) é fundado em } 1969\end{array}$ \\
\hline $\begin{array}{l}\text { Década } \\
\text { de } 70\end{array}$ & Criação e consolidação do MRP ( Material Requirement Planning); \\
\hline $\begin{array}{l}\text { Década } \\
\text { de } 80\end{array}$ & $\begin{array}{l}\text { Criação do MRP II } \\
\text { Primeira Certificação PMP (Project Management Professional) } \\
\text { Criação do TQM (Total Quality Management) }\end{array}$ \\
\hline $\begin{array}{l}\text { Década } \\
\text { de } 90\end{array}$ & $\begin{array}{l}\text { Austrália e outras potências mundiais adotam o método C/SCSC } \\
\text { ERP (Enterprise Resource Planning) emerge nos EUA } \\
\text { Introdução dos conceitos de Engenharia Simultânea }\end{array}$ \\
\hline 1991 & Consagração do TQM (Total Quality Management) \\
\hline 1992 & Criação do C/SPMS (Cost/Schedule Performance Management Standard) canadense \\
\hline 1993 & $\begin{array}{l}\text { Formação do IPMC (International Performance Measurement Council) } \\
\text { DoC (Department of Commerce) americano passa a utilizar EVM (Earned Value } \\
\text { Management), uma variação do C/SCSC } \\
\text { Introdução dos conceitos de Re-Engenharia }\end{array}$ \\
\hline 1994 & FBI americano passa a utilizar o EVM. \\
\hline 1995 & $\begin{array}{l}\text { Estabelecimento do "Department of Transportation Performance Measurement } \\
\text { Council" nos EUA para medir desempenho de projetos }\end{array}$ \\
\hline 1996 & $\begin{array}{l}\text { OMB (Office of Management and Budget) americano edita o requisito A-11 exigindo } \\
\text { EVM em todos os contratos do governo; } \\
\text { EVM é acrescentado ao PMBOK; } \\
\text { DoD americano cria o EVM Implementation Guide; } \\
\text { O Gerenciamento de Riscos passa a ser incluído no planejamento e controle de } \\
\text { projetos; }\end{array}$ \\
\hline 1997 & $\begin{array}{l}\text { NASA cria a política de gerenciamento de performance baseado em EVM; } \\
\text { Surge o conceito de Cadeia Crítica (Critical Chain); }\end{array}$ \\
\hline 1998 & $\begin{array}{l}\text { EVM passa a ter uma normalização pela ANSI (American National Standards } \\
\text { Institute); }\end{array}$ \\
\hline 1999 & $\begin{array}{l}\text { PMA (Performance Measurement Association) se torna a primeira faculdade do PMI } \\
\text { com intuito de divulgar o EVM; } \\
\text { DoD americano adota as normas ANSI para EVM; }\end{array}$ \\
\hline 2000 & $\begin{array}{l}\text { PMBOK é atualizado com detalhamento do EVM; } \\
\text { Crescimento de equipes itinerantes e multinacionais; } \\
\text { APM (Association for Project Management - Inglaterra) edita normas para EVM; }\end{array}$ \\
\hline 2002 & fesa britânica passa a utilizar o EVM \\
\hline
\end{tabular}


No Brasil, o EVMS é pouco conhecido e praticamente não é utilizado sistematicamente, exceto por algumas subsidiárias de multinacionais dos EUA.

Se o governo brasileiro utilizasse o EVMS nos órgãos da administração teria um imenso ganho de produtividade em termos de gestão de custos e de controle orçamentário. Episódios lamentáveis relativos a gestão de recursos para o setor público no Brasil, apresentados freqüentemente na mídia, poderiam ser evitados, pois com o uso do EVMS não é possível mascarar realidades de custo e a verdade de Custo, Escopo e Prazo é revelada e explicitada.

A própria estrutura conceitual e metodológica do PMBOK foi construída segundo o método e a experiência do Departamento de Defesa, aliás, não é mera coincidência o fato de o PMI (Project Management Institute) ter sido fundado em 1969, um ano após a divulgação do C/SCSC.

\subsection{Avanço Físico do Projeto - AFP}

Análise do Avanço Físico do Projeto teve sua origem no Departamento de Defesa Americano (DOD) em 1967 para controlar e administrar riscos e custos de grandes projetos e programas. Foi inicialmente denominado Sistema de Controle de Critérios de Custo e Cronograma (C/SCSC).

Avanço Físico do Projeto é definido como sendo o trabalho efetivamente realizado no projeto, dentro de um determinado período de tempo. Segundo (FLEMING; KOPPELMAN, 1999a), a relação está no desempenho obtido comparado com o que foi gasto para obtê-lo.

Para (FLEMING; KOPPELMAN: 2000), o conceito de Valor Agregado (= AFP) aplicado em projetos consiste em empregar os conceitos de Valor Agregado (= AFP) utilizados no chão de fábrica a trabalhos não repetitivos e limitados no tempo (projetos).

Para (BASSO, 1991), por Valor Agregado (= AFP) entende-se o resultado de um trabalho. Fazer apenas força sem provocar deslocamento não gera trabalho. Este mesmo conceito deve ser transferido para sabermos se estamos ou não agregando valor (= AFP) a um produto ou a um serviço.

Sabe-se da física, que trabalho é o produto da força pelo deslocamento ( $T=F$ x d); fazer apenas força sem provocar deslocamento não gera trabalho. Este mesmo 
conceito deve ser transferido para saber-se se está ou não agregando valor a um produto ou serviço.

Para facilitar a compreensão vai-se recorrer a um simples exemplo que é o da usinagem de um eixo. Neste caso, agrega-se valor quando se está usinando o eixo dentro das especificações. Por outro lado, agrega-se apenas custo, e não valor, quando se inspeciona e se estoca este eixo.

(VARGAS, 2003), define Valor Agregado (= AFP) como sendo: A avaliação entre o que foi obtido em relação ao que foi realmente gasto e ao que se planejava gastar, onde se propõe que o valor a ser agregado inicialmente por uma atividade é o valor orçado para ela. Na medida em que cada atividade ou tarefa de um projeto é realizada, aquele valor inicialmente orçado para a atividade passa, agora, a constituir o Valor Agregado (= AFP) do projeto.

A relação entre os custos reais consumidos e o produto físico obtido no projeto através de uma quantidade específica de trabalho, ou seja: o que foi obtido pelo projeto em relação à quantidade de capital consumida para atingir este resultado, requer que as medidas de despesa-desempenho sejam estabelecidas dentro de um planejamento físico do projeto. Então, através da relação entre o valor do Avanço Físico do Projeto e o valor planejado do trabalho no tempo, pode se ter uma maior precisão no controle do que o tratamento isolado desses fatores.

Funciona como um tipo de "alarme", permitindo ao gerente do projeto avaliar se está consumindo mais dinheiro para realizar uma determinada tarefa ou se está apenas gastando mais naquele momento porque o desenrolar do projeto está sendo acelerado, permitindo que sejam tomadas ações corretivas e preventivas com a devida antecedência.

\subsection{O EVMS Compacto}

A versão compacta do EVMS é denominada de 10 "Earned Value" que busca evidenciar a essência do EVMS aplicável a quaisquer projetos, independente do tamanho, prazo, custos envolvidos, tipo de indústria e demais fatores.

Assim os 10 "Earned Value" consistem em: Definir o Escopo do Projeto; Criação de um Plano Analítico Integrado; Existência de um Sistema de Controle Formal de Planejamento; Designar um CAP (Mapas de Centro de Custos) individual e um 
responsável pelo monitoramento; Estabelecer uma Linha Base de Custo - CAPs; Efetuar medições do desempenho do planejamento; Realizar Medição da Performance de Custo; Re-estimar o desempenho final de custos (EAC); Conhecer qual o desempenho de custo e de prazo necessário para a obtenção das metas de custo e de prazo do projeto; Manter o Controle das Mudanças de Escopo do Projeto.

\subsubsection{Definir o Escopo do Projeto}

Deve ser definido todo o escopo do trabalho objeto do projeto, ou seja, $100 \%$ do escopo devem ser explicitados na fase de planejamento do projeto. O instrumento mais adequado para esta tarefa essencial do projeto deverá ser necessariamente a EAP. Embora pareça óbvio, a maioria das empresas tem dificuldade em obter os $100 \%$ do escopo do trabalho a ser executado, sobretudo para as empresas de software, para as quais tem sido crítico e causa de muitos projetos malogrados, a falta de uma definição clara de $100 \%$ do escopo do projeto.

Diz-se que tal requisito é básico, absolutamente essencial, pois se não houver definição de $100 \%$ do escopo, como se saber se está a $20 \%, 40 \%$ ou $60 \%$ do estágio de término do projeto. Além da EAP, também é imprescindível a utilização do processo de planejamento dos prazos e custos, decisão de se fazer ou adquirir (Make or Buy), avaliação e mensuração de riscos, dos orçamentos.

Atualmente é muito comum 0 uso de equipes multifuncionais para 0 desenvolvimento de projetos, assim é oportuno não só o uso da EAP para a explicitação de $100 \%$ do escopo do projeto, mas também a EAP integrada ao organograma funcional corporativo (apresentado na figura 4.4.1), que explicita o vínculo entre o pessoal interno da empresa e a EAP (WBS).

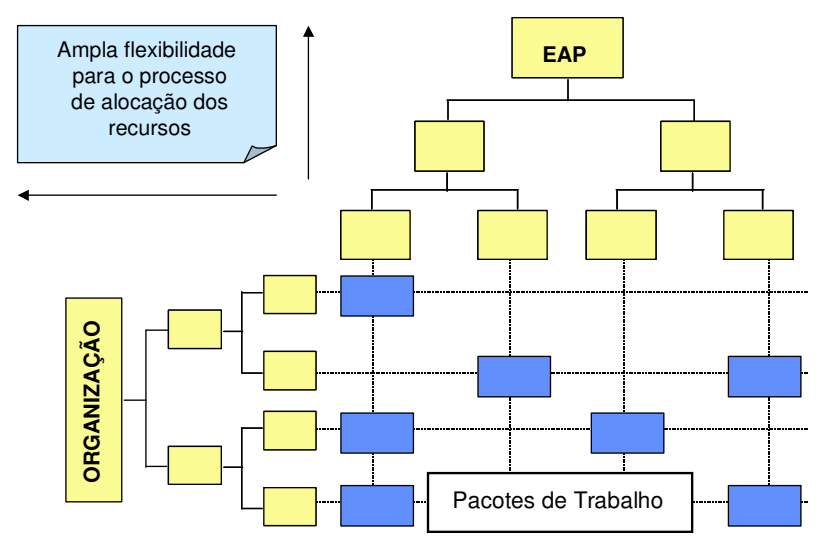

Figura 4.4.1 - Organograma funcional Corporativo 
Uma definição clara de $100 \%$ do escopo do projeto torna necessária a utilização de pacotes de trabalho de curto prazo para tarefas já identificadas, a data de início e término de sua execução, quem irão executá-las, quais serão seus resultados para o projeto e quanto irá custar. Neste sentido a divisão em pacotes de trabalho de curto e longo prazo é muito útil.

Pacotes de Trabalho detalhados de curto prazo.

\section{Planejamento de Pacotes de Trabalho}

Trabalho a ser realizado no futuro, sem uma clara definição de seu conteúdo. Todavia é autorizado, não precificado!

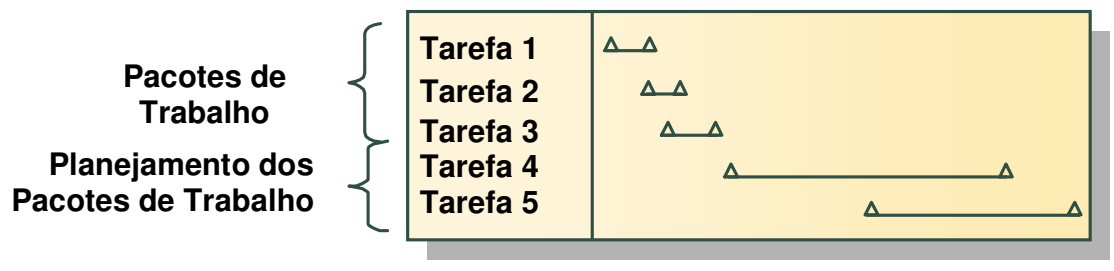

Figura 4.4.2 - Planejamento de Pacotes de Trabalho

\subsubsection{Criação de um Plano Analítico Integrado}

Todo projeto deverá conter um consistente Plano Analítico Integrado (PAI) que combine os processos críticos essenciais do projeto: 100\% do escopo do trabalho definido, inserido no planejamento do projeto, com seus custos estimados e o respectivo orçamento inicial autorizado, através dos CAPs ou "Mapas de Centro de Custo" como se denomina aqui no Brasil.

Para (FLEMING; KOPPELMAN 1999), os CAPs são vitais para a mensuração do desempenho do projeto, pois é através dos CAPs que o controle de desempenho será efetuado, o desempenho técnico de prazo e de custo será sumarizado nos CAPs e aí, então, será reportado para os níveis mais elevados do projeto.

Os elementos constitutivos dos CAPs são: Declaração de Trabalho (SOW); Planejamento (Data de Início e Fim de Cada Tarefa e sua Folga); Orçamento (Budget), expresso em \$ ou em Horas, ou qualquer outra unidade consistente de medida; Pessoa Responsável pelo Controle da Execução; Departamento Responsável; Tipo de Tarefa (padrão, rotineira); Subdivisão em Pacotes de Trabalho 
e Planejamento de Pacotes de Trabalho e o Método EVMS de Mensuração utilizado (marcos de entrega, fórmula, percentual de completude, padrões e nível de esforço utilizado).

\subsubsection{Existência de um Sistema de Controle Formal de Planejamento}

O trabalho programado planejado através de um planejamento previsto estimado constitui a base para o estabelecimento do valor planejado. Qualquer projeto deverá contemplar um sistema de controle. O EVMS do projeto será determinado a partir da confrontação do trabalho efetivamente realizado (EV) com o valor "meta/alvo", o valor planejado (PV), para um determinado período de tempo em função de uma data estabelecida de medição. É importante ressaltar que tanto o PV quanto o EV devem ser expressos na mesma unidade de medida, para haver consistência na mensuração de desempenho.

Para (FLEMING; KOPPELMAN, 1999), o sistema de Controle de Planejamento é absolutamente crítico, pois o EVMS somente poderá ser empregado se houver a existência de $100 \%$ do escopo do projeto por meio da EAP e do Planejamento Geral do Projeto.

\section{Indicadores do Earned Value}

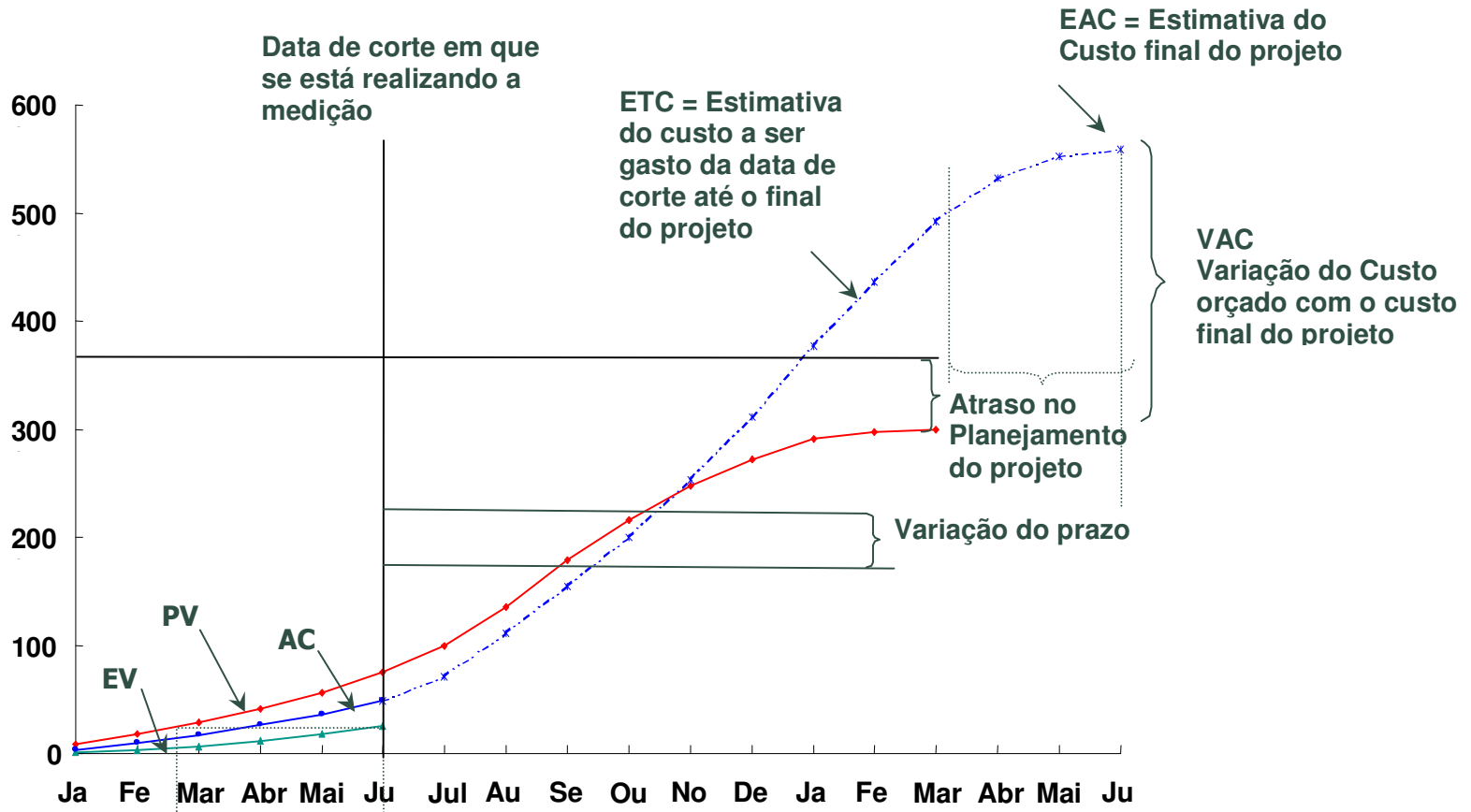

Figura 4.4.3 - Sistema de Controle Formal de Planejamento 


\subsubsection{Designar cada CAP individual a um responsável pelo monitoramento}

Cada CAP individual deverá ser designado a um "líder" responsável definido pela Matriz de Responsabilidades do Projeto. Será responsável pelo monitoramento do desempenho e pelo controle da sua execução. Deverá supervisionar a execução do trabalho, se o trabalho está atrasado, adiantado ou no prazo, se o CAP está abaixo, acima ou de acordo com o custo previsto, se o escopo está sendo mantido ou se está ocorrendo desvios de escopo.

A supervisão de cada CAP é essencial para manter-se o projeto dentro do prazo, do orçamento e do escopo, uma vez que a soma dos CAPs constitui a Linha de Base Orçamentária, a qual será objeto de medida de seu desempenho.

Não raro ocorre que um simples membro da empresa, que no organograma é apenas um simples empregado funcional, no projeto, seja designado como gerente responsável pelo CAPs.

\subsubsection{Estabelecer uma Linha Base de Custo - CAP's}

Com o Escopo do projeto concluído, deve ser elaborada a Estrutura Analítica do Projeto (EAP), deve se abrir os respectivos Mapas de Centro de Custos (CAPs) que irão representar a somatória dos Pacotes de Trabalho e do Planejamento dos Pacotes de Trabalho. Desnecessário é dizer que os CAPs relativos ao planejamento dos Pacotes de Trabalho, devem ser formalmente separados dos Pacotes de Trabalho. Procede-se ao processo de estimativa dos custos dos pacotes de trabalho, e posteriormente sua somatória agrupada através dos CAPs irá determinar a linha base orçamentária do projeto que constituirá a meta de custo e de prazo contra a qual o $A C$ e o EV serão confrontados. Através da somatória dos CAPs poderá também se obter o Fluxo de Caixa do Projeto.

Pelos critérios formais do EVMS, a linha base de custo, também conhecida como Linha de Custo, é a referência contra a qual será mensurado o desempenho do projeto. Constitui os custos totais necessários para a conclusão do projeto. Inclui o orçamento de recursos alocados (pacotes de trabalho) e o planejamento dos pacotes de trabalho, que são tarefas autorizadas porém ainda não contempladas analiticamente nos CAPs e, nem tampouco precificadas. 
Não inclui as reservas para o Gerente de Projeto fazer face às eventuais contingências ou incertezas do projeto. As eventuais contingências ou incertezas do projeto fazem parte do valor total contratado entre contratado e contratante.

Incluem também, os respectivos honorários, ou margem de rentabilidade, mudanças negociadas e autorizadas de escopo (aditivos de Contrato).

É importante observar que as eventuais contingências ou incertezas do projeto são determinadas em função da avaliação de risco do projeto, a qual quantificará os recursos necessários para fazer frente às contingências e incertezas do projeto, e eventualmente mitigar os riscos latentes associados.

Na figura 4.4.5 ilustra-se a estrutura da Medida do Desempenho Inicial do Projeto (PMB-Performance Measurement Baseline) e do Valor Inicial do Orçamento do Contrato CBB (Contract Budget Base).

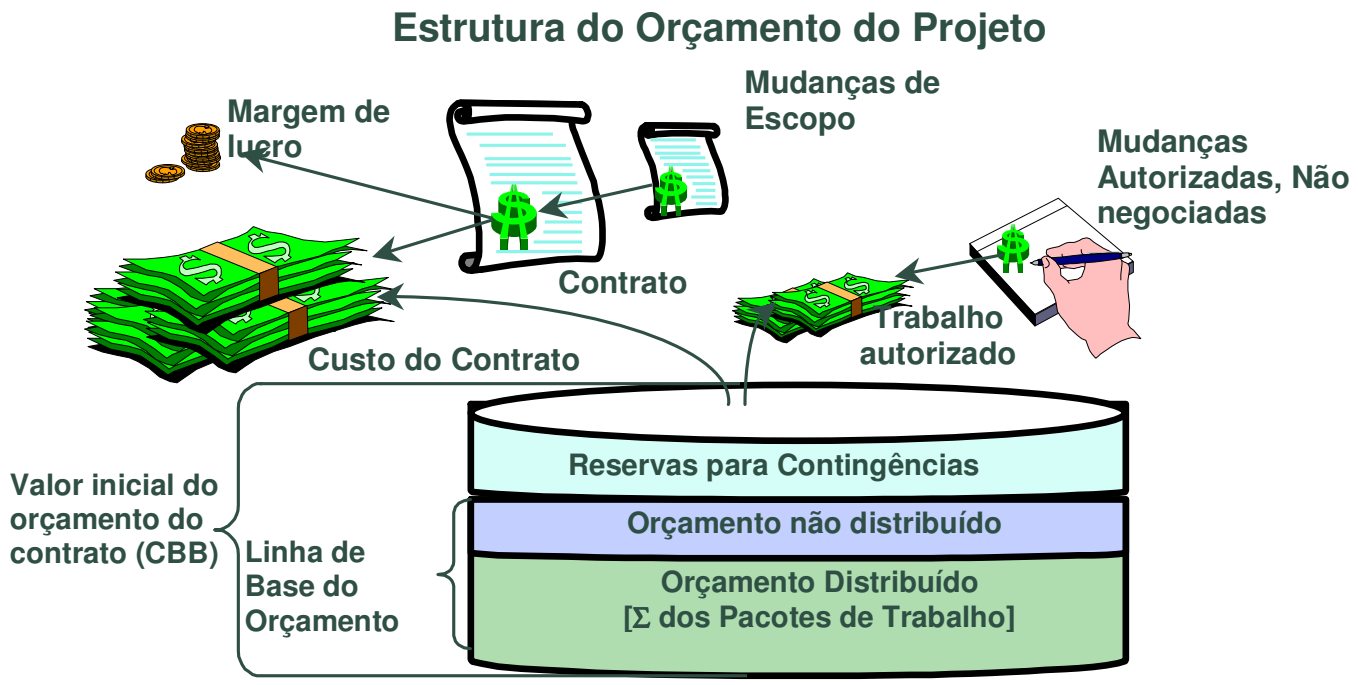

Figura 4.4.5 - Estrutura do orçamento do projeto

\subsubsection{Efetuar medições do desempenho do Planejamento}

Pelo menos mensalmente e já na fase inicial do projeto, com $5 \%$ de estágio de avanço deve-se efetuar medições dos prazos para se mensurar o estágio de desempenho do planejamento. Deve-se comparar o EV contra o PV ou o custo planejado para se obter a variação de prazo (SV = Schedule Variance = Variação do prazo de execução do Projeto) cuja fórmula é SV = EV - PV. Esta fórmula revelará 
em valores absolutos, a variação positiva ou negativa no avanço do planejamento. Mais interessante que a variação do planejamento (SV) em termos absolutos, é o cálculo do SPI = Schedule Performance Index = Índice de desempenho de prazo do projeto, cuja fórmula é SPI = EV / PV. Um SPI menor que 1 significa que o projeto está atrasado, um SPI maior que 1 significa que o projeto está adiantado, um SPI igual a 1 significa que se está exatamente dentro do planejado.

É interessante efetuar as medições por cada CAPs individualmente, pois assim o GP poderá identificar os pacotes de trabalho que possam por em risco a estabilidade do projeto, se, por exemplo, tal CAPs ou pacote fizer parte do caminho crítico.

É preciso tomar cuidado com o desempenho acima de 1.2, pois poderá significar que o Gerente de Projetos sobreestimou o tempo de execução das tarefas do pacote ou de todo projeto. Desempenhos abaixo de 0,8 dificilmente deixarão de acarretar horas-extras ao projeto e, conseqüentemente, aumentos irrecuperáveis de custo. Segundo FLEMING, KOPPELMAN (1999), a partir de 15\% de estágio de avanço os aumentos irrecuperáveis de custo irão significar necessariamente custos perdidos e irrecuperáveis.

\section{EV demonstra separadamente as variações de prazo e de custo!}
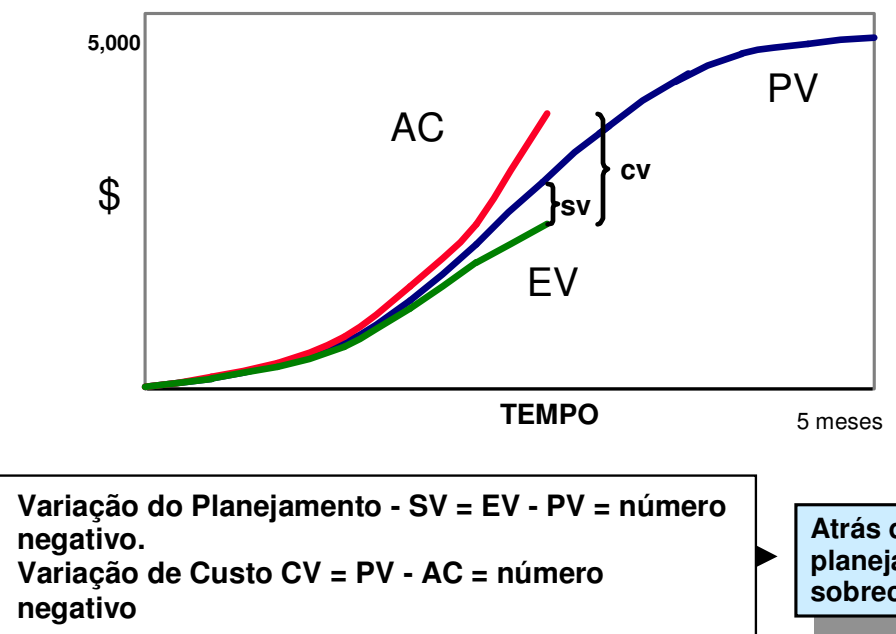


\subsubsection{Efetuar medições do desempenho do Custo}

Simultaneamente à medição da eficiência do planejamento, deverá ser efetuada a medição do desempenho de custo. A variação de custo em termos absolutos é dada pela diferença entre o $A C$ e $\circ \mathrm{EV}$. Ou seja, (CV = Cost Variance $=$ Variação do custo do Projeto) cuja fórmula é o CV = EV - AC. Compara-se o EV com o Custo Real do Trabalho Realizado (AC). Um CV negativo significa que o custo está superior ao inicialmente planejado. Um CV positivo significa economia de custo, ou incremento de produtividade. Um CV nulo significa eficiência de custo ou que o projeto está dentro do planejado.

Essencial para a avaliação do desempenho de custo é o CPI - Cost Performance Index - Índice de desempenho de custo do projeto, cuja fórmula é:

$$
C P I=E V / A C
$$

Um CPI maior que 1,0 é ótimo, igual a 1,0 é bom, e menor que 1,0 é ruim.

Tanto o SPI quanto o CPI, e como veremos mais adiante o EAC, são vitais para a avaliação periódica (no mínimo mensalmente) do desempenho do projeto. Servem para a tomada de ações corretivas em tempo hábil para a manutenção dos fatores críticos de sucesso do projeto.

\section{Variação de Custo}

EV = Quanto de trabalho foi efetivamente realizado!.

$A C=$ Quanto foi efetivamente gasto para realizar o trabalho?.

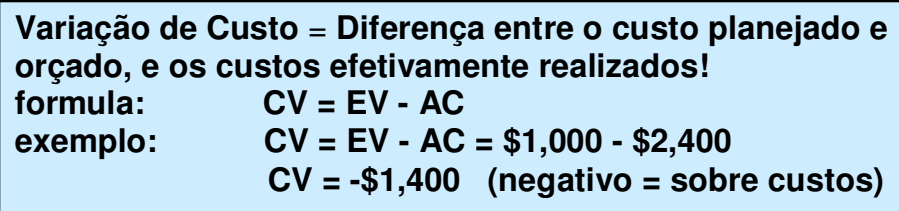

Figura 4.4.7 - Variação de Custo

Um outro indicador muito importante para o controle do projeto é o CR - Critical Ratio = Índice que determina a ponderação entre o Custo e o Prazo do projeto, e é obtido pela seguinte relação: 


$$
\mathrm{CR}=\mathrm{SPI}{ }^{*} \mathrm{CPI}
$$

mensurada rotineiramente a partir do estágio de avanço de $10 \%$ do tempo do planejado para o projeto.

$\mathrm{CR}=1$ significa que o projeto está perfeitamente dentro do custo e do prazo;

$0,8>$ CR <1 significa que se o GP tomar medidas corretivas adequadas o projeto ainda poderá ser entregue no prazo e talvez dentro do custo previsto;

0,5 > CR < 0,8 é motivo de alerta, e serão necessárias horas extras para se entregar o projeto dentro do prazo, porém certamente acima do custo;

$\mathrm{CR}<0,5$ poderá motivar o cancelamento do projeto;

$1>\mathrm{CR}<1,2$ pode significar ótima produtividade, queda de restrições;

CR > 1,2 poderá ser motivo de desconfiança, pois os prazos e custos podem ter sido superestimados.

\subsubsection{Re-estimar o Desempenho Final de Custos - EAC}

É muito útil para o Gerente de Projeto re-estimar mensalmente o desempenho final de custos do projeto através do (EAC). O EAC é, portanto, a soma do desempenho de custos reais incorridos $(A C)$ e do desempenho orçamentário dos valores restantes estimados que ainda faltam para serem gastos (ETC). O EAC é obtido através da seguinte relação: $E A C=A C+E T C$.

\subsubsection{Conhecer qual o desempenho de custo e de prazo necessário para a obtenção das metas de custo e de prazo do projeto}

Conhecer o trabalho remanescente do projeto, ou seja, quantos pacotes de trabalhos ainda restam para serem executados, quantas tarefas ainda existem a realizar, é essencial para a tomada de ações corretivas pelo GP. Adicionalmente importa para o GP, conhecer o orçamento que ainda resta para ser gasto na consecução das tarefas do projeto.

O índice de desempenho de custos de recuperação TCPI = indica qual é o desempenho que deverá ser obtido para a consecução das metas do projeto, revelase como um dos mais eficientes indicadores do EVMS. Por outro lado, um TCPI = Work Remaining / Cost Remaining = Indicador da relação entre o trabalho que ainda falta a ser realizado e do custo necessário para sua realização, calculado com base no BAC, poderá indicar um desempenho impossível de se atingir, se o CPI estiver 
ruim. Por exemplo: em torno de 0,50 o TCPI será calculado em função do BAC ou seja do custo inicial do projeto (recomendável), ou do EAC, ou seja, do custo reestimado do projeto. Um TCPI calculado em cima do BAC revela-se mais apropriado para a obtenção da eficiência em função do inicial do projeto, por outro lado um TCPI calculado em função do EAC poderá revelar pouca preocupação com a eficiência de custo.

O TCPI é obtido pela seguinte relação:

$$
\begin{gathered}
\text { TCPI }(\mathrm{EAC})=\mathrm{EAC}-\mathrm{EV} / \mathrm{EAC}-\mathrm{AC}(4.4 .9 .1) \\
\text { ou } \\
\mathrm{TCPI}(\mathrm{BAC})=\mathrm{BAC}-\mathrm{EV} / \mathrm{BAC}-\mathrm{AC}
\end{gathered}
$$

\subsubsection{Manter o Controle das Mudanças de Escopo do Projeto}

Para que haja uma adequada, eficiente e eficaz mensuração de desempenho, é necessário que haja $\mathrm{o}$ respeito às medidas de desempenho inicialmente estabelecidas no Projeto (PMB). Assim todas as mudanças de escopo que impliquem em aumento de tarefas e orçamento, precisarão ser devidamente controladas, para que não ocorram perturbações no PMB e a conseqüente ineficácia no processo de avaliação de desempenho.

\subsection{Medição e Cálculo do Avanço Físico}

(HARROFF, 2000); (FLEMING; KOPPELMAN 1999a), subdividem a Medição do Valor Agregado (= AFP) em sete diferentes métodos, e (VARGAS, 2003) os descreve como sendo: Marcos com valores ponderados, Fórmula fixa por CAP (Mapa de Centro de Custo), Percentual Completo, Percentual Completo com marcos de controle, Unidades Equivalentes, CAP's com características compartilhadas e Nível de esforço. Nas tabelas a seguir o marco de controle será identificado através de um losango $\diamond$. Nos itens a seguir, o termo Valor Agregado será substituído por Avanço Físico do Projeto - AFP.

\subsubsection{Marcos com valores ponderados}

Normalmente indicados para células de controle (CAPs), em que a duração seja maior do que um período de controle. (exemplo: duas semanas para projetos avaliados semanalmente ou três meses para projetos avaliados mensalmente). 
A célula de controle é convertida em dois ou mais marcos de controle onde cada um deles é definido por uma entrega parcial do trabalho, gerando, conseqüentemente, um custo específico. A soma dos custos para se atingir cada um desses marcos é o custo do CAP.

Na tabela 4.5.1 são definidos 3 marcos totalizando $R \$ .200,00$ para um CAP com a duração de três meses.

Tabela 4.5.1 - Medição do Avanço Físico do Projeto através de marcos com valores ponderados

\begin{tabular}{|c|c|c|c|c|}
\hline CAP & Jan & Fev & Mar & Total \\
\hline CAP A & $\diamond$ & $\diamond$ & $\bigotimes_{75}$ & 200 \\
\hline
\end{tabular}

\subsubsection{Fórmula fixa por CAP}

É o método que divide o CAP em duas partes que, somadas, complementam os $100 \%$ dos trabalhos. As fórmulas usualmente utilizadas são 25/75, 50/50 e 75/25. A fórmula 25/75 divide o trabalho em duas partes: o primeiro ponto é atingido imediatamente com o início do CAP (25\% dos custos já são contabilizados); os outros $75 \%$ dos custos somente são contabilizados quando o trabalho efetivamente termina. A fórmula $50 / 50$ indica que $50 \%$ dos custos serão contabilizados com o início do trabalho e 50\% com o seu término. A fórmula $75 / 25$ indica que $75 \%$ dos custos serão contabilizados com o início do trabalho e $25 \%$ com o seu término.

Na tabela 4.5.2 é utilizada a fórmula fixa por tarefa (25/75) para um CAP com duração de três meses.

Tabela 4.5.2 - Medição do Avanço Físico do Projeto através de fórmula fixa 25/75

\begin{tabular}{|c|c|c|c|c|}
\hline CAP & Jan & Fev & Mar & Total \\
\hline CAP A & $\searrow$ & & $\bigotimes_{150}$ & 200 \\
\hline
\end{tabular}

\subsubsection{Percentual Completo}

É o método que atribuí a cada CAP um determinado percentual completo (entre 0 e $100 \%$ ) a cada ciclo de controle. Este percentual é multiplicado pelo custo previsto do CAP com o objetivo de determinar a parcela do orçamento já realizada. 
É grande a sua utilização nos projetos devido à facilidade de uso, sendo o mecanismo padrão de entrada de valores do avanço físico na maioria dos softwares de gerenciamento de projetos.

Na tabela 4.5.3 mostra-se uma distribuição financeira linear para um CAP com a duração de três meses.

Tabela 4.5.3 - Medição do Avanço Físico do Projeto através do percentual completo

\begin{tabular}{|c|c|c|c|c|}
\hline CAP & Jan & Fev & Mar & Total \\
\hline CAP A & 67 & 67 & 66 & 200 \\
\hline
\end{tabular}

\subsubsection{Percentual Completo com marcos de controle}

É uma combinação dos métodos de percentual completo com o de marcos com valores ponderados. Uma parte do controle é realizada através da introdução dos percentuais completos de cada CAP e em determinados momentos da execução do trabalho, onde entregas são facilmente identificáveis, marcos de controle são inseridos de modo a garantir a precisão do percentual completo inserido, funcionando como uma espécie de duplo controle.

$\mathrm{Na}$ tabela 4.5.4 mostra-se uma distribuição financeira linear para um CAP com a duração de três meses.

Tabela 4.5.4 - Medição do Avanço Físico do Projeto através do percentual completo com marcos de controle no final de cada mês

\begin{tabular}{|c|c|c|c|c|}
\hline CAP & Jan & Fev & Mar & Total \\
\hline \multirow{2}{*}{ CAP A } & 67 & 67 & 66 & \multirow{2}{*}{200} \\
\hline & $33 \%$ & $67 \%$ & $100 \%$ & \\
\hline
\end{tabular}

\subsubsection{Unidades equivalentes}

É o método que calcula o Avanço Físico com base em unidades produzidas ou realizadas de elementos individuais de custos, empregado em trabalhos repetitivos ou onde os CAPs são definidos em termos de consumo direto de recursos. Exemplificando, supondo-se que num determinado projeto de construção civil tenha que se realizar um trabalho de pavimentação asfáltica de $80 \mathrm{~m}^{2}$ em 3 meses, com avaliações mensais. Ao final do primeiro mês, o percentual completo é determinado de maneira objetiva através da medição da quantidade de pavimento realizada, 
neste caso, de $42 \mathrm{~m}^{2}$. O EV é calculado através do percentual completo de $52,5 \%$ (42/200) multiplicado pelo orçamento do CAP que é de $200\left(52,5^{\star} 200=105\right)$.

Na tabela 4.5.5 mostra-se a medição do Avanço Físico do Projeto através de unidades equivalentes para uma célula de controle CAP com a duração de três meses onde uma determinada unidade de medida é convertida em valores a partir de um custo por unidade.

Tabela 4.5.5 - Medição do Avanço Físico do Projeto através de unidades equivalentes para uma célula de controle CAP

\begin{tabular}{|c|c|c|c|c|}
\hline CAP & Jan & Fev & Mar & Total \\
\hline \multirow{2}{*}{ CAP A } & $42 \mathrm{~m} 2$ & $19 \mathrm{~m} 2$ & $19 \mathrm{~m} 2$ & $80 \mathrm{~m} 2$ \\
\cline { 2 - 5 } & $52,5 \%$ & $23,75 \%$ & $23,75 \%$ & $100 \%$ \\
\cline { 2 - 5 } & 105 & 47,5 & 47,5 & 200 \\
\hline
\end{tabular}

\subsubsection{CAPs com Características compartilhadas}

É o método empregado quando um determinado CAP tem uma relação direta com outro, denominado "base de medida". A realização do CAP e seu desempenho são associados diretamente ao de sua base de medida, normalmente calculada segundo outro método de medição do Avanço Físico do Projeto. Por exemplo, quando a base de medida está $50 \%$ completa, o CAP relacionado também está 50\% completo por analogia. Na tabela 4.5.6 mostra-se a medição do Avanço Físico do Projeto com auxílio de CAPs com características compartilhadas onde um CAP de referência atua como base de medida para o CAP analisado.

Tabela 4.5.6 - Medição do Avanço Físico do Projeto através de CAPs com características compartilhadas

\begin{tabular}{|c|c|c|c|c|}
\hline CAP & Jan & Fev & Mar & Total \\
\hline $\begin{array}{c}\text { CAP de } \\
\text { Referencia }\end{array}$ & 50 & 50 & 100 & 200 \\
\hline CAP Analisado & 75 & 75 & 150 & 300 \\
\hline
\end{tabular}

\subsubsection{Nível de esforço}

Atividades do nível de esforço são os trabalhos indiretos realizados no projeto. $O$ nível de esforço é o trabalho que engloba as atividades o escritório do projeto, a documentação, os serviços indiretos para o time, e todas as outras atividades de suporte, não associado à produção do produto final do projeto. 
Normalmente, os custos indiretos são: Salários de executivos e de funcionários administrativos; Despesas contábeis e legais: Aluguéis, Telefones, Luz e outros itens de serviços, Viagens de executivos, Contribuições, Custos de recrutamento; Seguros da estrutura administrativa. 


\section{PROCESSO ATUAL DE GERENCIAMENTO DE PROJETOS E CONTROLE DO AVANÇO FÍSICO DO PROJETO}

\subsection{Processo atual de Gerenciamento de Projetos}

Idealmente, os processos de gerenciamento de projetos existentes em uma empresa deveriam seguir as recomendações do PMBOK, e outros procedimentos relacionados, tais como; a norma da (International Organization for Standardization) ISO9002, a Metodologia de Diagnóstico e Avaliação da Maturidade de desenvolvimento de Software - CMM (Capability Maturity Model) nível 2, e do sistema de Controle da Qualidade.

A empresa que será objeto de análise e considerações é uma multinacional atuando na área Metro-Ferroviária; sendo que a unidade na qual o autor trabalha está relacionada à área de Projetos e Implantação de Sistemas de Sinalização de via e de Supervisão e Controle Local e Centralizado.

\subsubsection{Controle dos Custos}

O controle dos custos da mão de obra utilizado no projeto, na contratação de serviços de terceiros, na fabricação e ou aquisição de materiais e equipamentos, são disponibilizados pela área financeira, por um Sistema de Controle Administrativo (SAP). Os custos relacionados ao trabalho utilizado nos projetos, são decorrentes do lançamento de horas realizado diariamente no sistema de apontamento de horas existente. Essas informações são então extraídas do SAP pelo controlador de custos do projeto, para atualização de todos os custos incorridos mensalmente em cada um dos pacotes de trabalho, em uma planilha auxiliar gerada, por exemplo, pelo aplicativo Excel. Essas informações são então disponibilizadas para consulta ao gerente de projetos, aos responsáveis pelos pacotes de trabalho e demais áreas envolvidas no projeto, no diretório do projeto, localizado no servidor central da empresa.

\subsubsection{Atualização do planejamento do projeto}

Mensalmente são disponibilizados, através do sistema de planejamento Primavera, aos responsáveis pelos pacotes de trabalho, relatórios contendo para cada atividade e para cada recurso alocado na atividade, o trabalho ainda a incorrer (em dias ou horas), distribuído mensalmente para a conclusão de cada atividade. 
A atualização do trabalho realizado em cada atividade do projeto é realizada em duas etapas: A primeira atualização é realizada quinzenalmente pelos responsáveis pelos pacotes de trabalho, com o responsável pela atualização do planejamento, indicando para cada atividade, quantos dias (horas) de trabalho foram gastos no período em cada uma das atividades. A segunda atualização é realizada ao final do mês, onde são novamente atualizadas, consolidadas ou alteradas as atualizações realizadas na quinzena anterior e complementado com o trabalho realizado na segunda quinzena do mês.

Realizadas às atualizações, é gerada uma nova versão do planejamento do projeto, onde são extraídos os custos a incorrer, que é o trabalho necessário para a conclusão das atividades até o final do projeto (ETC - Estimate to Complete). São também disponibilizados relatórios para cada responsável pelos pacotes de trabalho, contendo a quantidade de trabalho ainda restante em cada uma das atividades e com a identificação do funcionário alocado a atividade.

Através da nova revisão do planejamento, pode-se também analisar o caminho crítico do projeto, verificando as atividades que estão atrasadas e ocasionando atrasos em outras atividades dependentes.

\subsubsection{Disponibilidade dos relatórios de custos e recursos mensais}

A partir do quinto dia útil do mês subseqüente, todos os custos lançados no mês anterior estão disponíveis aos responsáveis pelos pacotes de trabalho e ao Gerente do Projeto no diretório do projeto, localizado no servidor central da empresa.

Com as informações do orçamento inicial do projeto (PV), do custo da mão de obra real incorrido disponibilizado pelo SAP (AC), do Avanço Físico do Projeto (EV), e dos Custos a Incorrer (ETC) disponibilizado com auxílio do aplicativo Primavera, pode-se então realizar análises de desempenho do projeto, e tomar as ações preventivas e corretivas necessárias.

Também são disponibilizadas para análise, as demais informações relacionadas à contratação de serviços de terceiros, aquisição de materiais e equipamentos, viagens e estadias, e demais despesas. 


\subsection{Deficiências e Virtudes}

Não há implantado na empresa um sistema que faça a medição real do Avanço Físico do Projeto, ocasionando desta forma um problema ao Gerente do Projeto, pois ele não tem como comparar o andamento dos custos reais incorridos com o Avanço Físico do Projeto.

Atualmente, está em processo de implantação na empresa um projeto mundial, onde está sendo disponibilizado um relatório para cada pacote de trabalho, contendo todas as informações e curvas de custos, prazos e qualidade, do Avanço Físico do Projeto e dos marcos das entregas definidos em cada pacote de trabalho. Desta forma, cada responsável pelo pacote de trabalho analisa os índices de desempenho do projeto, justificando no relatório os desvios apresentados e as ações corretivas e/ou preventivas necessárias para sanar os desvios.

Até o décimo dia do mês subseqüente, todos os relatórios dos pacotes de trabalho são enviados ao Gerente do Projeto, onde então são integrados a uma metodologia que consolida os diversos pacotes de trabalho, dando as informações de desempenho global do projeto do mês anterior.

Entretanto, o controle do Avanço Físico do Projeto continua a ser realizado por meio do método de Percentual Completo (utilizando-se marcos de entrega). Mensalmente são estimados os percentuais de avanço de cada marco de entrega comparados com os do orçamento inicial do projeto (Baseline), e gerada a curva do Avanço Físico do pacote de trabalho. Esta metodologia adotada continua ainda com uma grande imprecisão no cálculo do andamento físico do projeto, pois o valor do avanço continua sendo atribuído ao término de um conjunto de atividades (marcos de entrega). É atualizado empiricamente pelo responsável, baseado na sua experiência, pois não há uma metodologia disponível que permita realizar uma melhor atualização do avanço físico de cada tarefa.

$\mathrm{Na}$ tabela 5.2 são apresentados os critérios atuais adotados para a definição e medição do Avanço Físico do Projeto. 
Tabela 5.2 - Cálculo atual do Avanço Físico do Projeto

\begin{tabular}{|c|c|c|c|c|c|c|c|c|}
\hline & Milestones & & PESO & dez-05 & jan-06 & fev-06 & mar-06 & abr-06 \\
\hline M1 & Elaboração das Especificações Técnicas & Já Concluída & $10,0 \%$ & $0 \%$ & $20 \%$ & $60 \%$ & $80 \%$ & $100 \%$ \\
\hline M2 & Fabricação e Aquisição de Materiais/Equipame & Não Concluida & $20,0 \%$ & $0 \%$ & $0 \%$ & $15 \%$ & $35 \%$ & $35 \%$ \\
\hline M3 & Projeto de Construção do CCO & Não Concluida & $10,0 \%$ & $0 \%$ & $15 \%$ & $35 \%$ & $50 \%$ & $60 \%$ \\
\hline M4 & Desenvolvimento de Software & Não Concluida & $20,0 \%$ & $0 \%$ & $5 \%$ & $50 \%$ & $50 \%$ & $65 \%$ \\
\hline M5 & Integração e Testes em Fábrica & Não Concluida & $10,0 \%$ & & & & & \\
\hline M6 & Elab. Procedimentos Testes de Fábrica e Camp & Não Concluida & $10,0 \%$ & & & & & \\
\hline M7 & Projeto de Desenv.e Testes PLOs e CLPs & Não Concluida & $10,0 \%$ & & & & & \\
\hline M8 & Projetos de Instalação em Campo & Não Concluida & $10,0 \%$ & & & & & \\
\hline M9 & Testes de Integração em Campo & Não Concluida & $0,0 \%$ & & & & & \\
\hline \multirow[t]{3}{*}{ M10 } & & & & & & & & \\
\hline & Total para os milestones $=$ & & $100 \%$ & & & & & \\
\hline & Avanço Físico do Projeto (BCWP) & & & & & & & \\
\hline M1 & Elaboração das Especificações Técnicas & & & $0 \%$ & $2 \%$ & $6 \%$ & $8 \%$ & $10 \%$ \\
\hline M2 & Fabricação e Aquisição de Materiais/Equipame & & & $0 \%$ & $0 \%$ & $3 \%$ & $7 \%$ & $7 \%$ \\
\hline M3 & Projeto de Construção do CCO & & & $0 \%$ & $2 \%$ & $4 \%$ & $5 \%$ & $6 \%$ \\
\hline M4 & Desenvolvimento de Software & & & $0 \%$ & $1 \%$ & $10 \%$ & $10 \%$ & $13 \%$ \\
\hline M5 & Integração e Testes em Fábrica & & & $0 \%$ & $0 \%$ & $0 \%$ & $0 \%$ & $0 \%$ \\
\hline M6 & Elab. Procedimentos Testes de Fábrica e Camf & & & $0 \%$ & $0 \%$ & $0 \%$ & $0 \%$ & $0 \%$ \\
\hline M7 & Projeto de Desenv.e Testes PLOs e CLPs & & & $0 \%$ & $0 \%$ & $0 \%$ & $0 \%$ & $0 \%$ \\
\hline M8 & Projetos de Instalação em Campo & & & $0 \%$ & $0 \%$ & $0 \%$ & $0 \%$ & $0 \%$ \\
\hline M9 & Testes de Integração em Campo & & & $0 \%$ & $0 \%$ & $0 \%$ & $0 \%$ & $0 \%$ \\
\hline \multirow[t]{3}{*}{ M10 } & 0 & & & $0 \%$ & $0 \%$ & $0 \%$ & $0 \%$ & $0 \%$ \\
\hline & Total Avanço Físico do projeto no mês = & & & $0 \%$ & $5 \%$ & $23 \%$ & $30 \%$ & $36 \%$ \\
\hline & Avanço Físico Inicial Planejado Projeto & & & & & & & \\
\hline M1 & Elaboração das Especificações Técnicas & & $10,0 \%$ & $0 \%$ & $15 \%$ & $50 \%$ & $75 \%$ & $100 \%$ \\
\hline M2 & Fabricação e Aquisição de Materiais/Equipame & & $20,0 \%$ & $0 \%$ & $5 \%$ & $20 \%$ & $35 \%$ & $40 \%$ \\
\hline M3 & Projeto de Construção do CCO & & $10,0 \%$ & $0 \%$ & $5 \%$ & $30 \%$ & $60 \%$ & $70 \%$ \\
\hline M4 & Desenvolvimento de Software & & $20,0 \%$ & $0 \%$ & $5 \%$ & $50 \%$ & $60 \%$ & $70 \%$ \\
\hline M5 & Integração e Testes em Fábrica & & $10,0 \%$ & & & & & \\
\hline M6 & Elab. Procedimentos Testes de Fábrica e Camp & & $10,0 \%$ & & & & & \\
\hline M7 & Projeto de Desenv.e Testes PLOs e CLPs & & $10,0 \%$ & & & & & \\
\hline M8 & Projetos de Instalação em Campo & & $10,0 \%$ & & & & & \\
\hline M9 & Testes de Integração em Campo & & $0,0 \%$ & & & & & \\
\hline \multirow[t]{2}{*}{ M10 } & 0 & & $0,0 \%$ & & & & & \\
\hline & Total Avanço Físico Planejado no mês = & & & $0 \%$ & $4 \%$ & $22 \%$ & $33 \%$ & $39 \%$ \\
\hline
\end{tabular}

- No quadro "milestones" são identificados no máximo dez marcos de entrega, e se o marco foi concluído (Reached) ou não concluído (Not Reached). No campo "Peso" é atribuído a cada um dos marcos de controle (milestones) dentro desse pacote de trabalho, um percentual (ex: 10\%, 20\%...), que indica o quanto de recursos cada um dos marcos de controle representa dentro do pacote de trabalho. Nas colunas dos meses, são atualizadas mensalmente as porcentagens acumuladas de cada um dos marcos de entrega até atingir os $100 \%$, indicando o término da atividade e o cumprimento do marco de entrega. Estes valores são estimados pelo líder do pacote de trabalho.

- No quadro "Avanço Físico Inicial Planejado do Projeto", aparecem às mesmas informações do quadro "milestones", porém na coluna mês, é atribuída, no início do projeto, uma estimativa mensal do Avanço Físico Planejado, para se alcançar cada um dos marcos de entrega.

- No quadro "Avanço Físico do Projeto (EV)", é calculado o andamento físico de cada marco de entrega multiplicando o percentual alocado no mês (ex: para a atividade $M 1$ - abril/06 $=100 \%$, no quadro "milestones") pelo peso atribuído para M1 de10\%, obtendo-se, portanto, um percentual de avanço do 
marco de entrega em abril/06 de 10\%. A seguir, é realizada a soma de todos esses percentuais calculados para cada marco de entrega, apresentando o Avanço Físico do mês de abril/06 desse pacote de trabalho, que no exemplo mostrado na tabela 5.2 é de $36 \%$.

Analisando a metodologia utilizada nos cálculos realizados, pode-se afirmar que a forma de medição é a normalmente utilizada em várias organizações, apresentando, portanto resultados ainda considerados imprecisos e ainda muito dependentes da subjetividade do técnico responsável.

\subsection{Proposição de Nova Metodologia de medição do trabalho realizado - Avanço Físico do Projeto - AFP}

Como já é consenso geral em todas as literaturas existentes sobre o Avanço Físico do Projeto, é praticamente impossível se determinar com $100 \%$ de precisão o avanço físico de um projeto, principalmente os que envolvem projetos de engenharia e desenvolvimento de software. Por melhor e mais complexa que seja a metodologia a ser empregada, sempre se dependerá de uma informação de subjetividade sobre o avanço físico de uma atividade, por menor que ela seja. Essa subjetividade pode ser observada na descrição do sistema atualmente existente apresentado no item anterior.

Segundo (VARGAS, 2003), o grande obstáculo na utilização do método do percentual completo é o elevado grau de subjetividade em sua avaliação, sendo influenciado diretamente pela percepção do avaliador. Como a entrada de dados é determinada de uma percepção individual do avaliador, o método do percentual completo é sujeito a maiores pressões pelo cliente ou alta gerência, podendo comprometer os resultados apurados.

Entretanto, analisando-se cada uma das metodologias já apresentadas, das implicações citadas por (VARGAS, 2003) e comparando com a metodologia atualmente utilizada na empresa e descrita no item 5.2, no presente trabalho apresenta-se uma proposição mais refinada de determinação do Avanço Físico do Projeto. Será utilizada a mesma metodologia de Percentual Completo, porém com inovações no cálculo dos percentuais de Avanço Físico de cada atividade do projeto. 


\subsubsection{Proposta de uma nova metodologia para cálculo do Avanço Físico}

A metodologia proposta a ser apresentada a seguir, tem como objetivo, implementar e analisar, o resultado do estudo mais detalhado na forma como é atualmente realizado o cálculo da medição do Avanço Físico do Projeto, e aplicar este estudo num projeto industrial, similar a um projeto em desenvolvimento. A partir desta etapa do trabalho, será utilizado, como sistema de planejamento do projeto, o MSProject, pela sua maior disponibilidade.

A metodologia consiste em se determinar o Avanço Físico do projeto de uma forma mais refinada, precisa e mais automatizada em relação à metodologia atualmente utilizada, e menos dependente da subjetividade do técnico responsável.

Consiste no desmembramento do planejamento do projeto em Pacotes de Trabalho, e no detalhamento das atividades de cada pacote de trabalho em uma ou em um conjunto de tarefas até um nível em que essas tarefas possam ser medidas, atribuindo-se a cada uma delas, a porcentagem de sua contribuição em relação ao projeto. Como exemplo, pode-se verificar no planejamento, que a atividade "Elaboração das ETEs do Projeto Básico dos Postos Locais (PLO) + Anal. Aprov. Cliente" requer 40 dias de trabalho para a execução da atividade, o que corresponde a $(40 / 200 * 4,09 \%)=0,82 \%$ da quantidade total de dias de todo o projeto que é de 4886 dias.

Tabela 5.3.1 - Porcentagem da atividade dentro do projeto

\begin{tabular}{|c|c|c|c|c|}
\hline Atividade & $\begin{array}{l}\text { Pacote de } \\
\text { Trabalho }\end{array}$ & Descrição das Atividades & $\begin{array}{c}\text { Dias } \\
\text { Previstos de } \\
\text { cada } \\
\text { Atividade }\end{array}$ & $\begin{array}{l}\% \text { de cada } \\
\text { Atividade }\end{array}$ \\
\hline & & Total de dias trabalhados & 4886 & \\
\hline \multirow[t]{3}{*}{ CÓDIGO CONTABIL } & & Acumulado & & \\
\hline & & Avanço físico mensal do projeto & & $100,00 \%$ \\
\hline & & Acumulado & & \\
\hline PROJ0120-2.2 & TIT & Elaboração das ETEs do Projeto Básico & 200 & $4,09 \%$ \\
\hline PROJ0120-2.2.1 & SE_ATS & Dos Postos Locais (PLO), + Análise Aprov.Cliente & 40 & $0,82 \%$ \\
\hline PROJ0120-2.2.2 & SE_ATS & Do Centro de Controle Operacional (CCO), + Anal.Aprov.Cliente & 80 & $1,64 \%$ \\
\hline PROJ0120-2.2.3 & SE_ATS & De Sinalização, + Anal.Aprov.Cliente & 80 & $1,64 \%$ \\
\hline PROJ0120-2.3 & TIT & Elaboração das ETEs Funcionais dos Equipamentos & 70 & $1,43 \%$ \\
\hline PROJ0120-2.3.1 & SE_ATS & Dos PCLs (Servidores,Redes,IHM) & 15 & $0,31 \%$ \\
\hline PROJ0120-2.3.2 & SE_ATS & Do CCO (Servidores,Redes,IHM,Consoles,Painéis) & 15 & $0,31 \%$ \\
\hline PROJ0120-2.3.3 & SE_ATS & Sinalização(CLPs,Maq.Chave,Sinaleiros,Cabos,PDF,No-Break) & 40 & $0,82 \%$ \\
\hline
\end{tabular}

Pode-se então afirmar, que com este método de medir o avanço físico de cada atividade, o grau de subjetividade do técnico responsável do pacote de trabalho, diminui substancialmente, tornando, portanto a medida mais próxima de sua realidade. 
As informações apresentadas na tabela 5.3.1, foram exportadas diretamente do aplicativo MSProject para uma planilha do aplicativo Excel, a qual é reorganizada e complementada com as informações do cálculo da porcentagem que cada uma das atividades contribui ao projeto.

\subsubsection{Cálculo da porcentagem do avanço físico mensal de cada atividade}

Para ser realizada uma medição do avanço físico mensal do projeto, a planilha apresentada na tabela 5.3.1 foi complementada com 2 novas colunas para cada mês, gerando então uma nova planilha apresentada na tabela 5.3.1.1. Na coluna, (total de dias já trabalhados), é apresentado para cada uma das atividades, o valor acumulado dos dias trabalhados nesta atividade em todos os meses previstos no planejamento. Na coluna (dias trabalhados Jan06), têm-se as células onde são colocados os dias gastos no mês na execução de cada atividade. Na coluna (\% do avanço físico no mês Jan06), é realizado o cálculo para se identificar através dos dias gastos no mês, qual foi à porcentagem de avanço de cada atividade no mês em que se está fazendo a medição.

Exemplo: Na atividade PROJ0120-2.2.1 - Elaboração das ETEs do Projeto Básico "Dos Postos Locais (PLO) + Anal. Aprov. Cliente" tem-se: O total de dias previstos para realizar a atividade PROJ0120-2.2.1 é de 40 dias; A porcentagem de contribuição desta atividade é de 0,82\% dentro do item PROJ0120-2.2 que é de $200 / 4886=4,09 \%$. Os 10 dias trabalhados na atividade PROJ0120-2.2.1 no mês (Jan06), correspondem a um Avanço Físico na atividade de 10/200*4,09\% = 0,20\%.

A tabela 5.3.1.1, a seguir, apresenta estas duas novas colunas.

Tabela 5.3.1.1 - Porcentagem do avanço físico mensal de cada atividade

\begin{tabular}{|c|c|c|c|c|c|c|c|}
\hline Atividade & $\begin{array}{l}\text { Pacotede } \\
\text { Trabelho }\end{array}$ & Descrição das Atividades & $\begin{array}{c}\text { Dias } \\
\text { Previstos de } \\
\text { cach } \\
\text { Atividacle }\end{array}$ & $\begin{array}{l}\text { \% decada } \\
\text { Atividade }\end{array}$ & $\begin{array}{l}\text { Total dasjá } \\
\text { trabalhados }\end{array}$ & $\begin{array}{c}\text { Dias } \\
\text { Trabalhados } \\
\text { Jan06 }\end{array}$ & $\begin{array}{c}\text { \% do } \\
\text { Avanço } \\
\text { Fisicono } \\
\text { mêstanoc }\end{array}$ \\
\hline & & Total de cias trabalhados & 4886 & & 457 & 70 & \\
\hline \multirow[t]{3}{*}{ CÓDIGOCONTABIL } & & Acumulado & & & & 70 & \\
\hline & & Avançofísicomensal do projeto & & $100,00 \%$ & & & $1,43 \%$ \\
\hline & & Acumulado & & & & & $1,43 \%$ \\
\hline PRO0120-22 & TIT & Eaboração das ElEs do Projeto Básioo & 200 & $4,09 \%$ & 200 & & $1,02 \%$ \\
\hline PRO0120-221 & SE ATS & Dos Postos Locais (PLO), + Análise Aprov. Ciente & 40 & $0,82 \%$ & 40 & 10 & $0,20 \%$ \\
\hline PRO0120-222 & SE ATS & Do Centro de Controle Operacional (COO), + Anal.Aprov. Cliente & 80 & $1,64 \%$ & 80 & 20 & $0,41 \%$ \\
\hline PRON0120-223 & SE ATS & De Sinalização, + Anal.Aprov.QAiente & 80 & $1,64 \%$ & 80 & 20 & $0,41 \%$ \\
\hline PRON0120-23 & TIT & Eaboração das EIES Funcionais dos Equipamentos & 70 & $1,43 \%$ & 38 & & $0,00 \%$ \\
\hline PRO0120-23.1 & SE ATS & Dos POLs (Senvidores, Redes,IHM) & 15 & $0,31 \%$ & 9 & 0 & $0,00 \%$ \\
\hline PROJ0120-23.2 & SE ATS & Do COO (Servidores, Redes,IHM,Consoles,Painés) & 15 & $0,31 \%$ & 9 & 0 & $0,00 \%$ \\
\hline PRO0120-23.3 & SE ATS & Sinalização(APs,Meq.Chave,Sinaleiros,Cabos,PDF,Nb-Break) & 40 & $0,82 \%$ & 20 & 0 & $0,00 \%$ \\
\hline
\end{tabular}


- Campo "Atividade": Contém o código do projeto e o número seqüencial da atividade no MSProject;

- Campo "Pacotes de Trabalho": Identifica o pacote de trabalho ao qual pertence às atividades;

- Campo "Descrição das Atividades": Contém a descrição da atividade a ser realizada;

- Campo "Dias Previstos de cada Atividade": Contém o número de dias previstos para a realização de cada atividade. Na primeira linha, é apresentado um número, o qual indica que o número de dias previstos para a realização de todas as atividades do item PROJ0120.2.2 que são de 200 dias. Nas linhas subseqüentes, são apresentados os números de dias previstos em cada uma das atividades, as quais somadas equivalem aos 200 dias;

- Campo "Porcentagem de cada Atividade" (Avanço Físico, (Baseline) do Pacote de Trabalho): Informa em porcentagem, a contribuição que cada atividade dará a uma atividade principal do projeto relacionada ao Avanço Físico do Projeto. No caso da atividade PROJ0120.2.2.1, ela contribui com 0,82\% $(40 / 200 * 4,09 \%)$ da atividade principal, que é de 200 horas (200horas / 4886 horas $=4,09 \%$;

- Campo "Total de Dias já Trabalhados": Contém a soma acumulada dos dias já trabalhados em cada uma das atividades em cada um dos meses;

- Campo "Dias trabalhados no mês (Jan06)": Nesta coluna, o responsável pelo controle das atividades faz a atualização da tabela, colocando em termos de número de dias trabalhados, o progresso realizado em cada uma das atividades;

- Campo "\% do avanço físico no mês": Após a entrada dos dados dos dias efetivamente trabalhados em cada atividade, a planilha atualiza automaticamente as informações. É então apresentada, a porcentagem do andamento físico da atividade, bem como, do avanço físico mensal de todas as atividades e do Avanço Físico Geral do Projeto.

Pode-se então verificar através da tabela 5.3.1.1, que com 10 dias de trabalho realizado no mês, a atividade PROJ0120.2.2.1 teve um avanço físico de 0,20\% em relação à porcentagem total de $0,82 \%$. 
Aplicando-se esta metodologia a todas as atividades que tiveram trabalhos realizados no mês, pode-se então afirmar que, a medição realizada é mais precisa do que a realizada atualmente na empresa.

\subsubsection{Cálculo da porcentagem do avanço físico mensal por pacotes de trabalho}

Com o desmembramento do planejamento do projeto em pacotes de trabalho e a identificação do pacote de trabalho (Exemplo: pacote do PC_ATS) ao qual pertence cada atividade, conforme apresentado na tabela 5.3.1.2, pode-se também determinar, para cada pacote de trabalho, quantos dias foram realmente trabalhados nas atividades e qual é a sua porcentagem de contribuição dentro do projeto. No pacote de trabalho da tabela 5.3.1.2, a quantidade total dos dias para realizar todas as atividades é de 995 dias de trabalho e a sua contribuição é de 20,0\% em relação a todo o projeto.

Tabela 5.3.1.2 - Conjunto de atividades e dias previstos pertencentes a um pacote de trabalho (pacote de trabalho da área PC_ATS)

\begin{tabular}{|c|c|c|c|c|}
\hline Atividade & $\begin{array}{c}\text { Pacote de } \\
\text { Trabalho }\end{array}$ & Descrição das Atividades & $\begin{array}{c}\text { Dias } \\
\text { Previstos } \\
\text { de cada } \\
\text { Atividade }\end{array}$ & $\begin{array}{c}\text { Avanço } \\
\text { Físico } \\
\text { Baseline do } \\
\text { WP }\end{array}$ \\
\hline & PC_ATS & Total de dias trabalhados & 995 & $100,00 \%$ \\
\hline Código Contábil & PC_ATS & Acumulado & $20 \%$ & \\
\hline & PC_ATS & Avanço físico mensal do projeto & & \\
\hline & PC_ATS & Acumulado & & \\
\hline PROJ0120-2.6.1 & PC_ATS & Aquisição/Insp/Testes Serv/Works/Est.Trab/etc & 60 & $6,03 \%$ \\
\hline PROJ0120-2.6.2 & PC_ATS & Aquisição Redes/Periféricos & 60 & $6,03 \%$ \\
\hline PROJ0120-2.6.3 & PC_ATS & Inspeção/Testes Rede Local/Entrega & 5 & $0,50 \%$ \\
\hline PROJ0120-2.6.4 & PC_ATS & Aquisição/Entrega Consoles e Painéis & 90 & $9,05 \%$ \\
\hline PROJ0120-2.6.5 & PC_ATS & Aquisição/Entrega No-Break CCO e PLOs & 90 & $9,05 \%$ \\
\hline PROJ0120-2.6.6 & PC_ATS & Aquisição/Entrega Maq. Chave/Sinaleiros e CDVs & 120 & $12,06 \%$ \\
\hline PROJ0120-2.6.7 & PC_ATS & Aquisição/Entrega Cabos Eletricos/Controle & 120 & $12,06 \%$ \\
\hline PROJ0120-2.6.8 & PC_ATS & Aquisição/Entrega Painel Distrib. Energia (PDF) & 120 & $12,06 \%$ \\
\hline PROJ0120-2.7.1 & PC_ATS & Elaboração do Projeto Executivo e Ergonômico & 80 & $8,04 \%$ \\
\hline PROJ0120-2.7.2 & PC_ATS & Contratação Empresa e Execução da Obra & 220 & $22,11 \%$ \\
\hline PROJ0120-2.7.3 & PC_ATS & Instalação dos Cabos Energia/Dados dos Equip & 10 & $1,01 \%$ \\
\hline PROJ0120-2.10.3.1 & PC_ATS & Desm.Emb.Trans. Equip. Tráfego & 5 & $0,50 \%$ \\
\hline PROJ0120-2.10.3.2 & PC_ATS & Desm.Emb.Trans. Equip. Energia & 5 & $0,50 \%$ \\
\hline PROJ0120-2.14.4.1 & PC_ATS & Desm/Emba./Transp. Equiptos LPA,CGO e JUN & 5 & $0,50 \%$ \\
\hline PROJ0120-2.14.4.2 & PC_ATS & Entrega dos Equip. na Estação LPA,CGO e JUN & 0 & $0,00 \%$ \\
\hline PROJ0120-2.14.4.3 & PC_ATS & Desm/Embal.Transp. Equiptos JUN e VIN & 5 & $0,50 \%$ \\
\hline PROJ0120-2.14.4.4 & PC_ATS & Entrega dos Equip. na Estação JUN e VIN & 0 & $0,00 \%$ \\
\hline
\end{tabular}

Interagindo desta forma para os demais pacotes de trabalho, pode-se afirmar que os responsáveis técnicos terão maior facilidade em atualizar o Avanço Físico do Projeto, uma melhor visibilidade e um melhor controle das atividades e dos indicadores de desempenho do projeto, necessários para o gerenciamento e para 
reportar de modo preciso o estado atual e do desempenho de seu pacote de trabalho, ao Gerente do Projeto.

\subsubsection{Cálculo da porcentagem do avanço físico mensal do projeto}

Para a determinação do avanço físico mensal do projeto, deve-se então aplicar o mesmo processo descrito no item 5.3.1.2 para cada atividade que teve trabalho realizado no mês. Na tabela 5.3.1.3 apresenta-se apenas um segmento do avanço físico mensal do projeto, após serem atualizados os trabalhos realizados em cada atividade no mês de Jan06, que corresponde a 1,43\% (70dias/4886dias) no mês em que se está realizando a medição.

Entretanto, considerando que o planejamento do projeto em estudo abriga mais de 140 atividades, e que estas atividades são pertencentes a diversos pacotes de trabalho, a sua utilização ainda é difícil de ser gerenciada. Cada responsável pelo seu pacote de trabalho gasta ainda muito tempo para identificar e dar o andamento físico de cada atividade. Continua ainda difícil de identificar, em qual pacote de trabalho e qual atividade é que está ocasionando o atraso no andamento físico do projeto, em relação ao planejamento inicial do projeto.

Tabela 5.3.1.3 - Cálculo do avanço físico mensal do projeto

\begin{tabular}{|c|c|c|c|c|c|c|c|c|c|c|}
\hline Atividade & $\begin{array}{r}\text { Pacote de } \\
\text { Trabalho }\end{array}$ & Descrição das Atividades & \begin{tabular}{|c|} 
Dias \\
Previstos de \\
cada \\
Atividade \\
\end{tabular} & $\begin{array}{l}\% \text { de cada } \\
\text { Atividade }\end{array}$ & $\begin{array}{l}\text { Total dias já } \\
\text { trabalhados }\end{array}$ & \begin{tabular}{|c|} 
Dias \\
Trabalhados \\
Jan06
\end{tabular} & $\begin{array}{c}\% \text { do } \\
\text { Avancoo } \\
\text { Fisiso no } \\
\text { mêsJan06 }\end{array}$ & $\begin{array}{c}\text { Dias } \\
\text { Trabalhados } \\
\text { mês Fev06 }\end{array}$ & $\begin{array}{c}\% \text { do } \\
\text { Avancoo } \\
\text { Fisico no } \\
\text { mês Fevo6 }\end{array}$ & $\begin{array}{c}\text { Dias } \\
\text { Trabalhados } \\
\text { mês Maro6 }\end{array}$ \\
\hline & & Total de dias trabalhados & 4886 & & 457 & 70 & & 100 & & 99 \\
\hline CODIGO CONTABIL & & Acumulado & & & & 70 & & 170 & & 269 \\
\hline & & Avanço físico mensal do projeto & & $100,00 \%$ & & & $1,43 \%$ & & $2,05 \%$ & \\
\hline & & Acumulado & & & & & $1,43 \%$ & & $3,48 \%$ & \\
\hline PROJ0120-1 & SM_MGT & Início do projeto & & & & & & & & \\
\hline PROJ0120-1.1 & SM_MGT & Data de Início do Projeto & & & & & & & & \\
\hline PROJ0120-2 & 0 & Geral & & & & & & & & \\
\hline PROJ0120-2.1 & TIT & Gerenciamento do Projeto & 900 & $18,42 \%$ & 138 & & $0,41 \%$ & & $0,82 \%$ & \\
\hline PROJ0120-2.1.1 & SM_MGT & Coordenação do Projeto & 180 & $3,68 \%$ & 27 & 5 & $0,10 \%$ & 8 & $0,16 \%$ & 7 \\
\hline PROJ0120-2.1.2 & SM_MGT & Planejamento \& Controle & 180 & $3,68 \%$ & 27 & 3 & $0,06 \%$ & 8 & $0,16 \%$ & 8 \\
\hline PROJ0120-2.1.3 & SM_MGT & Gerenciamento da Qualidade & 180 & $3,68 \%$ & 28 & $\frac{4}{4}$ & $0,08 \%$ & 8 & $0,16 \%$ & 8 \\
\hline PROJ0120-2.1.4 & SM_MGT & Gerenciamento da Configuração & 180 & $3,68 \%$ & 28 & 4 & $0,08 \%$ & 8 & $0,16 \%$ & 8 \\
\hline PROJ0120-2.1.5 & SM_MGT & Controle dos Custos & 180 & $3,68 \%$ & 28 & 4 & $0,08 \%$ & 8 & $0,16 \%$ & 8 \\
\hline PROJ0120-2.2 & $\overline{T I T}$ & Elaboração das ETEs do Projeto Básico & 200 & $4,09 \%$ & 200 & & $1,02 \%$ & & $1,23 \%$ & \\
\hline PROJ0120-2.2.1 & SE_ATS & Dos Postos Locais (PLO), + Análise Aprov.Cliente & 40 & $0,82 \%$ & 40 & 10 & $0,20 \%$ & 20 & $0,41 \%$ & 10 \\
\hline PROJ0120-2.2.2 & SE_ATS & Do Centro de Controle Operacional (CCO), + Anal.Aprov.Cliente & 80 & $1,64 \%$ & 80 & 20 & $0,41 \%$ & 20 & $0,41 \%$ & 20 \\
\hline PROJ0120-2.2.3 & SE_ATS & De Sinalização, + Anal.Aprov.Cliente & 80 & $1,64 \%$ & 80 & 20 & $0,41 \%$ & 20 & $0,41 \%$ & 20 \\
\hline PROJ0120-2.3 & TIT & Elaboração das ETEs Funcionais dos Equipamentos & 70 & $1,43 \%$ & 38 & & $0,00 \%$ & & $0,00 \%$ & \\
\hline PROJ0120-2.3.1 & SE_ATS & Dos PCLs (Servidores,Redes,IHM) & 15 & $0,31 \%$ & 9 & 0 & $0,00 \%$ & 0 & $0,00 \%$ & 0 \\
\hline PROJ0120-2.3.2 & SEATS & Do CCO (Servidores,Redes,IHM,Consoles,Painéis) & $\frac{15}{15}$ & $0,31 \%$ & 9 & 0 & $0,00 \%$ & 0 & $0,00 \%$ & 0 \\
\hline PROJ0120-2.3.3 & SE_ATS & Sinalização(CLPs,Maq.Chave,Sinaleiros,Cabos,PDF,No-Break) & 40 & $0,82 \%$ & 20 & 0 & $0,00 \%$ & 0 & $0,00 \%$ & 0 \\
\hline PROJ0120-2.4 & TIT & Elaboraçāo Esp. Requisitos Software - ERSs & 300 & $6,14 \%$ & $70=$ & & $0,00 \%$ & & $0,00 \%$ & \\
\hline \begin{tabular}{|l|l|l} 
PROJ0120-2.4.1 \\
\end{tabular} & AP_ATS & Software CLPS & 50 & $1,02 \%$ & 0 & 0 & $0,00 \%$ & 0 & $0,00 \%$ & 0 \\
\hline PROJ0120-2.4.2 & AP ATS & IHM e Funcionalidades PLO's & 50 & $1,02 \%$ & 40 & 0 & $0,00 \%$ & 0 & $0,00 \%$ & 10 \\
\hline PROJ0120-2.4.3 & AP_ATS & IHM e Funcion. Tráfego CCO & 100 & $2,05 \%$ & 15 & 0 & $0,00 \%$ & 0 & $0,00 \%$ & 0 \\
\hline PROJ0120-2.4.4 & AP_ATS & IHM e Funcional Energia CCO & 100 & $2,05 \%$ & 15 & 0 & $0,00 \%$ & 0 & $0,00 \%$ & 0 \\
\hline PROJ0120-2.5 & TIT & Fabricação dos Equipamentos & 306 & $6,26 \%$ & 0 & & $0,00 \%$ & & $0,00 \%$ & \\
\hline PROJ0120-2.5.1 & P_ATS & Projeto, Aquisição Material e Fabricação CLPS & 90 & $1,84 \%$ & 0 & 0 & $0,00 \%$ & 0 & $0,00 \%$ & 0 \\
\hline PROJ0120-2.5.2 & P ATS & Testes Hardware/Inspeção, Entrega CLPs & 2 & $0,04 \%$ & 0 & 0 & $0,00 \%$ & 0 & $0,00 \%$ & 0 \\
\hline PROJ0120-2.5.3 & P_ATS & Projeto, Aquisição Material e Fabricação do SMCT & 120 & $2,46 \%$ & 0 & 0 & $0,00 \%$ & 0 & $0,00 \%$ & 0 \\
\hline PROJ0120-2.5.4 & P ATS & Testes Hardware/Inspeção,Entrega SMCT & 2 & $0,04 \%$ & 0 & 0 & $0,00 \%$ & 0 & $0,00 \%$ & 0 \\
\hline PROJ0120-2.5.5 & P_ATS & Projeto, Aquisição Material Gabinetes Servidores & 90 & $1,84 \%$ & 0 & 0 & $0,00 \%$ & 0 & $0,00 \%$ & 0 \\
\hline PROJ0120-2.5.6 & P_ATS & Testes Hardware/Inspeçāo, Entrega Gab.Servidores & $\frac{2}{2}$ & $\frac{1,047 \%}{0,04 \%}$ & 0 & 0 & $0,00 \%$ & 0 & $0,00 \%$ & 0 \\
\hline PROJ0120-2.6 & TIT & Aquisiçāo de Suprimentos & 665 & $13,61 \%$ & 0 & & $0,00 \%$ & & $0,00 \%$ & \\
\hline PROJ0120-2.6.1 & PCAATS & Aquisiçăo/lnsp/Testes Serv/Works/Est. Trab/etc & 60 & $1,23 \%$ & 0 & 0 & $0,00 \%$ & 0 & $0,00 \%$ & 0 \\
\hline PROJ0120-2.6.2 & PC ATS & Aquisiçāo Redes/Periféricos & 60 & $1,23 \%$ & 0 & 0 & $0,00 \%$ & 0 & $0,00 \%$ & 0 \\
\hline PROJ0120-2.6.3 & PC_ATS & Inspeçăo/Testes Rede Local/Entrega & $\frac{5}{5}$ & $0,10 \%$ & 0 & 0 & $0,00 \%$ & 0 & $0,00 \%$ & 0 \\
\hline PROJ0120-2.6.4 & PC ATS & Aquisiçāo/Entrega Consoles e Painéis & 90 & $1,84 \%$ & 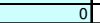 & 0 & $0,00 \%$ & 0 & $0,00 \%$ & 0 \\
\hline PROJ0120-2.6.5 & PC ATS & Aquisição/Entrega No-Break CCO e PLOs & 90 & $1,84 \%$ & 0 & 0 & $0,00 \%$ & 0 & $0,00 \%$ & 0 \\
\hline PROJ0120-2.6.6 & PC ATS & Aquisiçāo/Entrega Maq. Chave/Sinaleiros e CDVs & 120 & $2,46 \%$ & 0 & 0 & $0,00 \%$ & 0 & $0,00 \%$ & 0 \\
\hline PROJ0120-2.6.7 & PC_ATS & $\begin{array}{l}\text { Aquisicăa/Entrega Cabos Eletricos/Controle } \\
\end{array}$ & 120 & $\frac{2,40 \%}{2,46 \%}$ & 0 & $\frac{0}{0}$ & $0,00 \%$ & 0 & $0,00 \%$ & $\frac{0}{0}$ \\
\hline PROJ0120-2.6.8 & PC_ATS & Aquisiçāo/Entrega Painel Distrib. Energia (PDF) & 120 & $2,46 \%$ & 0 & 0 & $0,00 \%$ & 0 & $0,00 \%$ & 0 \\
\hline PROJ0120-2.7 & TIT & Projeto de Construçâa do CCO & 310 & $6,34 \%$ & 1 & & $0,00 \%$ & & $0,00 \%$ & \\
\hline PROJ0120-2.7.1 & PC_ATS & Elaboração do Projeto Executivo e Ergonômico & 80 & $1,64 \%$ & 1 & 0 & $0,00 \%$ & 0 & $0,00 \%$ & 0 \\
\hline PROJ0120-2.7.2 & PCAATS & Contratação Empresa e Execução da Obra & 220 & $4,50 \%$ & 0 & 0 & $0,00 \%$ & 0 & $0,00 \%$ & 0 \\
\hline PROJ0120-2.7.3 & PC_ATS & Instalação dos Cabos Energia/Dados dos Equip & 10 & $0,20 \%$ & 0 & 0 & $0,00 \%$ & 0 & $0,00 \%$ & 0 \\
\hline
\end{tabular}




\subsubsection{Alterações a serem implementadas nos sistemas existentes}

\subsubsection{Complementação no Sistema de apontamento de horas}

Neste sistema haverá a necessidade de se realizar alterações, para permitir que quando do lançamento de horas diário, sejam apresentados os campos de preenchimento contendo:

O código do projeto com a identificação da atividade.

Exemplo: $\quad$ PROJ0120-2.7.1 - Elaboração do Projeto Executivo e Ergonômico PROJ0120 - Indica o número do projeto, que é o 0120;

2.7.1 - Indica o número seqüencial da atividade.

O código do pacote de trabalho no qual o funcionário esta trabalhando.

Exemplo: PC_ATS - Identifica o código do pacote de trabalho, que é o da área de Suprimentos.

\subsubsection{Complementação no Sistema SAP}

Neste sistema haverá a necessidade de realizar alterações para identificar e processar as novas informações dos lançamentos de horas. Também será necessário implementar alterações nos relatórios de saída, para apresentação das informações por pacote de trabalho aos responsáveis técnicos pelos pacotes de trabalho, dos custos e dos recursos (dias ou horas) gastos no mês.

\subsubsection{Alterações no sistema de planejamento Primavera}

Neste sistema haverá a necessidade de se adaptar os planejamentos, alterando-se a codificação dos projetos, a inclusão da numeração seqüencial de cada atividade e a inserção do campo para a identificação do pacote de trabalho ao qual cada uma das atividades pertence.

\subsubsection{Geração de Relatório Consolidado}

Deverá ser disponibilizado mensalmente, um relatório consolidado contendo todas as atividades pertencentes ao pacote de trabalho, dos recursos de mão de obra já consumidos, dos recursos ainda existentes, das informações do avanço físico de cada atividade e do pacote de trabalho. Será utilizado pelos responsáveis de cada pacote de trabalho, para avaliar o desempenho dos recursos do seu pacote de trabalho, das ações a serem tomadas para sanar as anomalias detectadas, bem como, utilizado para realizar as duas atualizações do planejamento, conforme já descrito anteriormente. 


\section{APLICAÇÃO DA NOVA METODOLOGIA EM UM SISTEMA DE CONTROLE METRO - FERROVIÁRIO}

\subsection{Introdução}

O objetivo deste item do trabalho é o de consolidar de uma forma prática os processos de Gerenciamento de Custo e de Tempo do projeto descritos nos capítulos anteriores, e principalmente, da implementação dessa nova metodologia de cálculo do Avanço Físico do Projeto, num projeto industrial, similar ao de um projeto em desenvolvimento.

O projeto a ser apresentado no presente trabalho, consiste no fornecimento completo de um Sistema de Sinalização e Controle de Tráfego e Energia MetroFerroviário da Linha Alfa, composto basicamente das seguintes atividades: Planejamento e Gerenciamento do Projeto; Elaboração e execução do Projeto Básico e detalhado dos Sistemas de Sinalização, e do Sistema de Controle Centralizado de Controle de Tráfego e de Energia; Fabricação e Aquisição de equipamentos, contemplando (Equipamentos de Controle da Movimentação de Trens; Equipamentos de Sinalização de via; Equipamentos para os Postos Locais e do Centro de Controle de Operações); Projeto de Instalação, Supervisão de montagem e Comissionamento; Testes de Integração e Aceitação em Fábrica e Campo; Treinamento dos Sistemas de Sinalização, de Controle de Tráfego e de Energia; Comissionamento dos sistemas de Controle de Tráfego e de Energia; Documentação "As-built" do projeto; Garantia de 24 meses de todo o fornecimento.

Trata-se de um projeto de grande porte e com muitas interações com os diversos setores de engenharia da empresa e de fornecedores.

\subsection{Gerenciamento da Integração}

Segundo o (PMBOK, 2004), a área de conhecimento em Gerenciamento de Integração do Projeto inclui os processos e as atividades necessárias para identificar, definir, combinar, unificar e coordenar os diversos processos e atividades de gerenciamento de projetos dentro dos grupos de processos de gerenciamento de projetos. No contexto do gerenciamento de projetos, a integração inclui características de unificação, consolidação, articulações e ações integradoras que são essenciais para o término do projeto e atender com sucesso às necessidades dos clientes e de outras partes interessadas. 


\subsubsection{Reunião de transferência do projeto "Transfer Meeting".}

É a reunião onde a área comercial (responsável pela elaboração da proposta técnica e comercial), promoverá com o objetivo de transferir para a área de projetos, as propostas técnica e comercial, todas as documentações recebidas do cliente, as perguntas e respostas ocorridas durante a fase de elaboração das propostas, as negociações realizadas, o cronograma macro geral acordado com o cliente, as premissas e restrições do projeto.

\subsubsection{Elaboração do Plano de Gerenciamento do Projeto (PGP)}

O Plano de Gerenciamento do Projeto (PGP) é o plano geral do projeto que centraliza toda a informação do projeto e coordena, junto com o Plano de Desenvolvimento do Projeto (PDP), os demais planos recomendados. Portanto, o Gerente de Projetos deverá elaborar o PGP conforme tabela abaixo:

Tabela 6.2.2 - Plano de Gerenciamento do Projeto

\begin{tabular}{|c|c|c|}
\hline Plano & Objetivo & Foco \\
\hline $\begin{array}{l}\text { PGP - } \\
\text { Plano de } \\
\text { Gerencia- } \\
\text { mento do } \\
\text { Projeto }\end{array}$ & $\begin{array}{l}\text { Especificar a organização } \\
\text { geral e os aspectos } \\
\text { gerenciais para a } \\
\text { execução do projeto. } \\
\text { (No campo à direita, } \\
\text { aparecem os demais } \\
\text { planos referenciados pelo } \\
\text { PGP). }\end{array}$ & $\begin{array}{l}\text { Estabelecer: } \\
\text { I. Apresentação Geral do Projeto } \\
\text { I.1 Cliente } \\
\text { I.2 Elementos Chave do Projeto } \\
\text { I.3 Contrato } \\
\text { II. Estratégia de Execução do Projeto } \\
\text { II.1 Organização e Responsabilidades. } \\
\text { II.2 Riscos e Oportunidades } \\
\text { II.3 Gerenciamento do Tempo (Planejamento e } \\
\text { Controle) } \\
\text { II.4 Controle de Custo } \\
\text { II.5 Recursos Humanos } \\
\text { II.6 Gerênciamento da Qualidade (PGQ). } \\
\text { II.7 Comunicação e Controle de Documentos } \\
\text { II.8 Indicadores de desempenho do projeto } \\
\text { III. Plano de Desenvolvimento do Projeto (PDP) }\end{array}$ \\
\hline
\end{tabular}

\subsubsection{Reunião de Abertura do Projeto (“Launch Meeting”)}

É a primeira reunião oficial do projeto convocada pelo gerente de projeto, na qual deverão estar presentes todos os gerentes envolvidos no projeto, (desenvolvimento, sistemas, RAMS (Reliability, Availability, Maintainability, Safety) fabricação, implantação, suprimentos, qualidade, etc.) e demais participantes no projeto. Nesta reunião são apresentados utilizando o PGP, o escopo do projeto, a arquitetura do sistema, o cronograma do projeto, os prazos de entrega de cada etapa do projeto, 
os custos envolvidos para cada pacote de trabalho, os marcos contratuais de recebimento, os riscos envolvidos, as premissas e restrições do projeto.

São também definidos nesta reunião todos os demais planos do projeto a serem elaborados, os responsáveis pela sua elaboração e os responsáveis pela sua aprovação conforme tabelas a seguir:

Tabela 6.2.3 - Definição dos Planos do Projeto a serem elaborados

\begin{tabular}{|c|c|c|}
\hline Plano & Objetivo & Foco \\
\hline $\begin{array}{l}\text { PGQ - Plano } \\
\text { de Garantia } \\
\text { da Qualidade }\end{array}$ & $\begin{array}{l}\text { Descrever as ações de Garantia da } \\
\text { Qualidade a serem aplicadas no } \\
\text { projeto em questão. }\end{array}$ & 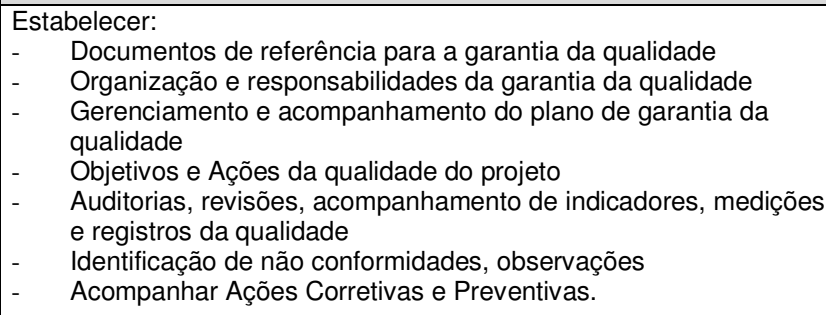 \\
\hline $\begin{array}{l}\text { PSG - Plano } \\
\text { de Segurança }\end{array}$ & $\begin{array}{l}\text { Descrever como o projeto deverá } \\
\text { ser conduzido para atender os } \\
\text { requisitos de segurança } \\
\text { estabelecidos }\end{array}$ & $\begin{array}{ll}- & \text { Critérios e ações durante o projeto. } \\
- & \text { Inspeções e Verificação durante o projeto } \\
- & \text { Análise de segurança para liberação }\end{array}$ \\
\hline $\begin{array}{l}\text { PVV - Plano } \\
\text { de } \\
\text { Verificação e } \\
\text { Validação }\end{array}$ & $\begin{array}{l}\text { Descrever o processo para } \\
\text { realização de Inspeções, Revisões, } \\
\text { Testes e Validações. }\end{array}$ & $\begin{array}{ll}- & \text { ACPs (Análise Critica dos Sistemas) } \\
- & \text { Revisões Técnicas e Inspeções de documentos } \\
- & \text { Inspeções de recebimento } \\
- & \text { Inspeções e testes no processo de fabricação } \\
- & \text { Calibração e Aferição de Equipamento de Teste } \\
- & \text { Testes e Validações e Integração de subsistemas }\end{array}$ \\
\hline $\begin{array}{l}\text { PIM - Plano } \\
\text { de } \\
\text { Implantação }\end{array}$ & Descrever Implantação do Sistema. & $\begin{array}{ll}\text { - } & \text { Estratégia e Cronograma de entrega } \\
\text { - } & \text { Ambiente/Condições de Teste, Integração e Implantação Campo } \\
\text { - } & \text { Critérios de aceitação }\end{array}$ \\
\hline $\begin{array}{l}\text { PGC - Plano } \\
\text { de Gerência } \\
\text { de } \\
\text { Configuração }\end{array}$ & $\begin{array}{l}\text { Descrever Gerência de } \\
\text { Configuração. }\end{array}$ & $\begin{array}{ll}- & \text { Organização, Recursos e Responsabilidades. } \\
\text { - } & \text { Identificação das Configurações } \\
\text { - } & \text { Controle e distribuição das Configurações } \\
\text { - } & \text { Acompanhamento de Estado e Auditoria } \\
\text { - } & \text { Controles das Interfaces } \\
\text { - } & \text { Programação da Gerência de Configuração }\end{array}$ \\
\hline $\begin{array}{l}\text { PDP - Plano } \\
\text { de } \\
\text { Desenvolvi- } \\
\text { mento do } \\
\text { Projeto }\end{array}$ & $\begin{array}{l}\text { Especificar o processo de } \\
\text { desenvolvimento que será utilizado } \\
\text { pelo projeto. }\end{array}$ & \begin{tabular}{|ll}
- & Ciclo de Vida - Fases de Desenvolvimento. \\
- & Gerência de Configuração e Modificação, (PGC). \\
- & Segurança e Confiabilidade dos Produtos, (PSG). \\
- & Verificação e Validação, (PVV). \\
- & Engenharia de Sistemas \\
- & Desenvolvimento de Software \\
- & Desenvolvimento de Hardware e Fabricação \\
- & Implantação do Sistema, (PIM).
\end{tabular} \\
\hline
\end{tabular}




\subsubsection{Definição dos responsáveis pela elaboração e aprovação de cada Plano do Projeto}

Tabela 6.2.3.1 - Definição das Responsabilidades dos Planos do Projeto a serem elaborados

\begin{tabular}{|c|c|c|c|}
\hline Plano & Quem Elabora & Quem Revisa & Quem Aprova \\
\hline$P G Q$ & $\begin{array}{l}\text { - } \quad \text { Gerente de Garantia da } \\
\text { Qualidade }\end{array}$ & $\begin{array}{ll}\text { - } & \text { Qualidade } \\
\text { - } & \text { Responsáveis de Subsistema } \\
\text { - } \quad \text { Coordenador Técnico do } \\
\quad \text { Projeto }\end{array}$ & - $\quad$ Gerente de Projeto \\
\hline PDP & $\begin{array}{l}\text { - Coordenador Técnico do } \\
\text { Projeto }\end{array}$ & $\begin{array}{ll}\text { - } & \text { Qualidade } \\
\text { - } & \text { Responsáveis de Subsistema } \\
\text { - } & \text { Coordenador de Software }\end{array}$ & - $\quad$ Gerente de Projeto \\
\hline PSG & $\begin{array}{l}\text { - Coordenador Técnico do } \\
\text { Projeto }\end{array}$ & $\begin{array}{ll}\text { - } & \text { Equipe RAMS } \\
\text { - } & \text { Coordenador de Projeto } \\
\text { - } & \text { Responsáveis de Subsistema }\end{array}$ & - $\quad$ Gerente de Projeto \\
\hline PVV & $\begin{array}{ll}\text { - } & \text { Coordenador Técnico do } \\
& \text { Projeto } \\
\text { - } \quad \text { Responsáveis de } \\
\text { Subsistema } \\
\text { - } \quad \text { Coordenador de Software }\end{array}$ & - $\quad$ Qualidade & Gerente de Projeto \\
\hline PIM & $\begin{array}{l}\text { - } \quad \text { Coordenador Geral de } \\
\text { Instalação e } \\
\text { Comissionamento }\end{array}$ & $\begin{array}{ll}\text { - } & \text { Qualidade } \\
\text { - } & \text { Coordenador Técnico do } \\
& \text { Projeto } \\
\text { - } \quad \text { Responsáveis de Subsistema } \\
\text { - } \quad \text { Coordenador de Software }\end{array}$ & Gerente de Projeto \\
\hline PGC & $\begin{array}{l}\text { - Coordenador Técnico do } \\
\text { Projeto }\end{array}$ & $\begin{array}{ll}\text { - } & \text { Qualidade } \\
\text { - } & \text { Responsáveis de Subsistema } \\
\text { - } & \text { Coordenador de Software }\end{array}$ & - $\quad$ Gerente de Projeto \\
\hline
\end{tabular}




\subsubsection{Estrutura Organizacional do Projeto}

Define as áreas da empresa que estarão envolvidas durante todo o Ciclo de Vida do Projeto.

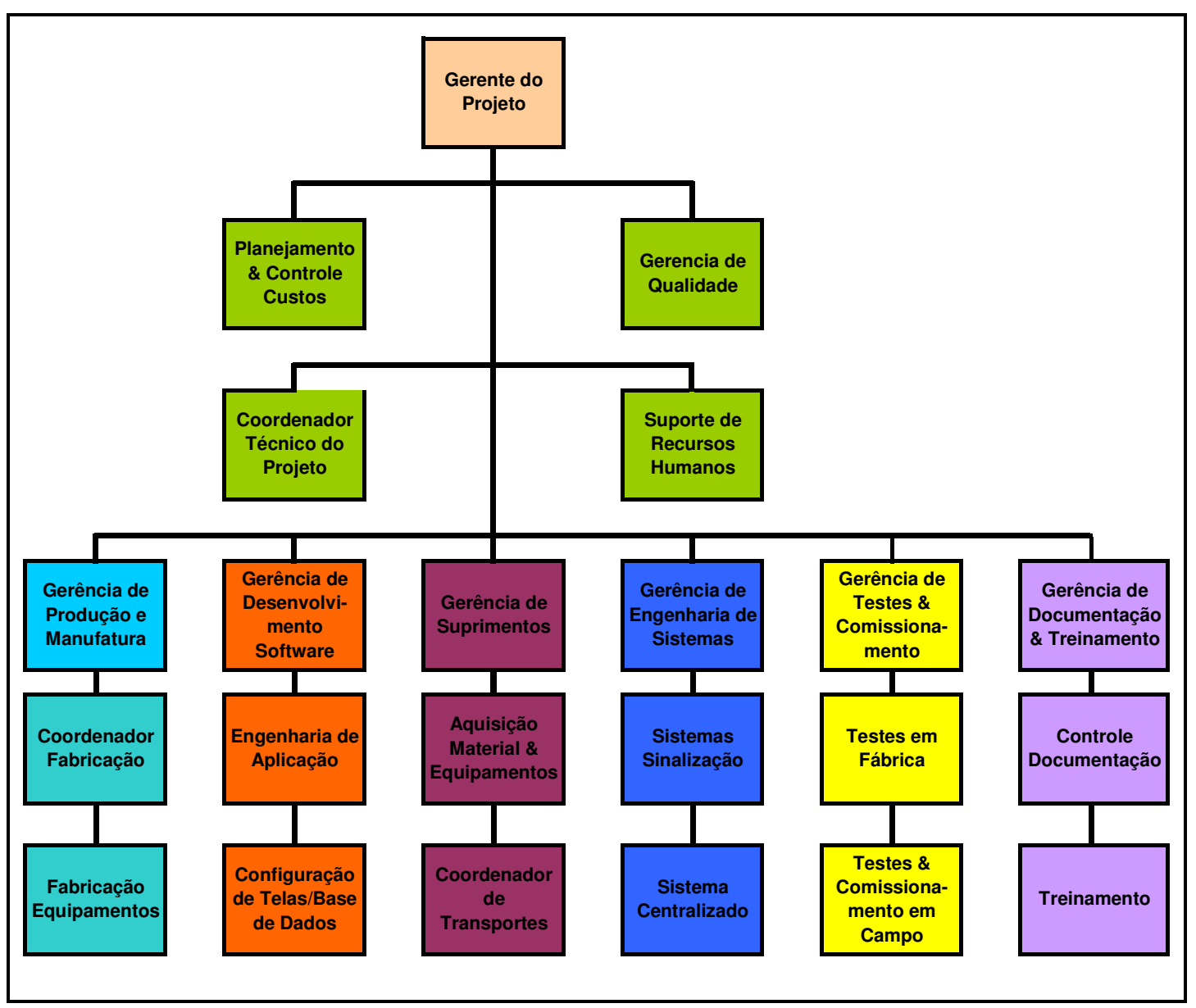

Figura 6.2.3.2 - Estrutura Organizacional do Projeto 


\subsection{Gerenciamento do escopo do projeto}

São os processos exigidos para assegurar que o projeto seja completado com sucesso incluindo todo e somente o trabalho requerido.

\subsubsection{Termo de abertura ou Project Charter}

O (PMBOK, 2004) define o "Project Charter" (Termo de abertura do projeto) como sendo o documento inicial do projeto assinado pela alta direção da empresa, que formalmente reconhece a existência e o início do projeto.

O Termo de Abertura do Projeto deve ser emitido por um dirigente externo ao projeto e de nível apropriado às necessidades do projeto. Ele supre o gerenciador do projeto da autoridade para aplicar recursos organizacionais às atividades do projeto.

Quando um produto ou serviço é executado mediante contrato celebrado, a descrição inicial do produto é geralmente fornecida pelo comprador.

Se o trabalho a ser executado é em si um projeto, a descrição do produto do comprador é uma declaração de trabalho (Statement of Work - SOW), a qual deverá conter: A necessidade do negócio para o qual o projeto foi empreendido; $A$ descrição do produto ou do projeto a ser desenvolvido; A Indicação do Gerente do Projeto, dando poderes para iniciar o Planejamento do Projeto.

É apresentado a seguir o Termo de Abertura do Projeto ou Project Charter do projeto, adotado como objeto de estudo neste trabalho. 
Tabela 6.3.1 - Termo de Abertura do Projeto ou Project Charter do Projeto

\section{Termo de Abertura ou "Project Charter" do Projeto da Linha Alfa}

Nome do Projeto: Projeto da Linha Alfa

Informamos, que no dia 15 de Março de 2005, firmamos contrato com a empresa Alfa Ferrovias de São Paulo, para o fornecimento de um Sistema de Supervisão e Controle de Tráfego e Energia para a Linha Alfa, necessária para atender a demanda hoje existente de transporte de passageiros no eixo entre São Paulo e Campinas, em razão do crescente aumento da demanda de passageiros, decorrente da transferência de famílias para as cidades ao longo desse trecho compreendido entre a cidade de São Paulo e a cidade de Campinas.

Projeto: Elaboração de Projeto, fabricação de equipamentos, instalação, testes e comissionamento do sistema, envolvendo basicamente os seguintes equipamentos e serviços:

- Planejamento e Gerenciamento do Projeto;

- Execução do Projeto Básico e Detalhado dos Sistemas de Sinalização e do Sistema de Controle Centralizado de Controle de Tráfego e de Energia;

- Fabricação e Aquisição de equipamentos de sinalização, contemplando:

$\checkmark$ Equipamentos de Controle da Movimentação de Trens;

$\checkmark$ Equipamentos de Sinalização de via;

$\checkmark$ Equipamentos para os Postos Locais e Centro de Controle;

- Projeto de Instalação e Supervisão de montagem e comissionamento;

- Testes de Integração e Aceitação em Fábrica e Campo;

- Treinamento dos Sistemas de Sinalização e de Controle de Tráfego e Energia;

- Comissionamento do Sistema de Sinalização e de Controle de Tráfego e Energia;

- Documentação "As-built" do projeto;

- Garantia de 24 meses de todo o fornecimento.

Responsabilidades: O projeto estará sob responsabilidade da Diretoria de Projetos; sendo designado como Gerente do Projeto, o Sr. Sergio Morelli.

Valor do fornecimento: $\mathrm{R} \$ 8.934 .660,25$

Prazo de Fornecimento: 24 meses a partir de 15 de Março de 2005.

Diretor Superintendente de Transporte Brasil

São Paulo, 03 de Março de 2005. 


\subsubsection{Planejamento do Escopo}

É uma ferramenta de planejamento que descreve como a equipe irá definir o escopo do projeto, desenvolver a declaração do escopo detalhada do projeto, definir e desenvolver a estrutura analítica do projeto, verificar o escopo do projeto e controlar o escopo do projeto .

\subsubsection{Objetivo do projeto}

Este fornecimento constitui, sob regime de empreitada global, na execução do projeto, fabricação, instalação, testes, treinamento de operação e manutenção, entrega e colocação em operação, do Sistema de Controle e Sinalização da Linha Alfa, num prazo total de 24 meses, após a assinatura do contrato.

O valor de todo o fornecimento é de $\mathrm{R} \$$. 8.934.660,25.

\subsubsection{Declaração de escopo}

\section{Estão incluídas no escopo as seguintes atividades:}

Execução das especificações funcionais dos sistemas de sinalização, Controle de Tráfego e Energia, do Projeto de Fabricação, de Instalação, Testes, Treinamento, Colocação em Operação, e Operação Assistida por 30 dias; Fabricação, testes isolados dos equipamentos e testes integrados em fábrica de todos os equipamentos e sistemas (Integração Hardware/Software); Supervisão em campo durante todo o período de Instalação, Montagem e Comissionamento; Treinamentos de Operação e Manutenção dos equipamentos, dos Sistemas de Sinalização e dos Sistemas de Controle de Tráfego e Energia; Entrega final após o término da Instalação, Montagem e do "Start-up" da Linha Alfa, dos desenhos e documentos "As-built" (projeto como implantado em campo); Garantia de 24 meses de todo o fornecimento, a partir do término do Comissionamento e entrada em operação do sistema.

\section{Não estão incluídas no escopo as seguintes atividades:}

Equipamentos para o descarregamento e local de armazenamento na Obra, de todos os materiais e equipamentos previstos no escopo de fornecimento;

Realização de Obras Civis, de Concretagem, etc; A execução do projeto executivo de infra-estrutura para a Instalação dos sistemas; $O$ fornecimento de equipamentos 
e insumos de montagem da infra-estrutura para montagem dos equipamentos em campo.

\subsubsection{Definição do Escopo}

Durante a fase de planejamento do projeto, o escopo do projeto é definido e descrito mais especificamente porque se conhecem mais informações sobre o projeto.

\subsubsection{Estrutura Analítica do Projeto (EAP), (Work Breakdown Structure - WBS)}

A Estrutura Analítica do Projeto - EAP (WBS - Work Breakdown Sctruture) é a metodologia utilizada para desmembrar um projeto em seus componentes e partes. É à base do planejamento do projeto e uma das técnicas mais importantes usadas na gestão de projeto. A estrutura de desmembramento de trabalho cria uma figura que facilita o entendimento de todas as partes de um projeto.

Os Objetivos da sua utilização são: assegurar que o projeto inclui todo o trabalho necessário, e que o projeto não inclui trabalho além do necessário.

As principais características são: É uma estrutura com arranjo de forma hierárquica; possui um objetivo ou um resultado tangível (entrega).

Abaixo é apresentada a Estrutura Analítica do Projeto - EAP da Linha Alfa.

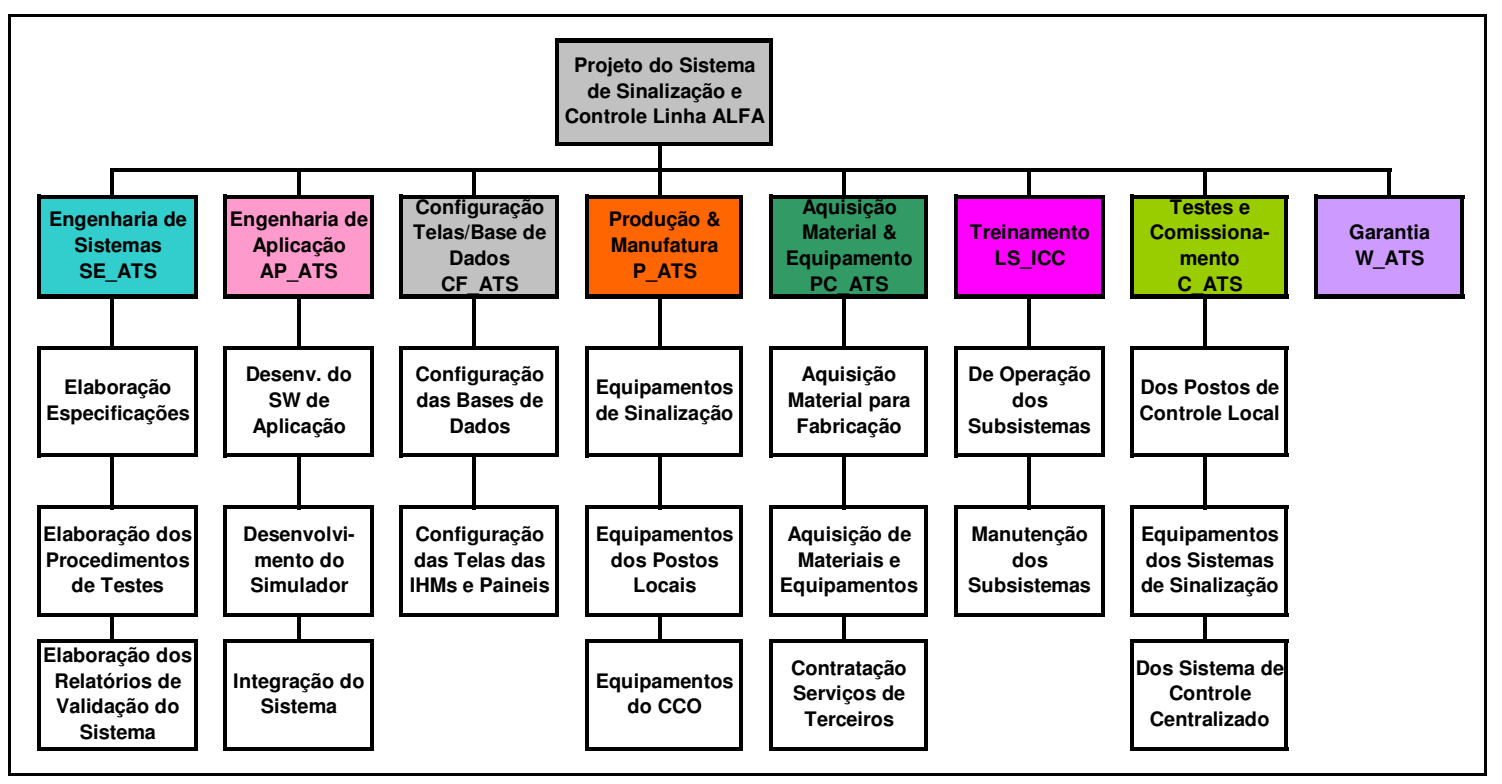

Figura 6.3.3.1 - Estrutura Analítica do Projeto -EAP 


\subsection{Gerenciamento de tempo do projeto}

O Gerenciamento de tempo do projeto inclui os processos necessários para identificar as atividades e ordená-las na seqüência correta. Inclui os processos necessários para monitorar as atividades e assegurar a conclusão do projeto no prazo estabelecido. Os principais processos do gerenciamento do tempo em um projeto são:

\subsubsection{Definição da Atividade}

Identificação das atividades específicas que devem ser executadas para produzir as várias entregas do projeto.

Tabela 6.4.1 - Definição e estimativa de duração de cada atividade

\begin{tabular}{|c|c|c|}
\hline Itens & Descrição da Atividade & $\begin{array}{l}\text { Duração } \\
\text { dias úteis }\end{array}$ \\
\hline & Gerenciamento do Projeto & \\
\hline 1 & Coordenação do Projeto & 180 \\
\hline 2 & Planejamento \& Controle & 180 \\
\hline 3 & Gerenciamento da Qualidade & 180 \\
\hline 4 & Gerenciamento da Configuração & 180 \\
\hline \multirow[t]{2}{*}{5} & Controle dos Custos & 180 \\
\hline & $\begin{array}{l}\text { Elaboração das ETEs do Projeto Básico } \\
\end{array}$ & \\
\hline 6 & Dos Postos Locais (PLO), + Análise Aprov.Cliente & 40 \\
\hline 7 & Do Centro de Controle Operacional (CCO), + Anal.Aprov.Clien & 80 \\
\hline \multirow[t]{2}{*}{8} & De Sinalização, + Anal-Aprov.Cliente & 80 \\
\hline & Elaboração das ETEs Funcionais dos Equipamentos & \\
\hline 9 & Dos PCLs (Servidores, Redes,IHM) & 15 \\
\hline 10 & Do CCO (Servidores,Redes,IHM,Consoles,Painéis) & 15 \\
\hline \multirow[t]{2}{*}{11} & Sinalização(CLPs,Maq-Chave,Sinaleiros, Cabos,PDF,No-Break) & 40 \\
\hline & Elaboração Esp. Requisitos Software - ERSs & \\
\hline 12 & Software CLPs & 50 \\
\hline 13 & IHM e Funcionalidades PLO's & 50 \\
\hline 14 & IHM e Funcion. Tráfego CCO & 100 \\
\hline \multirow{2}{*}{15} & IHM e Funcional Energia CCO & 100 \\
\hline & $\begin{array}{l}\text { Fabricação dos Equipamentos } \\
\end{array}$ & \\
\hline 16 & Projeto, Aquisição Material e Fabricação CLPs & 90 \\
\hline 17 & Testes Hardware/Inspeção,Entrega CLPs & 2 \\
\hline 18 & Projeto, Aquisição Material e Fabricação do SMCT & 120 \\
\hline 19 & Testes Hardware/Inspeção,Entrega SMCT & 2 \\
\hline 20 & Projeto, Aquisição Material Gabinetes Servidores & 90 \\
\hline \multirow[t]{2}{*}{21} & Testes Hardware/lnspeção, Entrega Gab.Servidores & 2 \\
\hline & Aquisição de Suprimentos & \\
\hline 22 & Aquisição/Insp/Testes Serv/Works/Est.Trab/etc & 60 \\
\hline 23 & Aquisição Redes/Periféricos & 60 \\
\hline 24 & Inspeção/Testes Rede Local/Entrega & 5 \\
\hline 25 & Aquisição/Entrega Consoles e Painéis & 90 \\
\hline 26 & Aquisição/Entrega No-Break CCO e PLOs & 90 \\
\hline 27 & Aquisição/Entrega Maq- Chave/Sinaleiros e CDVs & 120 \\
\hline 28 & Aquisição/Entrega Cabos Eletricos/Controle & 120 \\
\hline \multirow[t]{2}{*}{29} & Aquisição/Entrega Painel Distrib. Energia (PDF) & 120 \\
\hline & Projeto de Construção do CCO & \\
\hline 30 & Elaboração do Projeto Executivo e Ergonómico & 80 \\
\hline 31 & Contratação Empresa e Execução da Obra & 220 \\
\hline \multirow[t]{2}{*}{32} & Instalaçäo dos Cabos Energia/Dados dos Equip & 10 \\
\hline & Desenv/Testes Soft.Plataf. SMCT/CLPS & \\
\hline 33 & Desenv. Software SMCT LPA, CGO,JUN e VIN & 60 \\
\hline \multirow[t]{2}{*}{34} & Testes Softw.Plataf.Fábrica SMCT LPA,CGO,JUN e VIN & 20 \\
\hline & Desenvolvimento do Software do CCO & \\
\hline 35 & Sistema de Tráfego & \\
\hline 36 & Telas dos Setores LPA, JUN, VIN e CGO & 50 \\
\hline 37 & Telas de Painéis e de Diagnósticos & 40 \\
\hline 38 & Configuração BD da Topologia da via & 50 \\
\hline 39 & Configuração BD das Indicaçōes/Comandos & 40 \\
\hline 40 & Codificação Software/Manobras/Despachos & 80 \\
\hline 41 & Codificação do Simularor de Trens & 80 \\
\hline 42 & Sistema de Energia & \\
\hline 43 & Configuração Telas e Base Dados Energia & 80 \\
\hline 44 & Codificaçăo e Testes do Simulador de Ëne & 80 \\
\hline 45 & Codificação e Testes das Funçōes Energia & 80 \\
\hline
\end{tabular}




\subsubsection{Sequenciamento das Atividades}

É o processo de identificação de interdependências necessárias e ou desejáveis para a execução de cada uma das atividades do projeto.

\subsubsection{Estimativa de recursos das atividades}

Estimativa do tipo e das quantidades de recursos necessários para realizar cada atividade do cronograma.

\subsubsection{Estimativa de duração das atividades}

Estimativa do número de períodos de trabalho que serão necessários para completar cada uma das atividades identificadas no cronograma do projeto.

\subsubsection{Elaboração do Cronograma do Projeto}

Análise dos recursos necessários, das restrições do cronograma, durações e das seqüências de atividades, para criar o cronograma do projeto.

\subsubsection{Controle do Cronograma}

Realizar o controle das mudanças no cronograma do projeto.

Segundo (DINSMORE, 2004), Dentro dos processos de estimativa de duração de atividades destacam-se o PERT, o CPM e a técnica de Simulação de Monte Carlo.

PERT (Project Evaluation and Review Technique) é uma metodologia estatística de estimativa de prazos de duração das atividades desenvolvida pela NASA quando do desenvolvimento do Programa Polaris.

A premissa básica leva em conta uma média ponderada dos valores otimista (Ot), pessimista $(\mathrm{Pe})$ e mais provável $(\mathrm{Pr})$ de duração da atividade, ponderados pelos fatores 1,1 e 4 , respectivamente.

\section{Distribuição beta (PERT):}

Média: $=(\mathrm{Ot}+4 \mathrm{Pr}+\mathrm{Pe}) / 6$

Variância: $\left.\mathrm{s}^{2}=[\mathrm{Pe}-\mathrm{Ot}) / 6\right]^{2}$

Desvio Padrão: $\mathrm{s}=(\mathrm{Pe}-\mathrm{Ot}) / 6$ 
CPM (Critical Path Method) difere do PERT apenas pela forma de estimativa de duração das atividades, que é feita de maneira determinística, considerando apenas a duração mais provável das atividades.

A Simulação de Monte Carlo busca determinar uma curva entre a probabilidade de ocorrência e a duração da atividade ou plano em análise. Na simulação o projeto é "executado" várias vezes alterando-se as durações das atividades para fornecer uma distribuição estatística dos resultados calculados.

$\mathrm{Na}$ tabela 6.4.2 a seguir, apresenta-se uma parte de todas as atividades previstas no projeto Alfa, e as previsões de duração (em dias) de realização de cada uma delas.

Tabela 6.4.2 - Descrição e os prazos de execução de cada atividade

\begin{tabular}{|c|c|c|c|c|c|}
\hline Itens & Descrição da Atividade & $\begin{array}{c}\text { Prazos } \\
\text { Otimistas -Ot }\end{array}$ & $\begin{array}{c}\text { Prazos mais } \\
\text { prováveis - } \mathrm{Pr}\end{array}$ & \begin{tabular}{|c|} 
Prazos \\
pessimistas - \\
$\mathrm{Pe}$
\end{tabular} & $(\mathrm{Ot}+4 \mathrm{Pr}+\mathrm{Pe}) / 6$ \\
\hline & Gerenciamento do Projeto & & & & \\
\hline 1 & Coordenação do Projeto & 180 & 189 & 216 & 192 \\
\hline 2 & Planejamento \& Controle & 180 & 189 & 216 & 192 \\
\hline 3 & Gerenciamento da Qualidade & 180 & 189 & 216 & 192 \\
\hline 4 & Gerenciamento da Configuração & 180 & 189 & 216 & 192 \\
\hline \multirow[t]{2}{*}{5} & Controle dos Custos & 180 & 189 & 216 & 192 \\
\hline & Elaboração das ETEs do Projeto Básico & & & & \\
\hline 6 & Dos Postos Locais (PLO), + Análise Aprov.Cliente & 40 & 42 & 48 & 43 \\
\hline 7 & Do Centro de Controle Operacional (CCO), + Anal.Aprov.Clien & 80 & 84 & 96 & 85 \\
\hline \multirow[t]{2}{*}{8} & De Sinalização, + Anal.Aprov.Cliente & 80 & 84 & 96 & 85 \\
\hline & Elaboração das ETEs Funcionais dos Equipamentos & & & & \\
\hline 9 & Dos PCLs (Servidores, Redes, IHM) & 15 & 16 & 18 & 16 \\
\hline 10 & Do CCO (Servidores,Redes,IHM,Consoles,Painéis) & 15 & 16 & 18 & 16 \\
\hline \multirow[t]{2}{*}{11} & Sinalização(CLPs,Maq.Chave,Sinaleiros,Cabos,PDF,No-Break) & 40 & 42 & 48 & 43 \\
\hline & Elaboração Esp. Requisitos Software - ERSs & & & & \\
\hline 12 & Software CLPs & 50 & 53 & 60 & 53 \\
\hline 13 & IHM e Funcionalidades PLO's & 50 & 53 & 60 & 53 \\
\hline 14 & IHM e Funcion. Tráfego CCO & 100 & 105 & 120 & 107 \\
\hline \multirow[t]{2}{*}{15} & IHM e Funcional Energia CCO & 100 & 105 & 120 & 107 \\
\hline & Fabricação dos Equipamentos & & & & \\
\hline 16 & Projeto, Aquisição Material e Fabricação CLPs & 90 & 95 & 108 & 96 \\
\hline 17 & Testes Hardware/Inspeção,Entrega CLPs & 2 & 2 & 2 & 2 \\
\hline 18 & Projeto, Aquisição Material e Fabricação do SMCT & 120 & 126 & 144 & 128 \\
\hline 19 & Testes Hardware/Inspeção,Entrega SMCT & 2 & 2 & 2 & 2 \\
\hline 20 & Projeto, Aquisição Material Gabinetes Servidores & 90 & 95 & 108 & 96 \\
\hline \multirow[t]{2}{*}{21} & Testes Hardware/Inspeção, Entrega Gab.Servidores & 2 & 2 & 2 & 2 \\
\hline & Aquisição de Suprimentos & & & & \\
\hline 22 & Aquisição/Insp/Testes Serv/Works/Est.Trab/etc & 60 & 63 & 72 & 64 \\
\hline 23 & Aquisição Redes/Periféricos & 60 & 63 & 72 & 64 \\
\hline 24 & Inspeção/Testes Rede Local/Entrega & 5 & 5 & 6 & 5 \\
\hline 25 & Aquisição/Entrega Consoles e Painéis & 90 & 95 & 108 & 96 \\
\hline 26 & Aquisição/Entrega No-Break CCO e PLOs & 90 & 95 & 108 & 96 \\
\hline 27 & Aquisição/Entrega Maq. Chave/Sinaleiros e CDVs & 120 & 126 & 144 & 128 \\
\hline 28 & Aquisição/Entrega Cabos Eletricos/Controle & 120 & 126 & 144 & 128 \\
\hline \multirow[t]{2}{*}{29} & Aquisição/Entrega Painel Distrib. Energia (PDF) & 120 & 126 & 144 & 128 \\
\hline & Projeto de Construção do CCO & & & & \\
\hline 30 & Elaboração do Projeto Executivo e Ergonômico & 80 & 84 & 96 & 85 \\
\hline 31 & Contratacão Empresa e Execucão da Obra & 220 & 231 & 264 & 235 \\
\hline \multirow[t]{2}{*}{32} & Instalação dos Cabos Energia/Dados dos Equip & 10 & 11 & 12 & 11 \\
\hline & Desenv/Testes Soft.Plataf. SMCT/CLPs & & & & \\
\hline 33 & Desenv. Software SMCT LPA,CGO,JUN e VIN & 60 & 63 & 72 & 64 \\
\hline \multirow{2}{*}{34} & Testes Softw.Plataf.Fábrica SMCT LPA,CGO,JUN e VIN & 20 & 21 & 24 & 21 \\
\hline & Desenvolvimento do Software do CCO & & & & \\
\hline 35 & Sistema de Tráfego & & & & \\
\hline 36 & Telas dos Setores LPA, JUN, VIN e CGO & 50 & 53 & 60 & 53 \\
\hline 37 & Telas de Painéis e de Diagnósticos & 40 & 42 & 48 & 43 \\
\hline 38 & Configuração BD da Topologia da via & 50 & 53 & 60 & 53 \\
\hline 39 & Configuração BD das Indicações/Comandos & 40 & 42 & 48 & 43 \\
\hline 40 & Codificação Software/Manobras/Despachos & 80 & 84 & 96 & 85 \\
\hline 41 & Codificação do Simularor de Trens & 80 & 84 & 96 & 85 \\
\hline 42 & Sistema de Energia & & & & \\
\hline 43 & Configuração Telas e Base Dados Energia & 80 & 84 & 96 & 85 \\
\hline 44 & Codificação e Testes do Simulador de Energia & 80 & 84 & 96 & 85 \\
\hline 45 & Codificação e Testes das Funções Energia & 80 & 84 & 96 & 85 \\
\hline
\end{tabular}


Adicionalmente apresenta-se a descrição de cada uma das atividades previstas em cada uma das fases do projeto, e, em cada coluna, as estimativas de duração de cada atividade.

Tempo estimado (Te): É o tempo estimado de duração da atividade.

Prazos otimistas (Ot): São os prazos inicialmente atribuídos pelos especialistas de cada área, tomando como base na experiência de sua área.

Prazos mais prováveis (Pr): São os prazos inicialmente atribuídos pelos especialistas de cada área, tomando como base na experiência de sua área e das informações obtidas na base de dados da empresa, de projetos similares anteriormente realizados. Para a realização dos cálculos é atribuída uma margem de segurança nas estimativas de $5 \%$.

Prazos mais pessimistas (Pe): São os prazos atribuídos pelos especialistas de cada área, tomando como base a falta de informações adequadas para o entendimento das reais necessidades de trabalho de sua área. Para a realização dos cálculos é atribuída uma margem de segurança nas estimativas de 10\%.

Média ponderada dos prazos $\mathrm{Te}=\left(\mathrm{Ot}+\left(4^{*} \mathrm{Pr}\right)+\mathrm{Pe}\right) / 6$ : É o calculo da média ponderada dos cálculos realizados considerando os três parâmetros de prazos citados acima. É também, conhecida como função Beta Pert.

O estabelecimento de um Cronograma do projeto consiste em se determinar as datas de realizações mais prováveis das atividades em função das redes de atividades, da estimativa de duração das atividades, das restrições dos recursos e calendários.

A figura 6.4.3 apresenta-se o Cronograma do projeto realizado utilizando-se o Gráfico de Gantt do aplicativo MSProject, a qual apresenta todas as atividades previstas no projeto, escalonadas no tempo de sua execução, a duração, em dias, e suas atividades antecessoras e sucessoras.

Neste Cronograma, foram também criados os campos EDT e WPS. No campo EDT (ex: PROJ0120-2.3.1), foi criado o número seqüencial do projeto na empresa, 00120, e acrescentado o número seqüencial da atividade 2.3.1. No campo WPS (ex: SE_ATS), foi acrescentado o código que identifica a qual Pacote de Trabalho 
pertence á atividade do projeto. Esses códigos foram utilizados para determinar e controlar o Avanço Físico do Projeto e de cada um dos pacotes de trabalho, citado

no item 5 e detalhado no item 6.6.2 deste trabalho.

Figura 6.4.3 - Cronograma das atividades do projeto (Gráfico de Gantt)

\begin{tabular}{|c|c|c|c|c|c|c|c|c|c|c|}
\hline ld & o & EDT & wPS & Task Name & Traballho & Duraçāo & Inicio & Término & 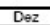 & Fev \\
\hline 1 & & PRODण20-1 & & Tricio do projeto & वd & & 0670106 & 0670106 & & \\
\hline 2 & & PROJ0120-1.1 & & Data de Inicio do Projeto to & od & od & $06 / 01 / 06$ & $06,01 / 06$ & & 01 \\
\hline 3 & & PROJ0120-2 & & Geral & $3.384,88 \mathrm{~d}$ & $485,88 d$ & $06 / 01.06$ & 16/11/07 & & \\
\hline 4 & & PROJ0120-2.1 & & Ge renciamento do Projeto & $2.425 \mathrm{~d}$ & $485,88 \mathrm{~d}$ & $06,01,06$ & $16 / 11 / 07$ & & \\
\hline 5 & 프 & PAOJ0120-2.1.1 & SM_MGT & Coordenaçäo do Projeto & $180 \mathrm{~d}$ & $485 d$ & $06 / 01 / 06$ & $16 / 11 / 07$ & & \\
\hline 6 & II & PROJ0120-2.1.2 & SM_MGT & Planejamento \& Controle & $180 d$ & $485 \mathrm{~d}$ & $06 / 01 / 06$ & $16 / 11 / 07$ & & \\
\hline 7 & & PROJ0120-2.1.3 & SM_MGT & Gerenciamento ds Qualidade & $180 d$ & $485 d$ & $06 / 01 / 06$ & $15 / 11 / 07$ & & \\
\hline 8 & & PROJ0120-2.1.4 & SM_MGT & Gerenciamento da Configuraçào & $180 d$ & $485 \mathrm{~d}$ & $06 / 01 / 06$ & $15 / 11 / 07$ & & \\
\hline 9 & & PAOJ0120-2.1.5 & SM_MGT & Controle dos Custos & $180 \mathrm{~d}$ & $485 \mathrm{~d}$ & $06 / 01 / 06$ & $15 / 11 / 07$ & & \\
\hline 10 & & PROJ0120-2.2 & & Elaboração das ETEs do Projeto Básico & $203 \mathrm{~d}$ & $79,88 \mathrm{~d}$ & $06,01.06$ & $27 / 04 / 06$ & & \\
\hline 11 & 2 & PAOJ0120-2.2.1 & SE_ATS & Dos Postos Locais (PLO), + Anallise Aprov. Clients & $40 \mathrm{~d}$ & $40 \mathrm{~d}$ & $06 / 01 / 06$ & $02 / 03 / 06$ & & \\
\hline 12 & & PROJ0120-2.2.2. & SE_ATS & Do Centro de Controle Operacional ( $\mathrm{CCO}$ ), + AnalAprov. Cliente & $80 \mathrm{~d}$ & $80 \mathrm{~d}$ & $06 / 01 / 06$ & $27 / 0406$ & & \\
\hline 13 & & PROJ0120-2.2.3 & SE_ATS & De Sinalizaçäa, + AnsilA prov. Cliente & $80 \mathrm{~d}$ & $80 \mathrm{~d}$ & $06 / 01 / 06$ & $27 / 0406$ & & \\
\hline 14 & & PROJ0120-2.3 & & Elaboração das ETEs Funcionais dos Equipamentos & $185 \mathrm{~d}$ & $39,88 \mathrm{~d}$ & 280406 & $22 / 06 / 06$ & & \\
\hline 15 & & PROJ0120-2.3.1 & SE_ATS & Dos PCLs (Servidare s, Redes, IHM) & $15 \mathrm{~d}$ & $15 d$ & $28 / 04 / 06$ & $18,05 / 06$ & & \\
\hline 16 & & PROJ0120-2.3.2 & SE_ATS & Do CCO (Servidares, Redes, IHM, Consoles, Paináis) & $15 \mathrm{~d}$ & $15 \mathrm{~d}$ & $28 / 04 / 06$ & $18,05 / 06$ & & \\
\hline 17 & & PAOJ0120-2.3.3 & SE_ATS & Sinalizaçäo(CLPs, Maq.Chave, Sinaleiros,Cabos, PDF,No-Break) & $40 \mathrm{~d}$ & $40 \mathrm{~d}$ & $28 / 04 / 06$ & $22 / 06 / 06$ & & \\
\hline 18 & & PROJ0120-2.4 & & Elaboraçāo Esp. Re quisitos Software - ERSs & $315,88 \mathrm{~d}$ & $139,88 \mathrm{~d}$ & $03 / 03,06$ & $1409 / 06$ & & \\
\hline 19 & & PROJ0120-2.4.1 & AP_ATS & Sotwase CLPs & $50 \mathrm{~d}$ & $50 \mathrm{~d}$ & $23 / 06 / 06$ & $31,08 / 06$ & & \\
\hline 20 & 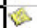 & PROJ0120-2.4.2 & AP_ATS & IHMe Funcionalidades PLO's & $50 \mathrm{~d}$ & $50 \mathrm{~d}$ & $03 / 03 / 06$ & $11 / 06 / 06$ & & \\
\hline 21 & & PROJ0120-2.4.3 & AP_ATS & $\mathbb{H} M$ M Fundion. Trálego $\mathrm{CCO}$ & $100 d$ & $100 \mathrm{~d}$ & $28 / 04 / 06$ & $14 / 09 / 06$ & & \\
\hline 22 & & PROJ0120-2.4.4 & AP_ATS & $\mathbb{H} M$ M Funcional Energia $C C O$ & $100 d$ & $100 \mathrm{~d}$ & $28 / 04 / 06$ & $14 / 09 / 06$ & & \\
\hline 23 & & PROJ0120-2.5 & & Fabricaçào dos Equipame ntos & $38 \mathrm{~d}$ & $146,88 \mathrm{~d}$ & 19/05:06 & $11 / 12 / 06$ & & \\
\hline 24 & & PROJ0120-2.5.1 & P_ATS & Projeto, Aquisiçào Materisal e Fabricaçằ CLPs & $90 \mathrm{~d}$ & $90 \mathrm{~d}$ & $19 / 05 / 06$ & $21 / 09 / 06$ & & \\
\hline 25 & & PAOJ0120-2.5.2 & P_ATS & Testes Hardware/lnspeçà ,Entrega CLPs & $2 d$ & $2 \mathrm{~d}$ & $2209 / 06$ & $25 / 09 / 06$ & & \\
\hline 26 & 프 & PROJ0120-2.5.3 & P_ATS & Projetb, Aquisiçao Material e Fabricaçào do SMCT & $120 d$ & $120 \mathrm{~d}$ & $23 / 06 / 06$ & $07 / 12 / 06$ & & \\
\hline 27 & 프 & PAOJ0120-2.5.4 & P_ATS & Testes Hardware/lnspeçà,Entreg a SMCT & $2 d$ & $2 \mathrm{~d}$ & $08 / 12 / 06$ & $11 / 12 / 06$ & & \\
\hline 28 & 프 & PROJ0120-2.5.5 & P_ATS & Projets, Aquisiç̧à Material Gabinntes Se vidores & $90 \mathrm{~d}$ & $90 \mathrm{~d}$ & 19/05/06 & $21 / 09 / 06$ & & \\
\hline 29 & 프 & PROJ0120-2.5.6 & P_ATS & Testes Hardware/lnspeçào, Ente ga Gab.Servidores & $2 d$ & $2 \mathrm{~d}$ & $2209 / 06$ & $25 / 09 / 06$ & & \\
\hline 30 & & PROJ0120-2.6 & & Aquisiçáo de Suprimentos & $800 \mathrm{~d}$ & $269,88 \mathrm{~d}$ & 19,05:06 & $31 / 05 / 07$ & & \\
\hline 31 & & PROJ0120-2.6.1 & PC_ATS & Aquisiçä//hsp/Teste s SerwW orks/Est Trab/etc & $60 \mathrm{~d}$ & $60 \mathrm{~d}$ & $19 / 05 / 06$ & $10,08 / 06$ & & \\
\hline 32 & & PAOJ0120-2.6.2 & PC_ATS & Aquisiçäo Rede s/Peritericoss & $60 \mathrm{~d}$ & $60 \mathrm{~d}$ & $1905 / 06$ & 10,0806 & & \\
\hline 33 & & PAOJ0120-2.6.3 & PC_ATS & InspecsaorTestes Rede Local Entrega & $5 d$ & $5 d$ & 2010006 & $26 / 10 / 06$ & & \\
\hline 34 & & PROJ0120-2.6.4 & PC_ATS & Aquisiçäa/Entrega Consoles \& Painélis & $90 \mathrm{~d}$ & $90 \mathrm{~d}$ & $07 / 12 / 06$ & $12 / 04 / 07$ & & \\
\hline 35 & & PROJ0120-2.6.5 & PC_ATS & Aquisiçàa óntrega No-Break $\mathrm{CCO} \in \mathrm{PLO}_{3}$ & $90 \mathrm{~d}$ & $90 \mathrm{~d}$ & $25 / 01 / 07$ & $31 / 05 / 07$ & & \\
\hline 36 & & PROJ0120-2.6.6 & PC_ATS & Aquisisça/Entregas Maq. Chave/Sinnaleiros e CDVs & $120 d$ & $120 \mathrm{~d}$ & $09 / 11 / 06$ & $26,04 / 07$ & & \\
\hline 37 & & PROJ0120-2.6.7 & PC_ATS & Aquisiçàa/Entrega Cabos Eetricos/Controle & $120 d$ & $120 \mathrm{~d}$ & $09 / 11 / 06$ & $26,04 / 07$ & & \\
\hline 38 & & PROJ0120-2.6.8 & PC_ATS & Aquisiçäa/Entregs Painel Distrib. Energia (PDF) & $120 \mathrm{~d}$ & $120 \mathrm{~d}$ & $09 / 11 / 06$ & $26,04 / 07$ & & \\
\hline 39 & & PROJ0120-2.7 & & Projeto de Construçáo do $\mathrm{CCO}$ & $272 \mathrm{~d}$ & $316,88 \mathrm{~d}$ & $28 / 04.06$ & $16 / 07 / 07$ & & \\
\hline 40 & 프 & PROJ0120-2.7.1 & PC_ATS & Elaboraçào do Projeto Exe cutivo e Ergonómico & $80 \mathrm{~d}$ & $80 \mathrm{~d}$ & $28 / 04 / 06$ & $17 / 08 / 06$ & & \\
\hline 41 & & PROJ0120-2.7.2 & PC_ATS & Contrataçào Empresa e Exe cuçăo da Obra & $220 \mathrm{~d}$ & $220 \mathrm{~d}$ & $18 / 0 \mathrm{Q} / 06$ & $21 / 06 / 07$ & & \\
\hline 42 & & PROJ0120-2.7.3 & PC_ATS & Instalaçào dos Cabos Energia/Dados dos Equip & $10 \mathrm{~d}$ & $10 \mathrm{~d}$ & $03 / 07 / 07$ & 16:07/07 & & \\
\hline 43 & & PROJ0120-2.8 & & Deservi/Te stes Soft.Plataf. SMCT/CLPs & $280 \mathrm{~d}$ & $79,88 d$ & 23,06,06 & $12 / 10 / 06$ & & \\
\hline 44 & & PROJ0120-2.8.1 & AP_ATS & Desenv. Software SMCT LPA,CGO,JUN e VIN & $60 \mathrm{~d}$ & $60 \mathrm{~d}$ & $23 / 06 / 06$ & $14,09 / 06$ & & \\
\hline 45 & & PROJ0120-2.8.2 & AP_ATS & Testes Softw.Plataf.Fabrics SMCT LPA,CGO,JUN $\in$ VIN & $20 \mathrm{~d}$ & $20 \mathrm{~d}$ & $15 / 09 / 06$ & $12 / 1006$ & & \\
\hline 46 & & PROJ0120-2.9 & & De servolvimento do Software do $\mathrm{CCO}$ & $530 \mathrm{~d}$ & $249,88 \mathrm{~d}$ & $12 / 05,06$ & $26 / 04 / 07$ & & \\
\hline 47 & & PROJ0120.2.9.1 & & Sistema de Trafego & $380 \mathrm{~d}$ & $189,88 \mathrm{~d}$ & 12/05:06 & $01 / 02 / 07$ & & \\
\hline 48 & & PRON0120-2.9.1.1 & CF_ATS & Telas dos Setores LPA, JUN, VIN e CGO & $50 d$ & $50 \mathrm{~d}$ & $15 / 09 / 06$ & $23 / 11 / 06$ & & \\
\hline 49 & & PRON0120-2.9.1.2 & CF_ATS & Tel as de Painśis e de Diagnósticas & $40 \mathrm{~d}$ & $40 \mathrm{~d}$ & $12 / 05 / 06$ & $06,07 / 06$ & & \\
\hline 50 & & PRON01 20-2.8.1.3 & CF_ATS & Configur açäo BD da Topalogia da via & $50 d$ & $50 \mathrm{~d}$ & $24 / 11 / 06$ & $01 / 02 / 07$ & & \\
\hline 51 & & PAON0120-2.9.1.4 & CF_ATS & Confgur açäo BD das Indicap̧oes/Comandos & $40 \mathrm{~d}$ & $40 \mathrm{~d}$ & $07 / 07 / 06$ & $31 / 08 / 06$ & & \\
\hline 52 & & PRON0120-2.9.1.5 & CF_ATS & Codficaça Software/Manobras Despachos & $80 \mathrm{~d}$ & $80 \mathrm{~d}$ & $15 / 0906$ & $04 / 01 / 07$ & & \\
\hline 53 & & PAON0120-2.8.1.6 & CF_ATS & Codificaça o do Sinvularar de Trens & $80 d$ & $80 d$ & $15 / 0906$ & $04 / 01 / 07$ & & \\
\hline 54 & & PROJ0120.2.9.2 & & Sistema de Energia & $150 \mathrm{~d}$ & $159,88 \mathrm{~d}$ & $15,09,06$ & $26 / 04 / 07$ & & \\
\hline 55 & & PRON0120-2.9.2.1 & CF_ATS & Confgur raça Telas e Base Dados Energia & $80 \mathrm{~d}$ & $80 d$ & $15 / 09 / 06$ & $04 / 01 / 07$ & & \\
\hline 56 & & PRON01 20-2.9.2.2 & CF_ATS & Codificaça o e Testes do Simul ador de Energia & $80 \mathrm{~d}$ & $80 \mathrm{~d}$ & $09 / 11 / 06$ & $01 / 03 / 07$ & & \\
\hline 57 & & PRON01 20-2.8.2.3 & CF_ATS & Codificaça & $80 \mathrm{~d}$ & $80 \mathrm{~d}$ & $05 / 01 / 07$ & $26,04 / 07$ & & \\
\hline 58 & & PROJ0120-2.10 & & Integraçáo/Te stes do Software CCO em Fábrica & $140 \mathrm{~d}$ & $136,88 \mathrm{~d}$ & $02 / 02,07$ & $13 / 08: 07$ & & \\
\hline 59 & & PROJ0120-2.10.1 & ATS & Trátego & $70 \mathrm{~d}$ & $89,88 \mathrm{~d}$ & $02 / 02,07$ & $07 / 06 / 07$ & & \\
\hline 60 & & PRON0120-2.10.1.1 & C_ATS & Integraçào Software Tráfego/Reotrada Pendênciss & $70 \mathrm{~d}$ & $70 \mathrm{~d}$ & 02/02/07 & $10,05 / 07$ & & \\
\hline 61 & & PRON0120-2.10.1.2 & C_ATS & Teste s Aoeitaçào Trátego of Cliente & $20 \mathrm{~d}$ & $20 d$ & $11 / 05 / 07$ & $07 / 06 / 07$ & & \\
\hline 62 & & PROJ0120-2.10.2 & & Energia & $50 \mathrm{~d}$ & $61,88 \mathrm{~d}$ & $27 / 04,07$ & $23 / 07 / 07$ & & \\
\hline 63 & & PRON0120-2.10.2.1 & C_ATS & Integraçäo Software Energia/Retr ada Pendencias & $40 d$ & $40 d$ & $27 / 04 / 07$ & $21 / 06 / 07$ & & \\
\hline 64 & & PRON0120-2.10.2.2 & C_ATS & Testes Acoitaçào Energia & $22 \mathrm{~d}$ & $22 \mathrm{~d}$ & $22 / 06 / 07$ & $23,07 / 07$ & & \\
\hline 65 & & PROJ0120-2.10.3 & & Desm/Embal./Transpor. Equip.Plataf.cco & $26 \mathrm{~d}$ & $36,88 \mathrm{~d}$ & $08,06,07$ & $30,07 / 07$ & & \\
\hline 66 & & PROJ0120-2.10.3.1 & PC_ATS & Desm.Emb.Trans. Equip. Tráfego & $5 d$ & $5 \mathrm{~d}$ & 0806,07 & $14,06: 07$ & & \\
\hline बा & & PRON0120-2.10.3.2 & PC_ATS & Desm.Emb.Trans. Equip. Energia & $5 d$ & $5 \mathrm{~d}$ & $24 / 07 / 07$ & $30,07 / 07$ & & \\
\hline 68 & & PROJ0120-2.10.4 & & Realizaçäo Treinamentos Ope raçáo CCO & $20 \mathrm{~d}$ & $29,88 \mathrm{~d}$ & 03/07:07 & 13/08:07 & & \\
\hline 69 & & PRON0120-2.10.4.1 & LS_ICC & Sistema de Tráfego & $10 \mathrm{~d}$ & $10 \mathrm{~d}$ & $03 / 07 / 07$ & $16,07 / 07$ & & \\
\hline 70 & III & PRON0120-2.10.4.2 & LS_ICC & Sistema de Energia & $10 \mathrm{~d}$ & $10 \mathrm{~d}$ & $03 / 07 / 07$ & $16,07 / 07$ & & \\
\hline 71 & & PRON0120-2.10.4.3 & LS_ICC & Configur açato Software & $20 \mathrm{~d}$ & $20 \mathrm{~d}$ & $17 / 07 / 07$ & $13 / 08 / 07$ & & \\
\hline 72 & & PROJ0120-2.11 & & Elaboraçāo Procedim. de Inspeçāo Te ste s Fábrica & $260 \mathrm{~d}$ & $254,88 \mathrm{~d}$ & $16,06,06$ & $07 / 06 / 07$ & & \\
\hline 73 & & PROJ0120-2.11.1 & & Elab. Proc.Inspe çāo dos Equip.Fabrica & $125 \mathrm{~d}$ & $144,88 \mathrm{~d}$ & $16,06,06$ & $0401 / 07$ & & \\
\hline 74 & & PRON0120-2.11.1.1 & SE_ATS & Elab/Aprova çào do PIS dos CLPs & $20 d$ & $20 \mathrm{~d}$ & $16 / 06 / 06$ & $13,07 / 06$ & & \\
\hline 75 & & PRON0120-2.11.1.2 & SE_ATS & Elab/Aprovaçắ do PIS Gabinetes Servidores & $20 \mathrm{~d}$ & $20 \mathrm{~d}$ & $25 / 08 / 06$ & $21 / 09 / 06$ & & \\
\hline 76 & & PRON0120-2.11.1.3 & SE_ATS & Elab/Aprovaçăa do PIS dos Equip. CCO,PLO & $20 \mathrm{~d}$ & $20 \mathrm{~d}$ & $2209 / 06$ & $19 / 10 / 06$ & & \\
\hline
\end{tabular}




\subsection{Gerenciamento de custos do projeto}

Inclui os processos envolvidos em planejamento, estimativa, orçamentação e controle de custos, de modo que seja possível terminar o projeto dentro do orçamento aprovado.

Segundo (HELDMAN, 2003), o gerenciamento de custos do projeto incluí os processos necessários para assegurar que o projeto será concluído dentro do orçamento aprovado.

\subsubsection{Relatório de Custos das Atividades}

Tabela 6.5.1 - Relatório dos custos das atividades distribuídos mensalmente

\begin{tabular}{|c|c|c|c|c|c|c|c|}
\hline & $\sqrt{\text { Janaito }}$ & Fevereiro & Marco & Abril & Maio & Junho & Jullno \\
\hline \multicolumn{8}{|l|}{ Inicio do projeto } \\
\hline \multicolumn{8}{|l|}{ Data de inicio do Projato } \\
\hline \multicolumn{8}{|l|}{ Geral } \\
\hline \multicolumn{8}{|l|}{ Gerenciamento do Projato } \\
\hline Coordenacto do Projpto & R\$\$13.700 & $R \$ 16,000$ & R\$\$18.400 & R\$\$ 16.000 & R\$\$ 18.400 & $\operatorname{R\$ } 17,600$ & $R \$ 16,800$ \\
\hline Planejamanto \& Controle & R\$\$6.850 & R\$\$8.000 & R\$\$9.200 & A\$\$8.000 & Ris9.200 & Ris8.800 & $\bar{R} \$ 90.400$ \\
\hline Gerenciamentito da Qualidado & R\$\$7.200 & R\$\$8.000 & R\$\$ & A\$\$8.000 & A 599.200 & Ris8,800 & $\bar{R} \$ \$ 9.400$ \\
\hline Gerencianentito da Configulaçio & R\$\$7.200 & R\$\$8.000 & R\$\$9.200 & R\$s8.000 & R 199.200 & Ris8.800 & $\operatorname{RS8.400}$ \\
\hline Controla dos Custos & R\$\$7.200 & R\$\$8.000 & R\$\$9.200 & A\$8.000 & R 199.200 & R\$\$8.800 & $\operatorname{RS9.400}$ \\
\hline \multicolumn{8}{|l|}{ Elaboraça das ETEs do Projato Básico } \\
\hline Dos Postos Locais (PLO), + Análise Aprov.Cliente & $R \$ 18.720$ & $R \$ 20.800$ & RS2:080 & & & & \\
\hline Do Canitro da Conitrola Opalacional (CCO), + Anal.Aprov,Cliente & R\$\$11.520 & $R \$ 12,800$ & R\$\$ $\$ 4.720$ & $\operatorname{R} \$ 12.160$ & & & \\
\hline De Sinalizaça0, + Anal.Aprov.Clientis & R\$\$11.520 & $R \$ 12,800$ & R\$\$14.720 & $\mathrm{R} \$ \$ 12: 160$ & & & \\
\hline \multicolumn{8}{|l|}{ Elaboraço das ETEs Funcionais dos Equipamentios } \\
\hline Dos PCLS (SaIVidores,Redes, IHIM) & & & & R\$S560 & R\$\$7,840 & & \\
\hline Do CCO (Servidores,Redes,JHM,Consoles,Painais) & & & & R\$\$\$50 & $\bar{R} \$ \overline{7}, 840$ & & \\
\hline Sinalizaça(CLPs,Maq,Chave,Sinalairos,Cabos,PDF,No-Break) & & & & A $\$ \$ 1.200$ & RS27,600 & R\$\$18.200 & \\
\hline \multicolumn{8}{|l|}{ Elaboracto Esp. Requisitos Sotwware - ERSs } \\
\hline Software CLPs & & & & & & RS\$3.840 & $\bar{R} \mathbf{R} 13.440$ \\
\hline IHN e Funcionalidadas PLO'S & & & R\$20.160 & $\mathrm{A} \$ \$ 18.200$ & As\$8640 & & \\
\hline THN e Funcion, Tratagocco & & & & A $\$ \$ 1.680$ & A\$\$38.640 & R\$\$36.960 & $\mathrm{R} \$ 335.280$ \\
\hline IHN e Funcional Energia CCO & & & & A $\$ \$ 1.520$ & R\$\$34.960 & R\$\$33.440 & R\$331.920 \\
\hline \multicolumn{8}{|l|}{ Fabricacao dos Equipamentos } \\
\hline 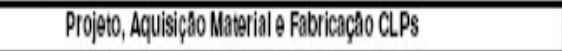 & & & & & Ris3.960 & RS99.680 & $\overline{R S 9} 2.240$ \\
\hline \multicolumn{8}{|l|}{ Testes HardWara Inspecho, Entrega CLPs } \\
\hline Projato, Aquisicgo Material a Fabricaça do SMCT & & & & & & Ris3.3.360 & $R \$ 11.760$ \\
\hline \multicolumn{8}{|l|}{ Testes Hardoware Inspecino, Entrega SMCT } \\
\hline Projoto, Aquisicgo Material Gabinates Servidoles & & & & & R 193.600 & Ris8.800 & $\bar{R} \$ \$ 9.400$ \\
\hline Testes Hardware Inspecio, Entrega Gab. Servidoores & & & & & & & \\
\hline
\end{tabular}


O relatório apresentado na tabela 6.5.1 é uma parte do relatório exportado diretamente do planejamento do projeto (MSProject), e apresentado no item 6.4.1. Apresenta os custos associados de cada uma das atividades, distribuídos nos meses previstos de execução de cada uma das atividades.

\subsubsection{Custos de Aquisição de Materiais, Equipamentos e Contratação de Serviços de Terceiros}

A tabela 6.5 .2 contém os custos previstos de aquisição de materiais e equipamentos e a contratação de serviços de terceiros, para execução de atividades não relacionadas a atividades normais da empresa, tais como elaboração de projetos de ergonomia, de construção civil, de instalações elétricas e hidráulicas, etc.

Tabela 6.5.2 - Custos de aquisição de Materiais e Equipamentos e Serviços de Terceiros

\begin{tabular}{|l|r|}
\hline \multicolumn{1}{|c|}{ GASTOS NA AQUISIÇÃO DE MATERIAIS E EQUIPAMENTOS } & Valor em R\$. \\
\hline Aquisição Material e Fabricação CLPs & $65.000,00$ \\
\hline Aquisição Material e Fabricação do SMCT & $48.000,00$ \\
\hline Aquisição Material Gabinetes Servidores & $56.000,00$ \\
\hline Aquisição/Insp/Testes Servidores/Works/Est.Trab/etc & $250.000,00$ \\
\hline Aquisição Redes/Periféricos & $75.000,00$ \\
\hline Aquisição/Entrega Consoles e Painéis & $780.000,00$ \\
\hline Aquisição/Entrega No-Break CCO e PLOs & $80.000,00$ \\
\hline Aquisição/Entrega Maq. Chave/Sinaleiros e CDVs & $868.000,00$ \\
\hline Aquisição/Entrega Cabos Eletricos/Controle & $313.500,00$ \\
\hline Aquisição/Entrega Painel Distrib. Energia (PDF) & $50.000,00$ \\
\hline Elaboração Projeto Construção do CCO & $80.000,00$ \\
\hline Contratação Empresa e Execução da Obra do CCO & $650.000,00$ \\
\hline Contratação de Seguros & $265.000,00$ \\
\hline & $3.580 .500,00$ \\
\hline
\end{tabular}

\subsubsection{Receitas do Projeto}

A tabela 6.5.3 apresenta todos os eventos previstos de receitas do projeto, a data prevista de sua realização, e o valor correspondente a ser faturado junto ao cliente. 
Tabela 6.5.3 - Receitas previstas do Projeto

\begin{tabular}{|c|c|c|c|c|c|}
\hline \multicolumn{6}{|c|}{ TABELA DE RECEITAS DO PROJETO } \\
\hline ITEM & Total Custos & Total Receitas & & & \\
\hline Mão de Obra & $3.742 .992,02$ & $4.566 .450,26$ & & & \\
\hline Materiais, Equipamentos, Seguros & $3.580 .500,00$ & $4.368 .210,00$ & & & \\
\hline Total & $7.323 .492,02$ & $8.934 .660,26$ & & & \\
\hline Evento & Evento & Data & Porcentagem & Valor em R\$. & Acumulado \\
\hline Assinatura do Contrato & 0 & 6/1/2006 & $10,00 \%$ & $893.466,03$ & $893.466,03$ \\
\hline Aprovação dos Projetos Básicos & 1 & $27 / 4 / 2006$ & $10,00 \%$ & $893.466,03$ & $1.786 .932,05$ \\
\hline Ińício Aquisição e Fabricação de Equipamentos & 2 & $19 / 5 / 2006$ & $5,00 \%$ & $446.733,01$ & $2.233 .665,07$ \\
\hline Aprovação dos Projetos Funcionais Equipamentos & 3 & $22 / 6 / 2006$ & $5,00 \%$ & $446.733,01$ & $2.680 .398,08$ \\
\hline Aprovação Projeto Executivo Construção CCO & 4 & 17/8/2006 & $5,00 \%$ & $446.733,01$ & $3.127 .131,09$ \\
\hline Aprovação Especificações Requisitos Software & 5 & $14 / 9 / 2006$ & $5,00 \%$ & $446.733,01$ & $3.573 .864,10$ \\
\hline Teste Aceitação em Fábrica dos Equipamentos & 6 & $25 / 9 / 2006$ & $5,00 \%$ & $446.733,01$ & $4.020 .597,12$ \\
\hline Aprovação dos Proc. Testes de Fábrica I & 7 & $1 / 3 / 2007$ & $2,50 \%$ & $223.366,51$ & 4.243.963,62 \\
\hline Testes Aceitação Equip. Adquirido Terceiros & 8 & $26 / 4 / 2007$ & $2,50 \%$ & $223.366,51$ & 4.467.330,13 \\
\hline Testes Aceitação Fábrica Software Tráfego & 9 & $7 / 6 / 2007$ & $2,50 \%$ & $223.366,51$ & $4.690 .696,64$ \\
\hline Aprovação dos Proc. Testes de Fábrica II & 10 & $7 / 6 / 2007$ & $2,50 \%$ & $223.366,51$ & $4.914 .063,14$ \\
\hline Aprovação dos Projetos Instal. Equip. Campo & 11 & $25 / 6 / 2007$ & $2,50 \%$ & $223.366,51$ & $5.137 .429,65$ \\
\hline Entrega dos Manuais de Operação/Manutenção & 12 & $2 / 7 / 2007$ & $2,50 \%$ & $223.366,51$ & $5.360 .796,16$ \\
\hline Testes Integração/Aceitação Fábrica dos PLOs & 13 & $23 / 7 / 2007$ & $5,00 \%$ & $446.733,01$ & $5.807 .529,17$ \\
\hline Testes Aceitação Fábrica Software Energia & 14 & $24 / 7 / 2007$ & $5,00 \%$ & $446.733,01$ & $6.254 .262,18$ \\
\hline Conclusão dos Treinamentos Oper/Manutenção & 15 & $13 / 8 / 2007$ & $2,50 \%$ & $223.366,51$ & $6.477 .628,69$ \\
\hline Aprovação dos PTSs de Campo & 16 & $17 / 8 / 2007$ & $2,50 \%$ & $223.366,51$ & $6.700 .995,20$ \\
\hline Testes Integrados dos PLOs em Campo & 17 & $24 / 8 / 2007$ & $5,00 \%$ & $446.733,01$ & $7.147 .728,21$ \\
\hline Projeto de Instal. Equipamentos CCO em Campo & 18 & $24 / 8 / 2007$ & $5,00 \%$ & $446.733,01$ & $7.594 .461,22$ \\
\hline Aprovação Realiz.Testes Estáticos de Energia & 19 & $14 / 9 / 2007$ & $5,00 \%$ & $446.733,01$ & $8.041 .194,24$ \\
\hline Aprov. Testes Estáticos/Dinamicos Tráfego Campo & 20 & $5 / 10 / 2007$ & $5,00 \%$ & $446.733,01$ & $8.487 .927,25$ \\
\hline Operação Assistida & 21 & $16 / 11 / 2007$ & $5,00 \%$ & $446.733,01$ & $8.934 .660,26$ \\
\hline TOTAL & & & $100,00 \%$ & $8.934 .660,26$ & \\
\hline
\end{tabular}

A tabela 6.5.3 contém, na coluna Total Custos, os custos previstos de mão de obra, aquisição de materiais e equipamentos, seguros, etc. Na coluna Total de Receitas são apresentados os valores a serem faturados junto ao cliente incorporados a uma margem bruta sobre os custos apresentados. $\mathrm{Na}$ coluna Eventos, estão discriminados todos os eventos que geram receitas durante o ciclo de vida do projeto, com as respectivas datas para cumprimento dos marcos de entrega dos trabalhos, e do valor em reais associado a cada faturamento.

\subsection{Implementação da Nova Metodologia em um projeto em desenvolvimento}

Apos analisados todos os conceitos sobre gerenciamento de projetos, custos, prazos e da nova metodologia proposta do cálculo do Avanço Físico do Projeto descrita neste capítulo e nos capítulos anteriores, serão apresentados, a seguir, os processos para a implementação desta metodologia em um projeto em desenvolvimento. 


\subsubsection{Cálculo do Avanço Físico do Projeto}

Para a alta administração da empresa e dos patrocinadores do projeto, é fundamental a apresentação de um índice confiável e mais próximo da realidade sobre o do Avanço Físico do Projeto (EV). Com este índice e os demais dois índices mais importantes do EVMS (PV) que corresponde ao planejamento inicial do projeto, e do (AC) que corresponde ao custo real incorrido no projeto, é possível realizar uma análise mais precisa do desempenho do projeto. Com auxílio dos três índices apresentados, a alta administração da empresa poderá verificar se o projeto está dentro do planejamento de custos e de prazo inicialmente previsto, identificar os desvios existentes, e tomar as ações necessárias para a correção das eventuais anomalias detectadas.

Para o Gerente do Projeto e demais área da empresa, além desse índice geral de Avanço Físico do Projeto, é necessário realizar um controle mais rígido e detalhado do avanço físico das atividades em execução. Uma nova metodologia de determinação do Avanço Físico do Projeto focando os Pacotes de Trabalho foi apresentada no capítulo 5 deste trabalho, a qual iremos implementá-la nos itens a seguir.

Na tabela 6.6.1, a seguir, apresenta-se a proposta de como calcular o Avanço Físico do Projeto por meio da definição de um valor percentual a cada uma das atividades do planejamento. A atualização dos dias trabalhados em cada uma das atividades, e os cálculos dos percentuais do avanço físico, são realizados automaticamente. Os dias trabalhados em cada atividade são inseridos pelo responsável do pacote de trabalho, na pasta da planilha que realiza o cálculo do avanço físico de seu pacote de trabalho. Como as planilhas estão interligadas, ao se realizar o andamento físico das atividades (em dias de trabalho efetivamente realizado na atividade), esses dias são transferidos automaticamente a esta planilha, e realizado o cálculo do avanço físico dessa atividade do projeto como um todo. 
Tabela 6.6.1 - Percentual do Avanço físico das atividades e do projeto

\begin{tabular}{|c|c|c|c|c|c|c|c|c|c|c|c|}
\hline Atividade & $\begin{array}{l}\text { Pacote de } \\
\text { Trabalho }\end{array}$ & Descrição das Atividades & \begin{tabular}{|c|} 
Dias \\
Previstos de \\
cada \\
Atividade
\end{tabular} & $\begin{array}{l}\text { \% de cada } \\
\text { Atividade }\end{array}$ & $\mid \begin{array}{l}\text { Total dias já } \\
\text { trabalhados }\end{array}$ & \begin{tabular}{|c} 
Dias \\
Trabalhados \\
Jan06
\end{tabular} & $\begin{array}{l}\text { \% do } \\
\text { Avanço } \\
\text { Fisico no } \\
\text { mêsJan06 }\end{array}$ & $\begin{array}{c}\text { Dias } \\
\text { Trabalhados } \\
\text { mês Fev06 }\end{array}$ & \begin{tabular}{|c|}
$\%$ do \\
Avanço \\
Fisico no \\
mês fevo6
\end{tabular} & $\begin{array}{c}\text { Dias } \\
\text { Trabalhados } \\
\text { més Mar06 }\end{array}$ & \begin{tabular}{|c|}
$\%$ do \\
Avanço \\
Fisicono \\
mês Mar06
\end{tabular} \\
\hline & & Total de dias trabalhados & 4886 & & 457 & 70 & & 100 & & 99 & \\
\hline CÓDIGOCONTABIL & & Acumulado & & & & 70 & & 170 & & 269 & \\
\hline & & Avanço físico mensal do projeto & & $100,00 \%$ & & & $1,43 \%$ & & $2,05 \%$ & & $203 \%$ \\
\hline & & Acumulado & & & & & $1,43 \%$ & & $3,48 \%$ & & $5,51 \%$ \\
\hline PRON0120-1 & SM MGT & Início do projeto & & & & & & & & & \\
\hline PRON0120-1.1 & SM MGT & Data de Início do Projeto & & & & & & & & & \\
\hline PRON0120-2 & 0 & Geral & & & & & & & & & \\
\hline PRON0120-2.1 & TIT & Gerenciamento do Projeto & 900 & $18,42 \%$ & 138 & & $0,41 \%$ & & $0,82 \%$ & & $0,80 \%$ \\
\hline PRON0120-2.1.1 & SM MGT & Coordenação do Projeto & 180 & $3,68 \%$ & 27. & 5 & $0,10 \%$ & 8 & $0,16 \%$ & 7 & $0,14 \%$ \\
\hline PRO10120-2.1.2 & SM MGT & Planejamento \& Controle & 180 & $3,68 \%$ & 27. & 3 & $0,06 \%$ & 8 & $0,16 \%$ & 8 & $0,16 \%$ \\
\hline PROV0120-2.1.3 & SM MGT & Gerenciamento da Qualidade & 180 & $3,68 \%$ & 28 & 4 & $0,08 \%$ & 8 & $0,16 \%$ & 8 & $0,16 \%$ \\
\hline PRON0120-2.1.4 & SM MGT & Gerenciamento da Configuração & 180 & $3,68 \%$ & 28 & 4 & $0,08 \%$ & 8 & $0,16 \%$ & 8 & $0,16 \%$ \\
\hline PRO10120-2.1.5 & SM MGT & Controle dos Custos & 180 & $3,68 \%$ & 28 & 4 & $0,08 \%$ & 8 & $0,16 \%$ & 8 & $0,16 \%$ \\
\hline PRO0120-2.2 & TाT & Eaboração das ETES do Projeto Básico & 200 & $4,09 \%$ & 200 & & $1,02 \%$ & & $1,23 \%$ & & $1,02 \%$ \\
\hline PROJ0120-2.2.1 & SE ATS & Dos Postos Locais (PLO), + Análise Aprov.Cliente & 40 & $0,82 \%$ & 40 & 10 & $0,20 \%$ & 20 & $0,41 \%$ & 10 & $0,20 \%$ \\
\hline PRO0120-2.2.2 & SE ATS & Do Centro de Controle Operacional (CCO), + Anal.Aprov.Cliente & 80 & $1,64 \%$ & 80 & 20 & $0,41 \%$ & 20 & $0,41 \%$ & 20 & $0,41 \%$ \\
\hline PRO10120-2.2.3 & SE ATS & De Sinalização, + Anal.Aprov.Cliente & 80 & $1,64 \%$ & 80 & 20 & $0,41 \%$ & 20 & $0,41 \%$ & 20 & $0,41 \%$ \\
\hline PRO0120-2.3 & TाT & Eaboração das ETEs Funcionais dos Equipamentos & 70 & $1,43 \%$ & 38 & & $0,00 \%$ & & $0,00 \%$ & & $0,00 \%$ \\
\hline PRON0120-2.3.1 & SE ATS & Dos PCLs (Senvidores,Redes,IHM) & 15 & $0,31 \%$ & 9 & $\overline{0}$ & $0,00 \%$ & $\overline{0}$ & $0,00 \%$ & 0 & $0,00 \%$ \\
\hline PRON0120-2.3.2 & SE ATS & Do CCO (Servidores,Redes,IHM,Consoles,Painéis) & 15 & $0,31 \%$ & 9 & 0 & $0,00 \%$ & 0 & $0,00 \%$ & 0 & $0,00 \%$ \\
\hline PRO10120-2.3.3 & SE ATS & Sinalização(CLPs,Maq.Chave,Sinaleiros,Cabos,PDF,No-Break) & 40 & $0,82 \%$ & 20 & 0 & $0,00 \%$ & 0 & $0,00 \%$ & 0 & $0,00 \%$ \\
\hline PRO0120-2.4 & TाT & Eaboração Esp. Requisitos Software - ERSs & 300 & $6,14 \%$ & 70 & & $0,00 \%$ & & $0,00 \%$ & & $0,20 \%$ \\
\hline PROJ0120-2.4.1 & AP ATS & Software CLPS & 50 & $1,02 \%$ & 0 & $\overline{0}$ & $0,00 \%$ & $\overline{0}$ & $0,00 \%$ & $\overline{0}$ & $0,00 \%$ \\
\hline PRON0120-2.4.2 & AP_ATS & IHMe Funcionalidades PLO's & 50 & $1,02 \%$ & 40 & 0 & $0,00 \%$ & 0 & $0,00 \%$ & 10 & $0,20 \%$ \\
\hline PRON0120-2.4.3 & AP ATS & IHMe Funcion. Tráfego CCO & 100 & $2,05 \%$ & 15 & 0 & $0,00 \%$ & 0 & $0,00 \%$ & 0 & $0,00 \%$ \\
\hline PRON0120-2.4.4 & AP_ATS & IHMe Funcional Energia CCO & 100 & $2,05 \%$ & 15 & 0 & $0,00 \%$ & 0 & $0,00 \%$ & 0 & $0,00 \%$ \\
\hline PRO0120-2.5 & TाT & Fabricação dos Equipamentos & 306 & $6,26 \%$ & 0 & & $0,00 \%$ & & $0,00 \%$ & & $0,00 \%$ \\
\hline PRON0120-2.5.1 & PATS & Projeto, Aquisição Material e Fabricação CLPS & 90 & $1,84 \%$ & 0 & 0 & $0,00 \%$ & 0 & $0,00 \%$ & 0 & $0,00 \%$ \\
\hline PRON0120-2.5.2 & PATS & Testes Hardware/Inspeção,Entrega CLPS & 2 & $0,04 \%$ & 0 & 0 & $0,00 \%$ & 0 & $0,00 \%$ & 0 & $0,00 \%$ \\
\hline PRON0120-2.5.3 & PATS & Projeto, Aquisição Material e Fabricação do SMCT & 120 & $2,46 \%$ & 0 & 0 & $0,00 \%$ & 0 & $0,00 \%$ & 0 & $0,00 \%$ \\
\hline PROV0120-2.5.4 & PATS & Testes Hardware/Inspeção,Entrega SMCT & 2 & $0,04 \%$ & 0 & 0 & $0,00 \%$ & 0 & $0,00 \%$ & 0 & $0,00 \%$ \\
\hline PRON0120-2.5.5 & P ATS & Projeto, Aquisição Material Gabinetes Servidores & 90 & $1,84 \%$ & 0 & 0 & $0,00 \%$ & 0 & $0,00 \%$ & 0 & $0,00 \%$ \\
\hline PRON0120-2.5.6 & P_ATS & Testes Hardware/Inspeção, Entrega Gab.Servidores & 2 & $0,04 \%$ & 0 & 0 & $0,00 \%$ & 0 & $0,00 \%$ & 0 & $0,00 \%$ \\
\hline PRO0120-2.6 & TाT & Aquisição de Suprimentos & 665 & $13,61 \%$ & $\overline{0}$ & & $0,00 \%$ & & $0,00 \%$ & & $0,00 \%$ \\
\hline PRON0120-2.6.1 & PC ATS & Aquisição/Insp/Testes Serv/Works/Est.Trab/etc & 60 & $1,23 \%$ & 0 & 0 & $0,00 \%$ & $\overline{0}$ & $0,00 \%$ & 0 & $0,00 \%$ \\
\hline PRON0120-2.6.2 & PC ATS & Aquisição Redes/Periféricos & 60 & $1,23 \%$ & 0 & 0 & $0,00 \%$ & 0 & $0,00 \%$ & 0 & $0,00 \%$ \\
\hline PRON0120-2.6.3 & PC ATS & Inspeção/Testes Rede Local/Entrega & 5 & $0,10 \%$ & 0 & 0 & $0,00 \%$ & 0 & $0,00 \%$ & 0 & $0,00 \%$ \\
\hline PROV0120-2.6.4 & PC ATS & Aquisição/Entrega Consoles e Painéis & 90 & $1,84 \%$ & 0 & 0 & $0,00 \%$ & 0 & $0,00 \%$ & 0 & $0,00 \%$ \\
\hline PRON0120-2.6.5 & PC ATS & Aquisição/Entrega No-Break CCO e PLOs & 90 & $1,84 \%$ & 0 & 0 & $0,00 \%$ & 0 & $0,00 \%$ & 0 & $0,00 \%$ \\
\hline PRON0120-2.6.6 & PC ATS & Aquisição/Entrega Maq. Chave/Sinaleiros e CDVs & 120 & $2,46 \%$ & 0 & 0 & $0,00 \%$ & 0 & $0,00 \%$ & 0 & $0,00 \%$ \\
\hline PRON0120-2.6.7 & PC ATS & Aquisição/Entrega Cabos 日etricos/Controle & 120 & $2,46 \%$ & 0 & 0 & $0,00 \%$ & 0 & $0,00 \%$ & 0 & $0,00 \%$ \\
\hline PRON0120-2.6.8 & PC_ATS & Aquisição/Entrega Painel Distrib. Energia (PDF) & 120 & $2,46 \%$ & 0 & 0 & $0,00 \%$ & 0 & $0,00 \%$ & 0 & $0,00 \%$ \\
\hline PRO0120-2.7 & TIT & Projeto de Construção do CCO & 310 & $6,34 \%$ & 1 & & $0,00 \%$ & & $0,00 \%$ & & $0,00 \%$ \\
\hline PROS0120-2.7.1 & PC_ATS & Eaboração do Projeto Executivo e Ergonômico & 80 & $1,64 \%$ & 1 & 0 & $0,00 \%$ & 0 & $0,00 \%$ & 0 & $0,00 \%$ \\
\hline PRON0120-2.7.2 & PC ATS & Contratação Empresa e Execução da Obra & 220 & $4,50 \%$ & 0 & 0 & $0,00 \%$ & 0 & $0,00 \%$ & 0 & $0,00 \%$ \\
\hline PRON0120-2.7.3 & PC ATS & Instalação dos Cabos Energia/Dados dos Equip & 10 & $0,20 \%$ & 0 & 0 & $0,00 \%$ & 0 & $0,00 \%$ & 0 & $0,00 \%$ \\
\hline
\end{tabular}

- Coluna "Atividade": Identifica o número do projeto e o código de cada uma das atividades, gerados automaticamente pelo MSProject;

- Coluna "Pacotes de Trabalho": Identifica o pacote de trabalho ao qual pertence às atividades;

- Coluna "Descrição das Atividades": Contém a descrição de cada uma das atividades. $\mathrm{Na}$ intersecção da linha Total de dias trabalhados, com as colunas Dias Trabalhados (Jan06, Fev06....), são somados os dias trabalhados em cada uma das atividades no mês (ex. no mês Fev06 foram trabalhados 100 dias). Na linha Acumulado, são somados o valor acumulado do mês anterior mais os dias trabalhados no mês atual (ex: acumulado de Jan06 $=70$ dias, Dias trabalhados mês Fev06 $=100$, totalizando um valor Acumulado até Fev06 $=70+100=170$ dias). Nas linhas Avanço Físico mensal do projeto e Acumulado são 
realizados os mesmos cálculos com os dias trabalhados, porém apresentando as porcentagens correspondentes ao Avanço Físico do Projeto no mês e do projeto total. Exemplo: Em Fev06 o Avanço Físico foi de 2,05\%, que somados aos 1,43\% do mês anterior, tem-se um total de $3,48 \%$;

- Coluna "Dias previstos de cada Atividade": Contém o número de dias previstos para a execução de cada atividade, e o total de dias previstos no projeto, que é de 4.886;

- Coluna “\% de cada Atividade": Identifica o percentual de contribuição de cada atividade dentro de cada um dos itens principais (Ex: atividade PROJ120-2.4.2 IHM e Funcionalidades dos PLO's, correspondem a 1,02\% do total do item PROJ120-2.4 - Elaboração Especificações de Requisitos Software - ERS) que é de $6,14 \%$;

- Coluna "Total dias já trabalhados": São os dias já trabalhados desde o mês de Janeiro 2006 até Abril de 2006, que são de 457 dias;

- Coluna "Dias trabalhados mês Mar06": São os dias efetivamente trabalhados pelos responsáveis na execução de cada uma das atividades, (Ex: na atividade PROJ120-2.4.2 - IHM e Funcionalidades dos PLO's, no mês de março foram trabalhados 10 dias nesta atividade). Portanto, os 10 dias trabalhados correspondem a um avanço físico de $0,20 \%$ dos $6,14 \%$ da atividade total;

- Coluna "\% do avanço físico no mês Mar06": este campo indica qual é à margem de contribuição que cada atividade e cada um dos módulos está contribuindo dentro do projeto como um todo. (Ex: No item PROJ120-2.4 Elaboração da Especificação de Requisitos de Software - ERS, é apresentado que a soma de todas as atividades pertencentes a este módulo quando concluído, corresponde a $6,14 \%$ do projeto como um todo, e que o avanço físico de todas as atividades desse módulo quando concluídas até o mês de março é de $0,20 \%$ );

Com as informações resultantes e disponibilizadas na tabela 6.6.1, obtém-se ao final de cada mês, qual foi o Avanço Físico do projeto efetivamente realizado no mês e do Avanço Físico de todo o projeto acumulado. Têm-se, portanto, uma visão geral do desempenho do projeto, e de informações a serem disponibilizadas nos relatórios gerenciais internos e para a alta direção da empresa. 


\subsubsection{Divisão do planejamento em Pacote de Trabalho}

No projeto do Sistema de Sinalização e Controle Metro-Ferroviário da Linha Alfa no qual se está aplicando esta metodologia, todas as atividades previstas no planejamento do projeto foram divididas em oito Pacotes de Trabalho, descritos a seguir. Para a geração das oito pastas dos pacotes de trabalho, foi criada uma nova planilha contendo oito pastas (SM_MGT, SE_ATS, AP_ATS, CF_ATS, P_ATS, PC_ATS, C_ATS E LS_ATS), tendo em cada uma das pastas, o mesmo conteúdo da planilha inicial de cálculo do Avanço Físico de todo o projeto, já descrita no item 6.6.1. A seguir, foi atribuído um filtro na coluna pacotes de trabalho, selecionando apenas as informações das atividades pertencentes ao pacote de trabalho a ser exibido na planilha.

Com a aplicação desse filtro é, então, possível determinar a quantidade de dias e as porcentagens associadas a cada atividade pertencente a cada pacote de trabalho. É então realizado automaticamente o cálculo pela planilha, considerando agora apenas as atividades pertencentes ao pacote de trabalho, apresentando o Avanço Físico de cada um dos pacotes de trabalho.

Entretanto, como todas as pastas desta planilha estão interligadas com a planilha do Avanço Físico do Projeto apresentada no item 6.6.1, ao se dar o avanço físico em cada atividade (dias trabalhados no mês) em cada um dos pacotes de trabalho, essas informações são também atualizadas automaticamente na planilha do Avanço Físico do Projeto. São apresentados a seguir, todos os pacotes de trabalho do projeto, através de tabelas, relacionando todas as atividades e a quantidade de dias previstos em cada atividade, e em cada pacote de trabalho.

SM_MGT - Pacote de trabalho onde estão previstas todas as atividades relacionadas ao Gerenciamento do Projeto (Gerente, Planejador e Controlador de Custos do Projeto).

Tabela 6.6.2.1 - Atividades relacionadas ao Gerenciamento do Projeto

\begin{tabular}{|c|c|c|c|c|c|c|c|c|c|c|c|}
\hline Atividade & $\begin{array}{c}\text { Pacote de } \\
\text { Trabalho }\end{array}$ & Descrição das Atividades & \begin{tabular}{|c|} 
Dias \\
Previstos de \\
cada \\
Atividade \\
\end{tabular} & $\begin{array}{c}\text { Avanço } \\
\text { Fisico } \\
\text { Baseline } \\
\text { do WP } \\
\end{array}$ & $\mid \begin{array}{l}\text { Total dias já } \\
\text { trabalhaddos }\end{array}$ & $\begin{array}{c}\text { Dias } \\
\text { Trabalha } \\
\text { dos mês } \\
\text { Jan } \\
\end{array}$ & \begin{tabular}{|c|} 
\% do \\
Avanço \\
Fisicono \\
mês Jan \\
\end{tabular} & $\begin{array}{c}\text { Dias } \\
\text { Trabalhat } \\
\text { dos mês } \\
\text { Fev } \\
\end{array}$ & \begin{tabular}{|c|}
$\%$ do \\
Avanço \\
Físicono no \\
mês Fev
\end{tabular} & \begin{tabular}{|c|} 
Dias \\
Trabalha \\
dos mês \\
Mar \\
\end{tabular} & \begin{tabular}{|c|}
$\%$ do \\
Avanço \\
Fisicono \\
mês Mar \\
\end{tabular} \\
\hline & SM MGT & Total de dias trabalhados & 900 & $100,00 \%$ & 138 & 20 & $2,22 \%$ & 40 & $4,44 \%$ & 39 & $4,33 \%$ \\
\hline Código Contábil & SM MGT & Acumulado & & & & 20 & & 60 & & 99 & \\
\hline & SMMGT & Avanço físicomensal do projeto & & & & & $0,00 \%$ & & $0,00 \%$ & & $0,00 \%$ \\
\hline & SM MGT & Acumulado & & & & & $0,00 \%$ & & $0,00 \%$ & & $0,00 \%$ \\
\hline PROJ0120-1 & SM MGT & Ińíio do projeto & 0 & & 0 & 0 & & 0 & & 0 & \\
\hline PROJ0120-1.1 & SM MGT & Data de Início do Projeto & 0 & $0,00 \%$ & 0 & 0 & & 0 & & 0 & \\
\hline PRO0120-2.1.1 & SMMGT & Coordenaçäo do Projeto & 180 & $20,00 \%$ & 27 & 5 & & 8 & & 7 & \\
\hline PROJ0120-2.1.2 & SM MGT & Planejamento \& Controle & 180 & $20,00 \%$ & 27 & 3 & & 8 & & 8 & \\
\hline PRO10120-2.1.3 & SM MGT & Gerenciamentio da Qualichade & 180 & $20,00 \%$ & 28 & 4 & & 8 & & 8 & \\
\hline PROJ0120-2.1.4 & SM MGT & Gerenciamento da Configuração & 180 & $20,00 \%$ & 28 & 4 & & 8 & & 8 & \\
\hline
\end{tabular}


SE_ATS - Pacote de trabalho da área de Engenharia de Sistemas, responsável pela elaboração das especificações técnicas dos sistemas e subsistemas, elaboração dos procedimentos de testes, verificação e validação dos sistemas em fábrica e Campo.

Tabela 6.6.2.2 - Atividades relacionadas a área de Engenharia de Sistemas

\begin{tabular}{|c|c|c|c|c|c|c|c|c|c|c|}
\hline Alividade & $\begin{array}{l}\text { Paoctede } \\
\text { Trabalho }\end{array}$ & Descriçãodas Alividades & $\begin{array}{c}\text { Das } \\
\text { Pevistos } \\
\text { decada } \\
\text { Alividace }\end{array}$ & \begin{tabular}{|c|} 
Avanço \\
Fisioo \\
Beselinedo \\
WP \\
\end{tabular} & $\begin{array}{l}\text { Total dasjá } \\
\text { trabalhados }\end{array}$ & $\begin{array}{c}\text { Das } \\
\text { Trabalha } \\
\text { dosmês } \\
\text { Jan }\end{array}$ & $\begin{array}{c}\text { \%db } \\
\text { Avanco } \\
\text { Fisicono } \\
\text { mêstan }\end{array}$ & $\begin{array}{c}\text { Das } \\
\text { Trabalha } \\
\text { dosmês } \\
\text { Fev }\end{array}$ & $\begin{array}{c}\text { \%cb } \\
\text { Avanço } \\
\text { Fisicono } \\
\text { mêsFev }\end{array}$ & $\begin{array}{c}\text { Das } \\
\text { Trabalha } \\
\text { dosmês } \\
\text { Mar } \\
\end{array}$ \\
\hline & SEATS & Total dediastrabalhedog & డ्ञ, & $100,0 \%$ & 238 & 50 & $7, \mathfrak{6} \%$ & 60 & $9,16 \%$ & 50 \\
\hline CódigoCantábil & SEATS & Aamiladd & & & & 50 & & 110 & & 160 \\
\hline & SEATS & Avanofísionmensal doprojetd & & & & & $7,63 \%$ & & $9,16 \%$ & \\
\hline & SEATS & Aamuladd & & & & & $7,63 \%$ & & $16,79 \%$ & \\
\hline $\mathrm{FPO} 0120221$ & SE ATS & Dosfostos Locas(F-O, +AnáliseAprov.Ciente & 40,0 & $6,11 \%$ & 40,00 & 10 & $1,53 \%$ & 20 & $305 \%$ & 10 \\
\hline $\mathrm{PFO} 0120222$ & SE ATS & Do Centrode Contride Qperaciond (CCO, +And.Aprov.Ciente & 80,0 & $1221 \%$ & 80,09 & 20 & $3,08 \%$ & 20 & $305 \%$ & 20 \\
\hline $\mathrm{FPO} 0120223$ & SEATS & DeSndizaçãa +Aral.Aprov.Ciente & 80,0 & $12,21 \%$ & 80,09 & 20 & $3,05 \%$ & 20 & $305 \%$ & 20 \\
\hline $\mathrm{PFO} 012023.1$ & SEATS & DosPas(ServidtresFedes/1HM & 15,0 & $2,29 \%$ & 9,09 & & $0,00 \%$ & & $0,00 \%$ & \\
\hline $\mathrm{FPO} 0120232$ & SEATS & DoCCO (Senvidures,Pedes,IHMConsdes,Painés) & 15,0 & $2,29 \%$ & 9,09 & & $0,00 \%$ & & $0,00 \%$ & \\
\hline $\mathrm{FOOD120233}$ & SEATS & 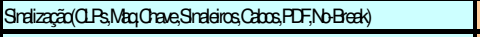 & 40,0 & $6,11 \%$ & 20,00 & & $0,00 \%$ & & $0,00 \%$ & \\
\hline PFOD120211.1.1 & SEATS & Ead/AproveçãocbFSchsaPs & 20,0 & $3,05 \%$ & $0,0 \mathrm{~g}$ & & $0,00 \%$ & & $0,00 \%$ & \\
\hline PFO120211.1.2 & SEATS & Ead/AproveçãodbPSGataintes Servidures & 20,0 & $3,05 \%$ & $0,0 \mathrm{q}$ & & $0,00 \%$ & & $0,00 \%$ & \\
\hline $\mathrm{FPQ} 0120211.1 .3$ & SEATS & Eab/AproveçãocbPSdosEqip COOFO & 20,0 & $3,05 \%$ & $0,0 \mathrm{q}$ & & $0,00 \%$ & & $0,00 \%$ & \\
\hline FPOD120211.1.4 & SEATS & Eab/AproaçãocbPSdosSMCIs & 20,0 & $3,05 \%$ & $0,0 \mathrm{q}$ & & $0,00 \%$ & & $0,00 \%$ & \\
\hline $\mathrm{FPO} 0120211.21$ & SE ATS & Ead/AproveçãoPocde Testes QPS Lirha & 20,0 & $3,05 \%$ & 0,09 & & $0,00 \%$ & & $0,00 \%$ & \\
\hline $\mathrm{FPO} 0120211.22$ & SEATS & Eab/Aprov. RocTestes Servidares e Periférioos & 20,0 & $3,05 \%$ & 0,00 & & $0,00 \%$ & & $0,00 \%$ & \\
\hline PROD120211.23 & SEATS & Edd/AproveçãoPISlsdaçãoeFlgidzzDdetrica & 20,0 & $3,05 \%$ & 0,09 & & $0,00 \%$ & & $0,00 \%$ & \\
\hline $\mathrm{FPO} 0120211.31$ & SEATS & Eab/AproveçãodbPIScdelitegação & 20,0 & $3,05 \%$ & $0,0 \mathrm{q}$ & & $0,00 \%$ & & $0,00 \%$ & \\
\hline FPO0120211.32 & EAATS & Edb/AproveçãoPISSotw Sstemade Trúfego & 30,0 & $4,58 \%$ & $0,0 \mathrm{q}$ & & $0,00 \%$ & & $0,00 \%$ & \\
\hline $\mathrm{FPOD120211.33}$ & EAATS & Ead/AproveçãoPISSAftw StstemadeEnerga & 30,0 & $4,58 \%$ & $0,0 \mathrm{q}$ & & $0,00 \%$ & & $0,00 \%$ & \\
\hline $\mathrm{FOOD1202121}$ & EAATS & Testes lsdadosdos $Q P S$ & 20,0 & $3,05 \%$ & $0,0 \mathrm{q}$ & & $0,00 \%$ & & $0,00 \%$ & \\
\hline $\mathrm{FPO} 01202122$ & SEATS & Testes Isdacts GechServ/ConsdesPaines & 20,0 & $3,05 \%$ & $0,0 \mathrm{q}$ & & $0,00 \%$ & & $0,00 \%$ & \\
\hline $\mathrm{FPOD1202123}$ & SEATS & Integradss SMCTLPAeCO & 2ु, & $3,82 \%$ & $0,0 \mathrm{~g}$ & & $0,00 \%$ & & $0,00 \%$ & \\
\hline $\mathrm{FPOD1202124}$ & EAATS & integradbsSMCTJUNeVAL & 20,0 & $3,05 \%$ & $0,0 \mathrm{~g}$ & & $0,00 \%$ & & $0,00 \%$ & \\
\hline $\mathrm{FPO} 01202125$ & SEATS & Estáiocos Comandos e lindcaçães de Trátego & 30,0 & $4,58 \%$ & $0,0 \mathrm{q}$ & & $0,00 \%$ & & $0,00 \%$ & \\
\hline PFO1202126 & SEATS & Estáiocos Comandbse lndcaçōes de Energa & 30,0 & $4,58 \%$ & $0,0 \mathrm{~g}$ & & $0,00 \%$ & & $0,00 \%$ & \\
\hline $\mathrm{PPOD1202127}$ & SEATS & Drêtioos Sstemade Tréfego & 20,0 & $3,05 \%$ & $0,0 \mathrm{q}$ & & $0,00 \%$ & & $0,00 \%$ & \\
\hline
\end{tabular}

AP_ATS - Pacote de trabalho da área de Aplicação, responsável pela adaptação e desenvolvimento de software básico e de aplicação, e demais aplicações necessárias para atendimento aos requisitos do projeto.

Tabela 6.6.2.3 - Atividades relacionadas a área de Aplicação

\begin{tabular}{|c|c|c|c|c|c|c|c|c|c|c|}
\hline Atividade & $\begin{array}{c}\text { Pacote de } \\
\text { Trabalho }\end{array}$ & Descrição das Atividades & $\begin{array}{c}\text { Dias } \\
\text { Previstos } \\
\text { de cada } \\
\text { Atividade }\end{array}$ & \begin{tabular}{|c|} 
Avanço \\
Físico \\
Baseline do \\
WP
\end{tabular} & $\begin{array}{l}\text { Total dias já } \\
\text { trabalhados }\end{array}$ & $\begin{array}{c}\text { Dias } \\
\text { Trabalha } \\
\text { dos mês } \\
\text { Jan }\end{array}$ & $\begin{array}{l}\% \text { do } \\
\text { Avanço } \\
\text { Fisico no } \\
\text { mês Jan }\end{array}$ & $\begin{array}{c}\text { Dias } \\
\text { Trabalha } \\
\text { dos mês } \\
\text { Fev }\end{array}$ & $\begin{array}{l}\% \text { do } \\
\text { Avanço } \\
\text { Fisicono } \\
\text { mês Fev } \\
\end{array}$ & $\begin{array}{c}\text { Dias } \\
\text { Trabalhar } \\
\text { dos mês } \\
\text { Mar } \\
\end{array}$ \\
\hline & AP_ATS & Total de dias trabalhados & 749 & $100,00 \%$ & 70 & 0 & $0,00 \%$ & 0 & $0,00 \%$ & 10 \\
\hline Código Contábil & AP_ATS & Acumulado & & & & 0 & & 0 & & 10 \\
\hline & AP_ATS & Avanço físico mensal do projeto & & & & & $0,00 \%$ & & $0,00 \%$ & \\
\hline & AP_ATS & Acumulado & & & & & $0,00 \%$ & & $0,00 \%$ & \\
\hline PRON0120-24.1 & AP_ATS & Software CLPS & 50 & $6,68 \%$ & $\mathbf{0}$ & 0 & $0,00 \%$ & 0 & $0,00 \%$ & 0 \\
\hline PROJ0120-24.2 & AP_ATS & IFMe Funcionalidades PLO's & 50 & $6,68 \%$ & 40 & 0 & $0,00 \%$ & 0 & $0,00 \%$ & 10 \\
\hline PRO0120-24.3 & AP_ATS & IHMe Funcion. Tráfego Cco & 100 & $13,35 \%$ & 15 & 0 & $0,00 \%$ & 0 & $0,00 \%$ & 0 \\
\hline PROJ0120-24.4 & AP_ATS & IFMe Funcional Energia $C c 0$ & 100 & $13,35 \%$ & 15 & 0 & $0,00 \%$ & 0 & $0,00 \%$ & 0 \\
\hline PRON0120-28.1 & AP_ATS & Desenv. Software SMCT LPACGO,JUN V VN & 60 & $8,01 \%$ & 0 & 0 & $0,00 \%$ & 0 & $0,00 \%$ & 0 \\
\hline PROJ0120-28.2 & AP_ATS & Testes Softw.Plataf.Fábrica SMCT LPA,GO,JUNe VIN & 20 & $2,67 \%$ & $\mathbf{0}$ & 0 & $0,00 \%$ & 0 & $0,00 \%$ & 0 \\
\hline PRON0120-214.1.1.1 & AP_ATS & Codificação Software e IHM dos CLS & 120 & $16,02 \%$ & 0 & 0 & $0,00 \%$ & 0 & $0,00 \%$ & 0 \\
\hline PRON0120-214.1.1.2 & AP_ATS & Codificaçăo Simulador dos CLPS & 40 & $5,34 \%$ & 0 & 0 & $0,00 \%$ & 0 & $0,00 \%$ & 0 \\
\hline PRON0120-214.1.1.3 & AP_ATS & Codificaçăo de Servidor para PLOS & 30 & $4,01 \%$ & 0 & 0 & $0,00 \%$ & 0 & $0,00 \%$ & 0 \\
\hline PRON0120-214.1.1.4 & AP_ATS & Desenv. Software Aplicativo dos PLOs & 105 & $14,02 \%$ & $\mathbf{0}$ & 0 & $0,00 \%$ & 0 & $0,00 \%$ & 0 \\
\hline PRON0120-214.2.1.3 & AP_ATS & Instalação Soft. CLP e SMCT de LPAe CGO & 2 & $0,27 \%$ & 0 & 0 & $0,00 \%$ & 0 & $0,00 \%$ & 0 \\
\hline PRON0120-214.2.1.4 & AP_ATS & Integr/Testes Internos e Testes Aceit.Cliente & 35 & $4,67 \%$ & 0 & 0 & $0,00 \%$ & 0 & $0,00 \%$ & 0 \\
\hline PRON0120-214.2.2.3 & AP_ATS & Instalação do Soft. CLP e SMCT JUNe VIN & 2 & $0,27 \%$ & 0 & 0 & $0,00 \%$ & 0 & $0,00 \%$ & 0 \\
\hline PROJ0120-214.2.2.4 & AP_ATS & Integr/Testes Internos e Testes Aceit.Cliente & 35 & $4,67 \%$ & 0 & 0 & $0,00 \%$ & 0 & $0,00 \%$ & 0 \\
\hline
\end{tabular}


CF_ATS - Pacote de trabalho da área de Configuração, responsável pela montagem das Bases de Dados e das Telas das IHM's.

Tabela 6.6.2.4 - Atividades relacionadas a área de Configuração

\begin{tabular}{|c|c|c|c|c|c|c|c|c|c|c|}
\hline Atividade & $\begin{array}{c}\text { Pacote de } \\
\text { Trabalho }\end{array}$ & Descrição das Atividades & \begin{tabular}{|c|} 
Dias \\
Previstos \\
de cada \\
Atividade \\
\end{tabular} & $\begin{array}{c}\text { Avanço } \\
\text { Fisico } \\
\text { Baseline do } \\
\text { WP }\end{array}$ & $\begin{array}{l}\text { Total dias já } \\
\text { trabalhadodos }\end{array}$ & $\begin{array}{c}\text { Dias } \\
\text { Trabalha } \\
\text { dosmês } \\
\text { Jan }\end{array}$ & $\begin{array}{c}\text { \% do } \\
\text { Avanço } \\
\text { Físicono no } \\
\text { mês Jan }\end{array}$ & $\begin{array}{c}\text { Dias } \\
\text { Trabalha } \\
\text { dos mês } \\
\text { Fev }\end{array}$ & $\begin{array}{c}\text { \% do } \\
\text { Avanço } \\
\text { Físicono no } \\
\text { mês Fev }\end{array}$ & $\begin{array}{c}\text { Dias } \\
\text { Trabalha } \\
\text { dosmês } \\
\text { Mar } \\
\end{array}$ \\
\hline & CF_ATS & Total de dias trabalhados & 700 & $100,00 \%$ & 10 & 0 & $0,00 \%$ & 0 & $0,00 \%$ & 0 \\
\hline \multirow[t]{3}{*}{ Código Contábil } & CF_ATS & Acumulado & & & & 0 & & 0 & & 0 \\
\hline & GF_ATS & Avanço físico mensal do projeto & & & & & $0,00 \%$ & & $0,00 \%$ & \\
\hline & CF_ATS & Acumulado & & & & & $0,00 \%$ & & $0,00 \%$ & \\
\hline PRO10120-29.1.1 & CF_ATS & Telas dos Setores LPA JUN, VNe CGO & 50 & $7,14 \%$ & 10 & 0 & $0,00 \%$ & 0 & $0,00 \%$ & 0 \\
\hline PRO10120-29.1.2 & CF_ATS & Telas de Painéis e de Diagnósticos & 40 & $5,71 \%$ & 0 & 0 & $0,00 \%$ & 0 & $0,00 \%$ & 0 \\
\hline PRO10120-29.1.3 & CF_ATS & Configuração BD da Topologia da via & 50 & $7,14 \%$ & 0 & 0 & $0,00 \%$ & 0 & $0,00 \%$ & 0 \\
\hline PRO10120-29.1.4 & CF_ATS & Configuração BD das Indicaçōes/Comandos & 40 & $5,71 \%$ & 0 & 0 & $0,00 \%$ & 0 & $0,00 \%$ & 0 \\
\hline PRO10120-29.1.5 & CF_ATS & Codificação Software/Manobras'Despachos & 80 & $11,43 \%$ & 0 & 0 & $0,00 \%$ & 0 & $0,00 \%$ & 0 \\
\hline PRO10120-29.1.6 & CF_ATS & Codificação do Simularor de Trens & 80 & $11,43 \%$ & $\mathbf{0}$ & 0 & $0,00 \%$ & 0 & $0,00 \%$ & 0 \\
\hline PRO10120-29.21 & CF_ATS & Configuração Telas e Base Dados Energia & 80 & $11,43 \%$ & 0 & 0 & $0,00 \%$ & 0 & $0,00 \%$ & 0 \\
\hline PRO10120-29.22 & CF_ATS & Codificaçäo e Testes do Simulador de Energia & 80 & $11,43 \%$ & 0 & 0 & $0,00 \%$ & 0 & $0,00 \%$ & 0 \\
\hline PRO10120-29.23 & CF_ATS & Codificação e Testes das Funçōes Energia & 80 & $11,43 \%$ & 0 & 0 & $0,00 \%$ & 0 & $0,00 \%$ & 0 \\
\hline PROO0120-214.1.1.5 & CF_ATS & Cont. Telas e Base Dados PLOS, LPA,CGO,JUNe UN & 120 & $17,14 \%$ & 0 & 0 & $0,00 \%$ & 0 & $0,00 \%$ & 0 \\
\hline
\end{tabular}

P_ATS - Pacote de trabalho da área de Engenharia de Produtos, responsável pela elaboração dos projetos e testes dos equipamentos a serem produzidos internamente na empresa.

Tabela 6.6.2.5 - Atividades relacionadas a área de Eng. de Produtos

\begin{tabular}{|c|c|c|c|c|c|c|c|c|c|c|}
\hline Aividace & $\begin{array}{c}\text { Paoctede } \\
\text { Trabalho }\end{array}$ & Descriçãodas Atividades & $\begin{array}{c}\text { Dlas } \\
\text { Pevistos } \\
\text { decach } \\
\text { Alividade }\end{array}$ & \begin{tabular}{|c|} 
Avanço \\
Fisio \\
Beselinedo \\
WP
\end{tabular} & $\begin{array}{l}\text { Total diasjá } \\
\text { trabalhedos }\end{array}$ & $\begin{array}{c}\text { Dlas } \\
\text { Trabelha } \\
\text { dosmês } \\
\text { Jan }\end{array}$ & $\begin{array}{c}\text { \%do } \\
\text { Avanço } \\
\text { Fisicono } \\
\text { mêsJan }\end{array}$ & $\begin{array}{c}\text { Dass } \\
\text { Trabalha } \\
\text { dosmês } \\
\text { Fev }\end{array}$ & $\begin{array}{l}\text { \%do } \\
\text { Avanço } \\
\text { Fisionno } \\
\text { mêsFev }\end{array}$ & $\begin{array}{c}\text { Das } \\
\text { Trabalha } \\
\text { dosmês } \\
\text { Mer }\end{array}$ \\
\hline & PATS & Todal dedias trabelhados & 306 & $100,00 \%$ & 0 & 0 & $0,00 \%$ & 0 & $0,00 \%$ & \\
\hline CódigoContábil & PATS & Aamulado & & & & 0 & & 0 & & \\
\hline & PATS & Avanofísicomensal doprojeto & & & & & $0,00 \%$ & & $0,00 \%$ & $0,00 \%$ \\
\hline & PATS & Aamuadd & & & & & $0,00 \%$ & & $0,00 \%$ & $0,00 \%$ \\
\hline PFO012025.1 & PATS & Prgiedo, AqisiçãoNateial eFabricação aPs & 90 & $29,41 \%$ & $0,0 \mathrm{~g}$ & 0 & $0,0 \%$ & 0 & $0,0 \% \%$ & 0 \\
\hline PFO0120252 & PATS & Testes Hadharellnspeçãa, Etrega aPS & 2 & $0,66 \%$ & 0,00 & 0 & $0,0 \%$ & 0 & $0,0 \% \%$ & 0 \\
\hline FAON12025.3 & PATS & 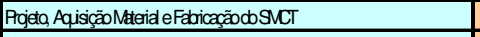 & 120 & $39,22 \%$ & $0,0 \mathrm{q}$ & 0 & $0,0 \% \%$ & 0 & $0,0 \% \%$ & 0 \\
\hline PFO012025.4 & PATS & Testes Hardharelrspescãa,EtregaSMCT & 2 & $0,65 \%$ & 0,00 & 0 & $0,0 \%$ & 0 & $0,00 \%$ & 0 \\
\hline PFOO120-25.5 & PATS & Prgjedo, AquisçãoNateria Gedintes Servidres & 90 & $29,41 \%$ & $0,0 \mathrm{q}$ & 0 & $0,0 \% \%$ & 0 & $0,00 \%$ & 0 \\
\hline PFO012025.6 & PATS & 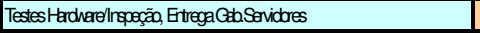 & 2 & $0,65 \%$ & $0,0 \mathrm{q}$ & 0 & $0,00 \%$ & 0 & $0,00 \%$ & 0 \\
\hline
\end{tabular}

PC_ATS - Pacote de trabalho da área de Suprimentos, responsável por todo o processo de aquisição e inspeção de materiais e equipamentos, e contratação de serviços de terceiros.

Tabela 6.6.2.6 - Atividades relacionadas a área de Suprimentos

\begin{tabular}{|c|c|c|c|c|c|c|c|c|c|c|}
\hline Atividade & $\begin{array}{c}\text { Pacote de } \\
\text { Trabalho }\end{array}$ & Descrição das Atividades & \begin{tabular}{|c|} 
Dias \\
Previstos \\
de cada \\
Atividade \\
\end{tabular} & \begin{tabular}{|c|} 
Avanço \\
Físico \\
Baseline do \\
WP \\
\end{tabular} & $\begin{array}{l}\text { Total dias já } \\
\text { trabalha-dos }\end{array}$ & $\begin{array}{c}\text { Dias } \\
\text { Trabalha- } \\
\text { dos mês } \\
\text { Jan } \\
\end{array}$ & $\begin{array}{c}\% \text { do } \\
\text { Avanço } \\
\text { Fisico no } \\
\text { mês Jan }\end{array}$ & $\begin{array}{c}\text { Dias } \\
\text { Trabalha- } \\
\text { dos mês } \\
\text { Fev } \\
\end{array}$ & $\begin{array}{l}\% \text { do } \\
\text { Avanço } \\
\text { Físico no } \\
\text { mês Fev }\end{array}$ & $\begin{array}{c}\text { Dias } \\
\text { Trabalha- } \\
\text { dos mês } \\
\text { Mar } \\
\end{array}$ \\
\hline & PC_ATS & Total de dias trabalhados & 995 & $100,00 \%$ & 0 & 0 & $0,00 \%$ & 0 & $0,00 \%$ & 0 \\
\hline Código Contábil & PC_ATS & Acumulado & $20 \%$ & & & 0 & & 0 & & 0 \\
\hline & PC_ATS & Avanço fisico mensal do projeto & & & & & $0,00 \%$ & & $0,00 \%$ & \\
\hline & PC_ATS & Acumulado & & & & & $0,00 \%$ & & $0,00 \%$ & \\
\hline PROJ0120-2.6.1 & PC_ATS & Aquisiçāo//nsp/Testes Serv/Works/Est.Trab/etc & 60 & $6,03 \%$ & 0 & 0 & $0,00 \%$ & 0 & $0,00 \%$ & 0 \\
\hline PROJ0120-2.6.2 & PC_ATS & Aquisição Redes/Periféricos & 60 & $6,03 \%$ & 0 & 0 & $0,00 \%$ & 0 & $0,00 \%$ & 0 \\
\hline PROJ0120-2.6.3 & PC_ATS & Inspeçāo/Testes Rede Local/Entrega & 5 & $0,50 \%$ & 0 & 0 & $0,00 \%$ & 0 & $0,00 \%$ & 0 \\
\hline PROJ0120-2.6.4 & PC_ATS & Aquisiçāo/Entrega Consoles e Painéis & 90 & $9,05 \%$ & 0 & 0 & $0,00 \%$ & 0 & $0,00 \%$ & 0 \\
\hline PROJ0120-2.6.5 & PC_ATS & Aquisiçăo/Entrega No-Break CCO e PLOs & 90 & $9,05 \%$ & 0 & 0 & $0,00 \%$ & 0 & $0,00 \%$ & 0 \\
\hline $\begin{array}{ll}\text { PROJ0120-2.6.6 } \\
\end{array}$ & PC_ATS & Aquisiçāo/Entrega Maq. Chave/Sinaleiros e CDVs & 120 & $12,06 \%$ & 0 & 0 & $0,00 \%$ & 0 & $0,00 \%$ & 0 \\
\hline PROJ0120-2.6.7 & PC_ATS & Aquisiçäo/Entrega Cabos Eletricos/Controle & 120 & $12,06 \%$ & 0 & 0 & $0,00 \%$ & 0 & $0,00 \%$ & 0 \\
\hline $\begin{array}{ll}\text { PROJ0120-2.6.8 } \\
\end{array}$ & PC_ATS & Aquisiçāo/Entrega Painel Distrib. Energia (PDF) & 120 & $12,06 \%$ & 0 & 0 & $0,00 \%$ & 0 & $0,00 \%$ & 0 \\
\hline PROJ0120-2.7.1 & PC_ATS & Elaboraçāo do Projeto Executivo e Ergonómico & 80 & $8,04 \%$ & 0 & 0 & $0,00 \%$ & 0 & $0,00 \%$ & 0 \\
\hline $\begin{array}{ll}\text { PROJ0120-2.7.2 } \\
\end{array}$ & PC_ATS & Contrataçāo Empresa e Execuçāo da Obra & 220 & $22,11 \%$ & 0 & 0 & $0,00 \%$ & 0 & $0,00 \%$ & 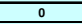 \\
\hline PROJ0120-2.7.3 & PC_ATS & Instalaçāo dos Cabos Energia/Dados dos Equip & 10 & $1,01 \%$ & 0 & 0 & $0,00 \%$ & 0 & $0,00 \%$ & 0 \\
\hline PROJ0120-2.10.3.1 & PC_ATS & Desm.Emb. Trans. Equip. Trátego & 5 & $0,50 \%$ & 0 & 0 & $0,00 \%$ & 0 & $0,00 \%$ & 0 \\
\hline PROJ0120-2.10.3.2 & PC_ATS & Desm.Emb.Trans. Equip. Energia & 5 & $0,50 \%$ & 0 & 0 & $0,00 \%$ & 0 & $0,00 \%$ & 0 \\
\hline PROJ0120-2.14.4.1 & PC_ATS & Desm/Emba./Transp. Equiptos LPA,CGO e JUN & 5 & $0,50 \%$ & 0 & 0 & $0,00 \%$ & 0 & $0,00 \%$ & 0 \\
\hline PROJ0120-2.14.4.2 & PC_ATS & Entrega dos Equip. na Estaçāo LPA,CGO e JUN & 0 & $0,00 \%$ & 0 & 0 & & 0 & & 0 \\
\hline PROJ0120-2.14.4.3 & PC_ATS & Desm/Embal.Transp. Equiptos JUN e VIN & 5 & $0,50 \%$ & 0 & 0 & $0,00 \%$ & 0 & $0,00 \%$ & 0 \\
\hline PROJ0120-2.14.4.4 & PC_ATS & Entrega dos Equip. na Estaçāo JUN e VIN & 0 & $0,00 \%$ & 0 & 0 & & 0 & & 0 \\
\hline
\end{tabular}


C_ATS - Pacote de trabalho da área de Engenharia de Testes de Integração em Fábrica e Comissionamento em Campo, responsável pela Supervisão de Instalação, testes isolados e integrados e de comissionamento em campo, de todos os equipamentos e de todos os subsistemas.

Tabela 6.6.2.7 - Atividades relacionadas a área de Engenharia de Testes de Integração em Fábrica e Comissionamento em Campo

\begin{tabular}{|c|c|c|c|c|c|c|c|c|c|c|}
\hline Atividade & $\begin{array}{c}\text { Pacotede } \\
\text { Trabalho }\end{array}$ & Descrição das Atividades & $\begin{array}{c}\text { Dias } \\
\text { Previstos } \\
\text { de cada } \\
\text { Atividade }\end{array}$ & $\begin{array}{c}\text { Avanço } \\
\text { Fisico } \\
\text { Baseline do } \\
\text { WP }\end{array}$ & $\begin{array}{l}\text { Total diasjá } \\
\text { trabalhados }\end{array}$ & $\begin{array}{c}\text { Dias } \\
\text { Trabalha } \\
\text { dosmês } \\
\text { Jan }\end{array}$ & $\begin{array}{c}\text { \% do } \\
\text { Avanço } \\
\text { Fisicono } \\
\text { mês Jan }\end{array}$ & $\begin{array}{c}\text { Dias } \\
\text { Trabalha } \\
\text { dos mês } \\
\text { Fev }\end{array}$ & $\begin{array}{c}\text { \% do } \\
\text { Avanço } \\
\text { Fisicono } \\
\text { mêsFev }\end{array}$ & $\begin{array}{c}\text { Dias } \\
\text { Trabalha } \\
\text { dosmês } \\
\text { Mar }\end{array}$ \\
\hline & C_ATS & Total de cias trabalhados & 426 & $100,00 \%$ & 0 & 0 & $0,00 \%$ & 0 & $0,00 \%$ & 0 \\
\hline & C ATS & Avançofísico mensal do projeto & & & & & $0,00 \%$ & & $0,00 \%$ & \\
\hline & C ATS & Acumulado & & & & & $0,00 \%$ & & $0,00 \%$ & \\
\hline PRO0120-210.1.1 & C ATS & Integração Softwere Tráfego/Retirada Pendências & 70 & $16,43 \%$ & 0 & 0 & $0,00 \%$ & 0 & $0,00 \%$ & 0 \\
\hline PROO0120-210.22 & C_ATS & Testes Aceitação Energia & 22 & $5,16 \%$ & 0 & 0 & $0,00 \%$ & 0 & $0,00 \%$ & 0 \\
\hline PROO120-214.21.1 & C ATS & Intetligagăa do CP P SMCTLPAe CGO & 5 & $1,17 \%$ & 0 & 0 & $0,00 \%$ & 0 & $0,00 \%$ & 0 \\
\hline PROO120-214.21.2 & C_ATS & Interligação Equip IIM+BDPLOLPAe CGO & 7 & $1,64 \%$ & 0 & 0 & $0,00 \%$ & 0 & $0,00 \%$ & 0 \\
\hline PROO120-214.221 & C ATS & Interligaçäo CPe SMCT JUNe UN & 5 & $1,17 \%$ & 0 & 0 & $0,00 \%$ & 0 & $0,00 \%$ & 0 \\
\hline PRO0120-214.222 & C_ATS & Intefligação Equip IHM+BD PLOSJUNe UN & 7 & $1,64 \%$ & 0 & 0 & $0,00 \%$ & 0 & $0,00 \%$ & 0 \\
\hline PROO120-215.1 & C ATS & Máquinas de Chave, Sinaleiros e CDVs & 40 & $9,39 \%$ & 0 & 0 & $0,00 \%$ & 0 & $0,00 \%$ & 0 \\
\hline PROO120-2162 & C ATS & Integraçãoentre CPSSSMCT/HM & 20 & $4,69 \%$ & 0 & 0 & $0,00 \%$ & 0 & $0,00 \%$ & 0 \\
\hline PROOO120-217.1 & C ATS & Fixação,Inst/MontagemTestes dos $\mathrm{Nb}$-Breaks & 10 & $235 \%$ & 0 & 0 & $0,00 \%$ & 0 & $0,00 \%$ & 0 \\
\hline PAOO120-217.2 & C ATS & Insta//Testes GabSServ/Consoles/Painéis Tráfego & 3 & $0,70 \%$ & 0 & 0 & $0,00 \%$ & 0 & $0,00 \%$ & 0 \\
\hline PROO120-217.3 & C_ATS & Insta/Testes Gab/Serv/Consoles/Painéis Energia & 3 & $0,70 \%$ & 0 & 0 & $0,00 \%$ & 0 & $0,00 \%$ & 0 \\
\hline PRO0120-2181 & C_ATS & Testes Integrados PLOS de LPACGO,JUNe UN & 20 & $4,69 \%$ & 0 & 0 & $0,00 \%$ & 0 & $0,00 \%$ & 0 \\
\hline PRO0120-2182 & C ATS & Estáticos e Dinâmicos Comandos/Indicaçäes Energia & 30 & $7,04 \%$ & 0 & 0 & $0,00 \%$ & 0 & $0,00 \%$ & 0 \\
\hline PROO120-2183 & C_ATS & Estálicos e Dinânicos Integ.Campo Tráfego do $~ C \infty 0$ & 30 & $7,04 \%$ & 0 & 0 & $0,00 \%$ & 0 & $0,00 \%$ & 0 \\
\hline PRO0120-219.1 & C ATS & Sistema de Tráfego/Energia & 30 & $7,04 \%$ & 0 & 0 & $0,00 \%$ & 0 & $0,00 \%$ & 0 \\
\hline
\end{tabular}

LS_ICC - Pacote de trabalho da área de Documentação e Treinamento, responsável pela supervisão e controle de toda a documentação do projeto, preparação dos Manuais de Operação e Manutenção dos Equipamentos e Sistemas, e da execução dos treinamentos junto ao cliente.

Tabela 6.6.2.8 - Atividades relacionadas a área de Documentação e Treinamento

\begin{tabular}{|c|c|c|c|c|c|c|c|c|c|c|}
\hline Atividade & $\begin{array}{c}\text { Pacote de } \\
\text { Trabalho }\end{array}$ & Descrição das Atividades & $\begin{array}{c}\text { Dias } \\
\text { Previstos } \\
\text { de cada } \\
\text { Atividade }\end{array}$ & $\begin{array}{c}\text { Avanço } \\
\text { Fisico } \\
\text { Baseline do } \\
\text { WP }\end{array}$ & $\begin{array}{l}\text { Total dias já } \\
\text { trabalhad dos }\end{array}$ & $\begin{array}{c}\text { Dias } \\
\text { Trabalha } \\
\text { dos mês } \\
\text { Jan }\end{array}$ & $\begin{array}{l}\% \text { do } \\
\text { Avanço } \\
\text { Fisico no } \\
\text { mês Jan }\end{array}$ & $\begin{array}{c}\text { Dias } \\
\text { Trabalha } \\
\text { dos mês } \\
\text { Fev }\end{array}$ & $\begin{array}{l}\% \text { do } \\
\text { Avanço } \\
\text { Fisicono } \\
\text { mês Fev }\end{array}$ & $\begin{array}{c}\text { Dias } \\
\text { Trabalha } \\
\text { dos mês } \\
\text { Mar }\end{array}$ \\
\hline & LSICC & Total de dias trabalhados & 155 & $100,00 \%$ & 0 & 0 & $0,00 \%$ & 0 & $0,00 \%$ & 0 \\
\hline \multirow[t]{3}{*}{ Código Contábil } & LSICC & Acumulado & & & & 0 & & 0 & & 0 \\
\hline & LSIOC & Avanço físico mensal do projeto & & & & & $0,00 \%$ & & $0,00 \%$ & \\
\hline & LSICC & Acumulado & & & & & $0,00 \%$ & & $0,00 \%$ & \\
\hline PRO0120-210.4.1 & LSICC & Sistema de Tráfego & 10 & $6,45 \%$ & $\mathbf{0}$ & 0 & $0,00 \%$ & 0 & $0,00 \%$ & 0 \\
\hline PRO0120-210.4.2 & LSIOC & Sistema de Energia & 10 & $6,45 \%$ & $\mathbf{0}$ & 0 & $0,00 \%$ & 0 & $0,00 \%$ & 0 \\
\hline PROO0120-210.4.3 & LSIOC & Configuração Software & 20 & $12,90 \%$ & 0 & 0 & $0,00 \%$ & 0 & $0,00 \%$ & 0 \\
\hline PRO10120-213.1 & LSIOC & Manutencão dos QPS & 20 & $12,90 \%$ & $\begin{array}{l}0 \\
\end{array}$ & 0 & $0,00 \%$ & 0 & $0,00 \%$ & 0 \\
\hline PRO10120-213.2 & LSICC & Manutenção dos PLOS & 20 & $12,90 \%$ & $\mathbf{0}$ & 0 & $0,00 \%$ & 0 & $0,00 \%$ & 0 \\
\hline PRO10120-213.3 & LSIOC & Qperação dos PLOS/CLPS & 20 & $12,90 \%$ & $\mathbf{0}$ & 0 & $0,00 \%$ & 0 & $0,00 \%$ & 0 \\
\hline PRO10120-213.4 & LSICC & Operação dos Sistemas de Trátego & 20 & $12,90 \%$ & 0 & 0 & $0,00 \%$ & 0 & $0,00 \%$ & 0 \\
\hline PRO10120-213.5 & LSICC & operação dos Sistemas de Energia & 20 & $12,90 \%$ & $\mathbf{0}$ & 0 & $0,00 \%$ & 0 & $0,00 \%$ & 0 \\
\hline PRO0120-214.3.1 & LSIOC & Manutenção dos QPS & 5 & $3,23 \%$ & 0 & 0 & $0,00 \%$ & 0 & $0,00 \%$ & 0 \\
\hline PRO10120-214.3.2 & LSIOC & Manutenção dos PLOS & 5 & $3,23 \%$ & 0 & 0 & $0,00 \%$ & 0 & $0,00 \%$ & 0 \\
\hline PRO0120-214.3.3 & LSIOC & Qperação dos PLOs/CLPS & 5 & $3,23 \%$ & 0 & 0 & $0,00 \%$ & 0 & $0,00 \%$ & 0 \\
\hline
\end{tabular}




\subsubsection{Atualização do Avanço Físico do Projeto em cada Pacote de Trabalho}

Para ser realizada a atualização desta planilha até o quinto dia útil do mês subseqüente ao trabalho realizado, cada responsável pelo seu pacote de trabalho terá disponível às seguintes informações extraídas do mês anterior, do Servidor Central da Empresa, e do planejamento através do aplicativo MSProject: O relatório do Avanço Físico do seu pacote de trabalho; O Planejamento atualizado até o dia 15 do mês anterior (contendo a atualização preliminar realizada na primeira quinzena do mês anterior); O relatório extraído do Sistema de Apontamento de Horas, informando os nomes e a quantidade de horas lançadas em cada uma das atividades por cada um dos funcionários que estão alocados ao projeto.

Com essas informações, cada responsável pelo seu pacote de trabalho deverá analisar e verificar, com todos os integrantes de sua equipe alocados no projeto: Os trabalhos efetivamente realizados e determinar o Avanço Físico de cada uma das atividades no mês atual da medição; Comparar com o Avanço Físico do mês anterior em cada uma das atividades e atualizar o progresso atual de cada atividade, na coluna \% do Avanço Físico no mês no relatório do Avanço Físico de seu pacote de trabalho; Verificar e caso haja distorções tanto no prazo como nos custos envolvidos, fazer um plano de ação para resolução dos problemas existentes e avisar o Gerente de Projetos das causas e efeitos que essas distorções podem causar ao andamento do projeto.

Depois de realizada a reunião com os integrantes da sua equipe, essas atualizações dos dias trabalhados em cada atividade são transferidas manualmente no formulário impresso da Planilha de Avanço Físico, e entregues ao Planejador do Projeto, para que ele faça as atualizações no Servidor Central da empresa. Juntamente com este formulário, é entregue ao Planejador do Projeto, o planejamento (MSProject) atualizado até o final do mês anterior, com as ações preventivas e/ou corretivas negociadas com os demais responsáveis pelos pacotes de trabalho e o Gerente de Projetos, e já implementadas neste planejamento.

\subsection{Demonstração dos cálculos do EVMS através de Tabelas e de Gráficos do Projeto}

Neste item, são apresentados as tabelas e os gráficos relacionados ao planejamento e andamento geral do projeto. As mesmas tabelas e gráficos podem ser geradas 
para cada um dos pacotes de trabalho, permitindo assim, uma análise mais detalhada do desempenho pelos responsáveis técnicos dos pacotes de trabalho.

\subsubsection{Etapa de Planejamento do Projeto}

Nesta etapa, são apresentadas às tabelas e os gráficos contendo os recursos de mão de obra de engenharia, de aquisição de materiais e equipamentos e da contratação de serviços de terceiros, distribuídos durante os meses de execução do projeto, necessários para a elaboração do planejamento inicial do projeto.

\subsubsection{Planejamento dos recursos iniciais de mão de obra do projeto (PV)}

Na tabela 6.7.1.1, a seguir, são apresentados mensalmente os custos dos recursos previstos em cada uma das atividades a serem gastos no projeto até a sua conclusão. Estes recursos são gerados através do uso do aplicativo MSProject, nos quais estão definidas todas as atividades, as durações (em dias) e os custos de cada um dos recursos da mão de obra, da aquisição de materiais e equipamentos e dos serviços de terceiros.

Tabela 6.7.1.1 - Planejamento dos custos mensais das Atividades

\begin{tabular}{|c|c|c|c|c|c|c|c|c|c|c|c|c|c|}
\hline Identifi & & & $\mathrm{jan} / 06$ & fev/06 & $\mathrm{mar} / 06$ & $a b r / 06$ & $\mathrm{mai} / 06$ & jun06 & jul/06 & ago/06 & set/06 & out/06 & nov/06 \\
\hline Atividade & Descrição das Atividades & $R^{3}$ & \multicolumn{11}{|c|}{ BCWS } \\
\hline PROJ0120-2.1 & Gerenciamento do Projeto & & & & & & & & & & & & \\
\hline PRO0120-21.1 & Coordenacão do Projeto & 388.000 & 8.435 & 16.870 & 16.870 & 16.870 & 16.870 & 16.870 & 16.870 & 16.870 & 16.870 & 16.870 & 16.870 \\
\hline PRO0120-21.2 & Planejamento \& Controle & 194.000 & 4.217 & 8.435 & 8.435 & 8.435 & 8.435 & 8.435 & 8.435 & 8.435 & 8.435 & 8.435 & 8.435 \\
\hline PROJ0120-21.3 & Gerenciamento da Qualidade & 194.000 & 4.217 & 8.435 & 8.435 & 8.435 & 8.435 & 8.435 & 8.435 & 8.435 & 8.435 & 8.435 & 8.435 \\
\hline PRON0120-21.4 & Gerenciamento da Configuração & 194.000 & 4.217 & 8.435 & 8.435 & 8.435 & 8.435 & 8.435 & 8.435 & 8.435 & 8.435 & 8.435 & 8.435 \\
\hline \begin{tabular}{|l|} 
PROD0120-2.21 \\
\end{tabular} & Dos Postos Locais (PLO), + Análise & 41.600 & 18.720 & 20.800 & 2080 & & & & & & & & \\
\hline PRO0120-2.22 & Do Centro de Controle Operacional (CCO), & 51.200 & 11.520 & 12800 & 14.720 & 12160 & & & & & & & \\
\hline PROJ0120-2.2.3 & De Sinalização, + Anal.Aprov.Cliente & 51.200 & 11.520 & 12800 & 14.720 & 12160 & & & & & & & \\
\hline PROJ0120-23 & $\begin{array}{l}\text { Gaboração das ETEs Funcionais dos } \\
\text { Equipamentos }\end{array}$ & & & & & & & & & & & & \\
\hline PRO0120-2.3.1 & Dos PCLs (Servidores, Redes,IHM) & 8.400 & & & & 560 & 7.840 & & & & & & \\
\hline PROJ0120-2.4.1 & Software CLPS & 32000 & & & & & & 3.840 & 13.440 & 14.720 & & & \\
\hline PROJ0120-2.4.2 & IHMe Funcionalidades PLO's & 48.000 & & & 20.160 & 19.200 & 8.640 & & & & & & \\
\hline PROV0120-24.3 & IIHe Funcion. Tráfego CCO & 168.000 & & & & 1.680 & 38.640 & 36.960 & 35.280 & 38.640 & 16.800 & & \\
\hline PRO0120-24.4 & IHMe Funcional Energia CCO & 152000 & & & & 1.520 & 34.960 & 33.440 & 31.920 & 34.960 & 15.200 & & \\
\hline
\end{tabular}

\subsection{Curva do planejamento dos recursos de mão de obra de engenharia}

Na figura 6.7.1.1.1, a seguir, apresenta-se a curva $S$ dos custos da mão de obra previstos no projeto e distribuídos durante os meses de execução do projeto, obtida com o auxílio do planejamento do projeto. 


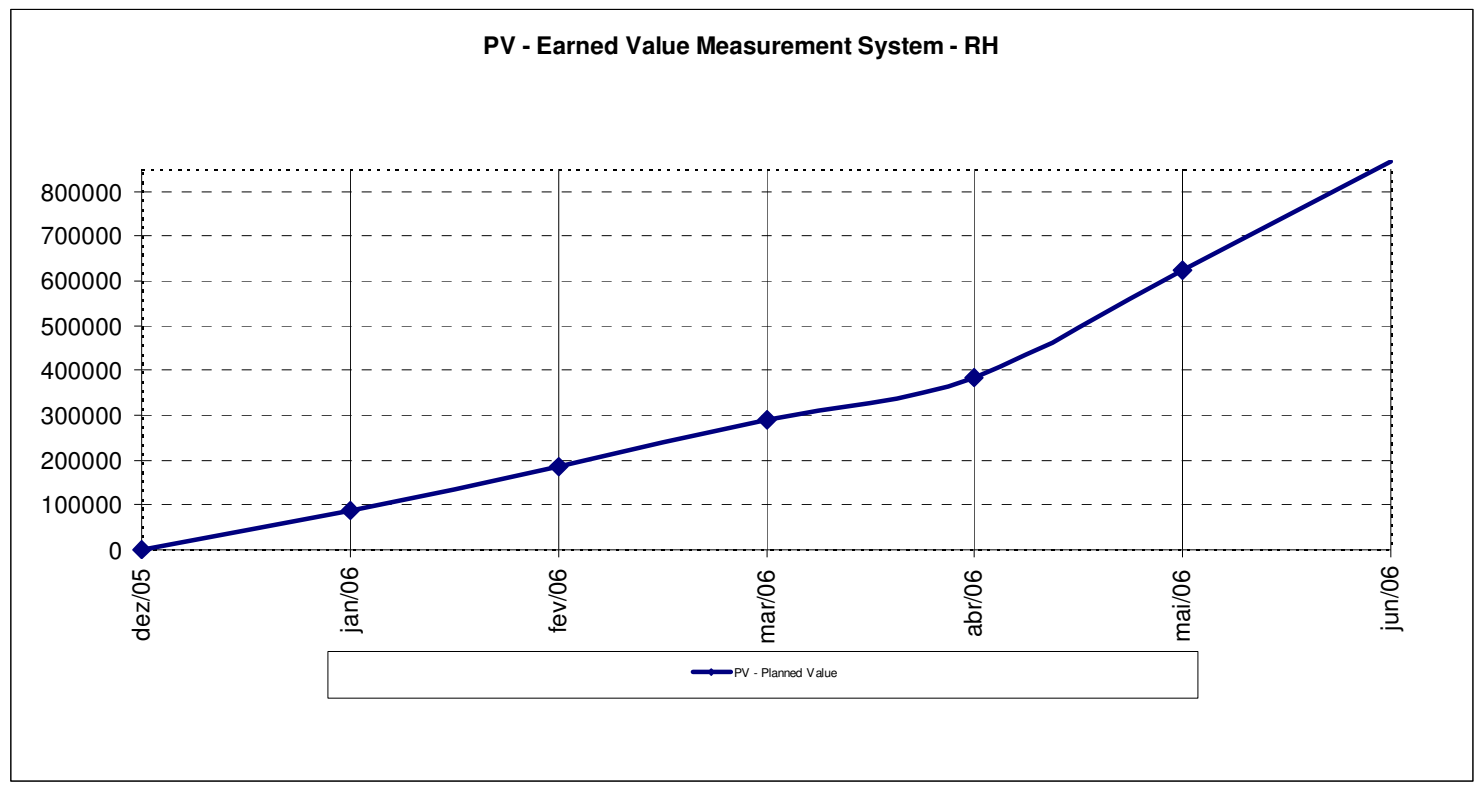

Figura 6.7.1.1.1 - Gráfico dos recursos de mão de obra de engenharia

\subsubsection{Planejamento dos custos iniciais de Aquisição de Materiais, Equipamentos e Serviços de Terceiros do projeto (PV)}

$\mathrm{Na}$ tabela 6.7.1.2, a seguir, são apresentados mensalmente os custos de aquisição de materiais, equipamentos e serviços de terceiros a serem gastos no projeto até a sua conclusão. Estes custos são distribuídos nos meses de acordo com a época de aquisição de cada material ou equipamento, ou quando da necessidade de contratação de serviços de terceiros.

Tabela 6.7.1.2 - Custos mensais para Aquisição de Materiais, Equipamentos e Serviço de terceiros.

\begin{tabular}{|c|c|c|c|c|c|c|c|c|c|c|c|c|c|}
\hline \multirow{2}{*}{$\begin{array}{l}\text { Austos de Aquisição de Materiais, Equipamentos } \\
\text { e Contratação de Senviços de Terceiros }\end{array}$} & \multirow{2}{*}{$\begin{array}{c}\text { Total } \\
\text { Orçado } \\
\mathbf{R} \$\end{array}$} & jan-06 & fev-06 & mer-06 & $\mid a b r-06$ & mai-06 & jun-06 & jul-06 & ago-06 & set-06 & out-06 & nov-06 & dez-06 \\
\hline & & \multicolumn{12}{|c|}{ BCWS } \\
\hline AquisiçãoMaterial eFabricação QPS & 65.000 & & & & & 6.500 & 28.500 & 30.000 & & & & & \\
\hline Aquisição Meterial eFabricação doSMCT & 48.000 & & & & & & 9.600 & 19.200 & 19.200 & & & & \\
\hline Aquisição Material Gabinetes Senvidores & 56.000 & & & & & & & & 5.600 & 20.400 & 30.000 & & \\
\hline Aquisiçãolnsp/Testes Serv/Works/Est.Trab/etc & 250.000 & & & & & 25.000 & 75.000 & 75.000 & 75.000 & & & & \\
\hline AquisiçãoRedes/Periféricos & 75.000 & & & & & 7.500 & 22500 & 22500 & 22500 & & & & \\
\hline Aquisição/Entrega Consolese Painéis & 780.000 & & & & 200.000 & & & & 200.000 & & & & 180.000 \\
\hline Aquisição/Entrega No-Break $\infty \mathrm{COPLO}$ & 80.000 & & & & & & & & & & & & \\
\hline Aquisição/Entrega Maq Chave/SinaleiroseCDVs & 868.000 & & & & 100.000 & & & 100.000 & & & & 368.000 & \\
\hline Aquisição/Entrega Cabos Betricos/Controle & 313.500 & & & & & & & & & & & 165.000 & \\
\hline Aquisição/Entrega Painel Distrib. Energia(PDF) & 50.000 & & & & & & & & & & & 5.000 & \\
\hline Eaboração Rrojeto Construção do COO & 80.000 & & & & 16.000 & 16.000 & 16.000 & 16.000 & 16.000 & & & & \\
\hline ContrataçãoEmpresae Exeaucão da Obra do $\propto 0$ C & 650.000 & & & & & & & & & 130.000 & & 130.000 & \\
\hline Contratação Seguros e Despesas Administração & 265.000 & 11.522 & 11.522 & 11.522 & 11.522 & 11.522 & 11.522 & 11.522 & 11.522 & 11.522 & 11.522 & 11.522 & 11.522 \\
\hline TOTAL & & 11.522 & 11.522 & 11.522 & 327.522 & 66.522 & 163.122 & 274.222 & 349.822 & 161.922 & 41.522 & 679.522 & 191.522 \\
\hline
\end{tabular}




\subsection{Curva do planejamento da Aquisição de Materiais e Equipamentos e Serviço de Terceiro}

A figura 6.7.1.2.1, a seguir, apresenta a curva $S$ dos recursos necessários, previstos e distribuídos durante os meses de execução do projeto, de acordo com o planejamento do projeto.

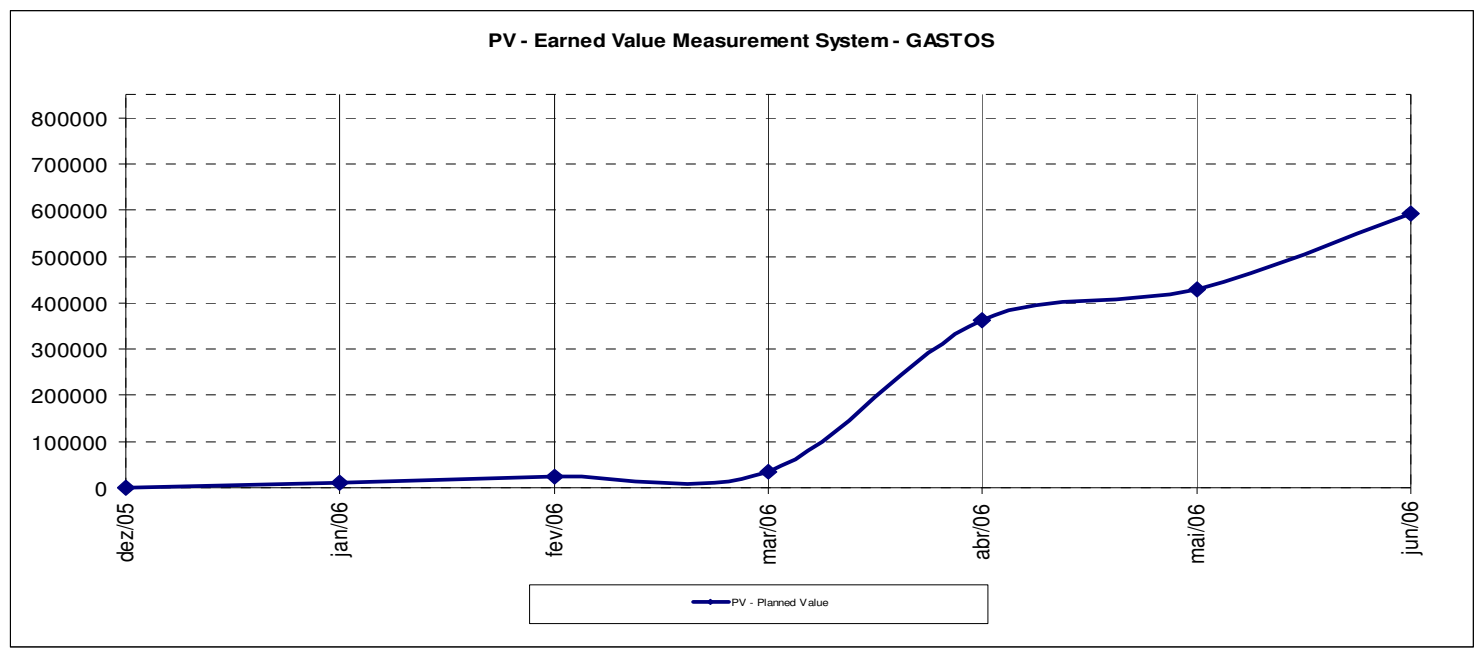

Figura 6.7.1.2.1 - Gráfico dos recursos da Aquisição de Materiais,Equipamentos e Serviço de Terceiros

\subsubsection{Curva do Planejamento Inicial do Projeto (BAC)}

$\mathrm{Na}$ Figura 6.7.1.3, a seguir, apresenta-se à curva do orçamento inicial do projeto (BAC), a qual contém a soma dos custos dos recursos de mão de obra de engenharia e dos custos para aquisição de materiais, equipamentos e da contratação de serviços de terceiros.

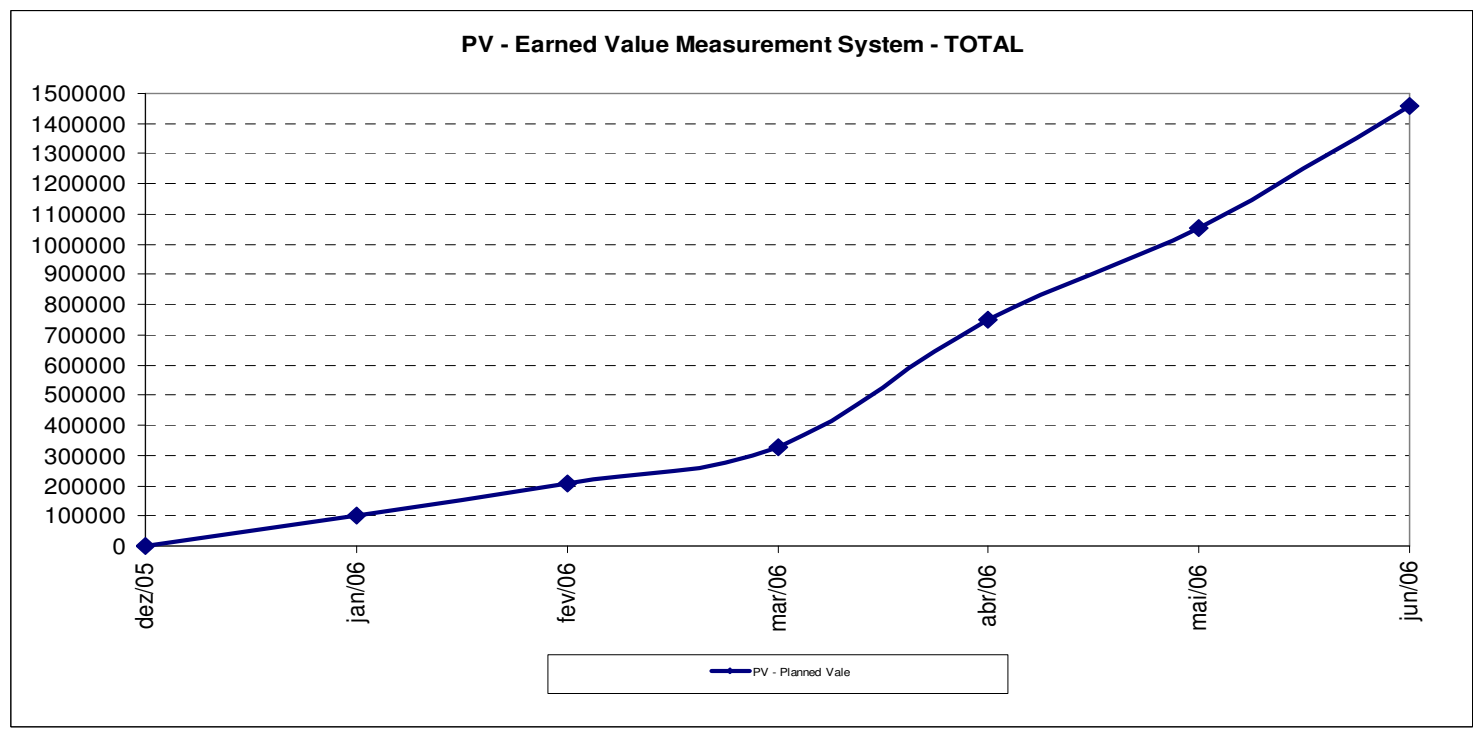

Figura 6.7.1.3 - Gráfico do Orçamento inicial do projeto (BAC) 


\subsubsection{Etapa de Controle do Projeto}

Nesta etapa, são apresentadas às tabelas e os gráficos contendo os recursos da mão de obra de engenharia efetivamente realizados (Avanço Físico do Projeto), da aquisição ou pagamento realizado de materiais e equipamentos e dos trabalhos efetivamente realizados pelos terceiros.

\subsubsection{Planilha do Cálculo do Avanço Físico do Projeto (EV)}

$\mathrm{Na}$ tabela 6.7.2.1, a seguir, a cada mês estão associadas duas colunas: $\mathrm{Na}$ coluna (porcentagem - \%), os valores são atualizados automaticamente quando é realizado o andamento físico de cada uma das atividades nos diversos pacotes de trabalho descritos anteriormente nos itens 6.6.2. e 6.6.3. Na coluna correspondente ao mês de realização das atividades, (ex: JAN06), são calculados também automaticamente os custos relacionados à porcentagem dos trabalhos da mão de obra efetivamente realizada. Esse cálculo é realizado multiplicando-se a porcentagem realizada pelo valor total da atividade contido nas planilhas dos custos mensais do planejamento inicial do projeto, apresentado nas tabelas 6.7.1.1 e 6.7.1.2. Exemplo: $\mathrm{Na}$ atividade PROJ0120-2.1.1 - Coordenação do projeto, no mês de Jan/06 tem-se um avanço físico de $2,78 \%$ (3\%), que multiplicado pelo custo total desta atividade de $R \$$. $388.000,00$ (na coluna Total Orçado $R \$$.) da tabela 6.7.1.1, equivale a um custo de $\mathrm{R} \$ .10 .777,78$.

Tabela 6.7.2.1 - Planilha do Cálculo do Avanço Físico do Projeto

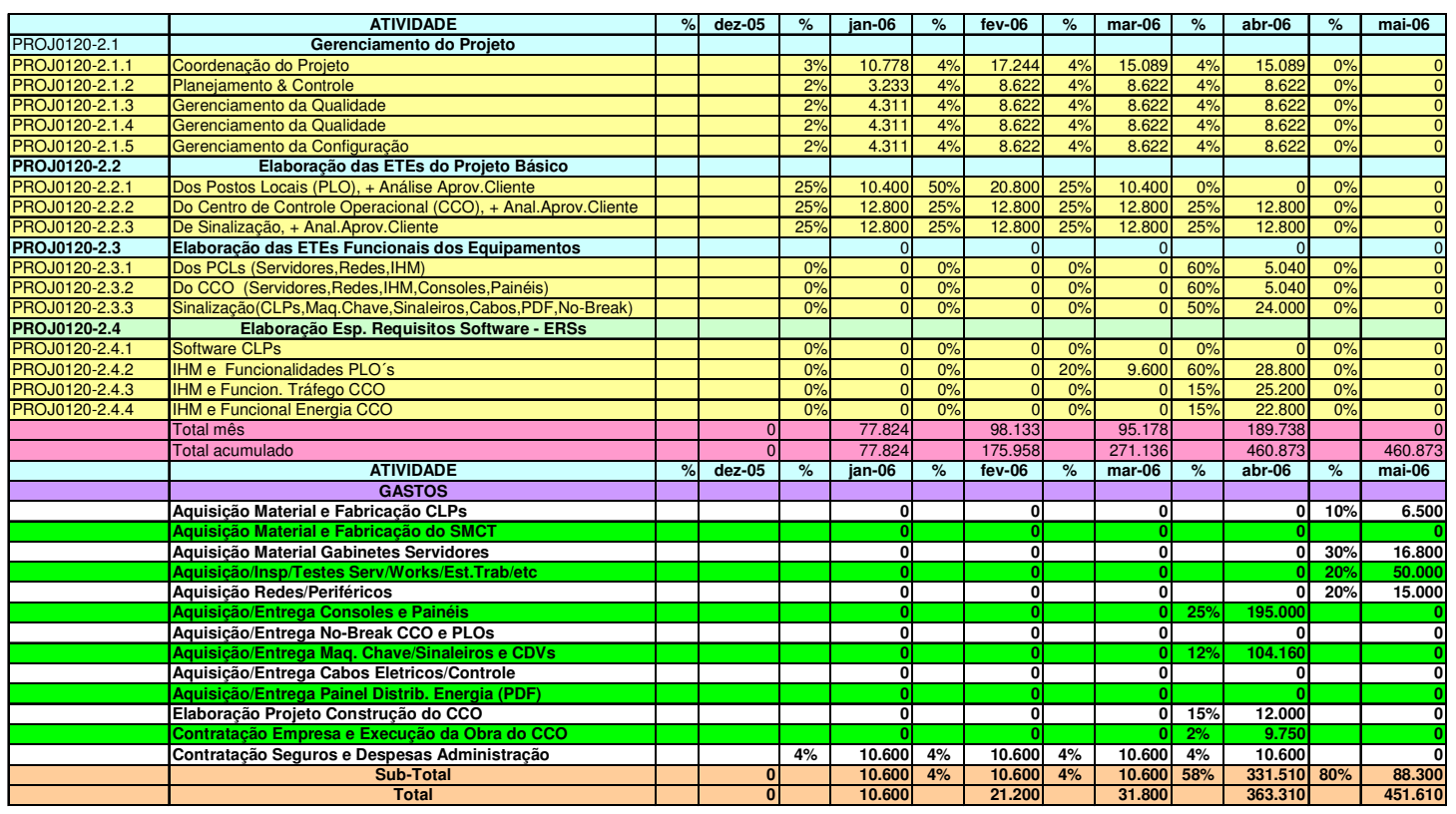




\subsubsection{Curvas dos cálculos do Avanço Físico do Projeto (EV)}

\subsection{Curva do Avanço Físico da mão de obra realizada no Projeto}

O cálculo dos custos relacionados ao trabalho efetivamente realizado é calculado automaticamente na planilha apresentada na tabela 6.7.2.1. As colunas contendo a porcentagem (\%) são atualizadas automaticamente quando é realizado o avanço físico de cada uma das atividades pelos responsáveis pelos pacotes de trabalho, conforme descrito anteriormente no item 6.6.2 e 6.6.3. Os custos apresentados nas colunas subseqüentes são calculados multiplicando a porcentagem realizada, com o valor dos custos de cada uma das atividades contidos na coluna total, da planilha do planejamento dos recursos iniciais de mão de obra do projeto (PV), apresentada na tabela 6.7.1.1.

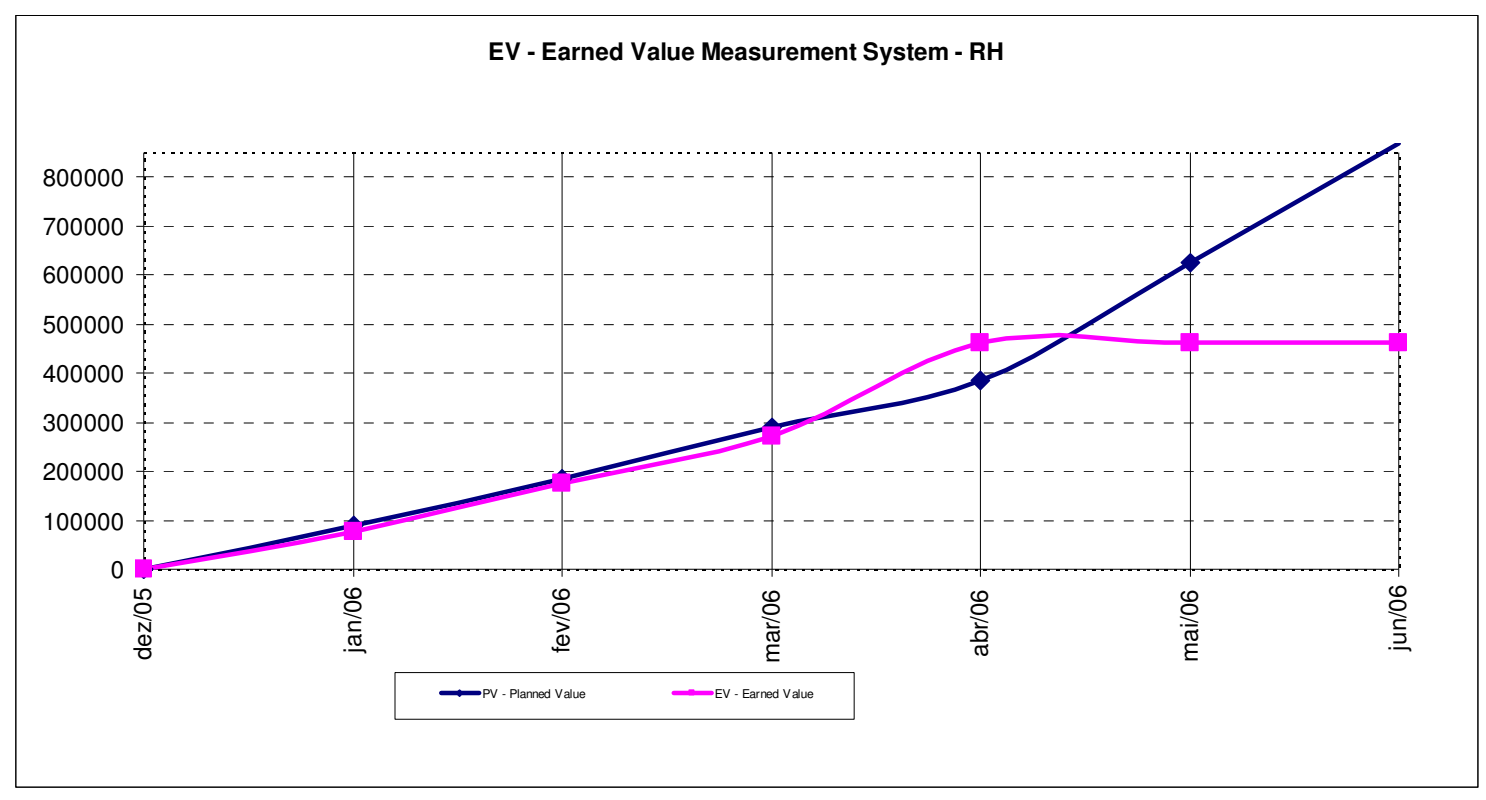

Figura 6.7.2.2.1 - Gráfico do Avanço Físico da mão de obra realizada

\subsection{Curva do Avanço Físico do Projeto relacionado à Aquisição de Materiais e Serviços e contratação de Serviços de Terceiros}

O cálculo dos custos relacionados à aquisição de materiais e equipamentos e de serviços de terceiros é calculado automaticamente na planilha da tabela 6.7.2.1. As colunas contendo a porcentagem (\%) são atualizadas automaticamente quando é realizado o avanço físico de cada uma das atividades pelos responsáveis pelos pacotes de trabalho, conforme descrito anteriormente no item 6.6.2 e 6.6.3. Os custos apresentados nas colunas subseqüentes são calculados multiplicando a 
porcentagem realizada, com o valor dos custos de cada uma das atividades contidos na coluna total, da planilha do Planejamento dos custos iniciais de Aquisição de Materiais, Equipamentos e Serviços de Terceiros do projeto (PV), apresentados na tabela 6.7.1.2.

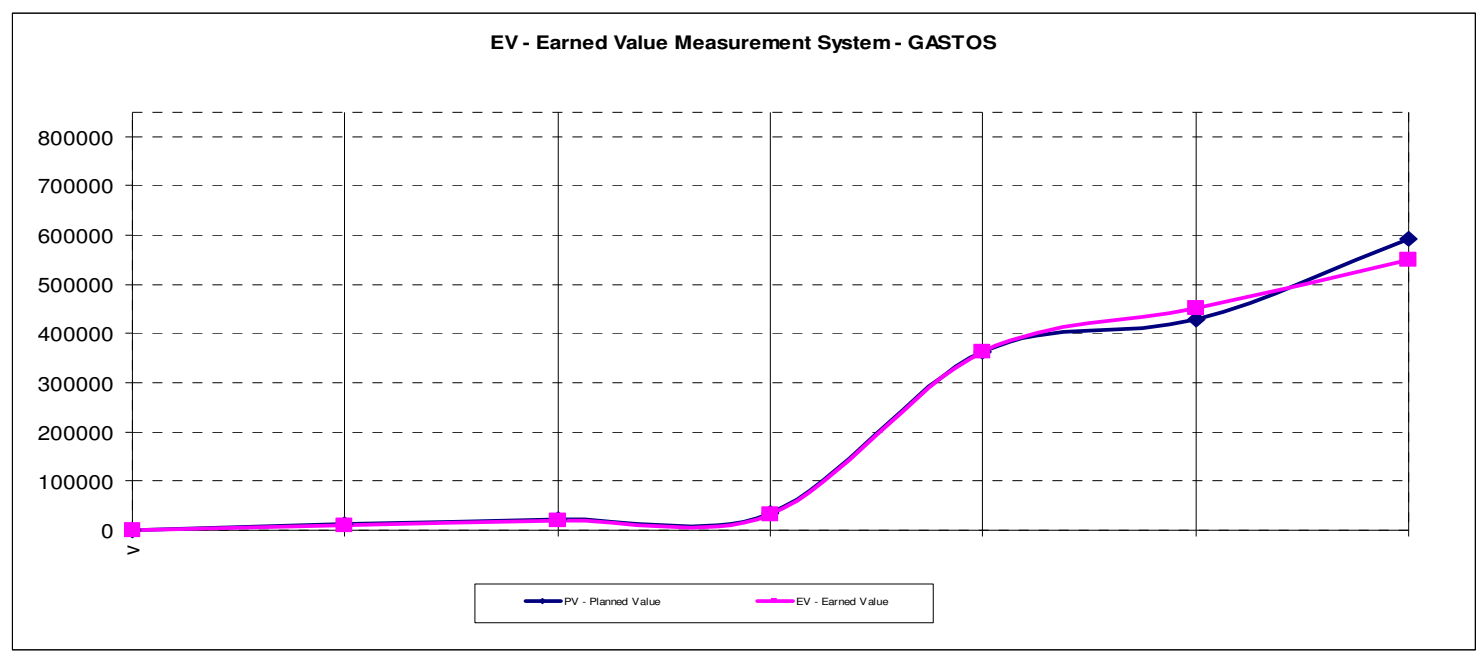

Figura 6.7.2.2.2 - Gráfico do Avanço Físico na aquisição de materiais, equipamentos e serviços de terceiros

\subsection{Cálculo do Avanço Físico total do Projeto}

Na figura 6.7.2.2.3, a seguir, apresenta-se à curva consolidada do Andamento Físico total do Projeto. Portanto, comparando-se a curva de Avanço físico do projeto EV com a curva do planejamento inicial do projeto PV (também chamada de Baseline), pode-se então verificar, se o projeto está em conformidade com o planejado, se está adiantado ou atrasado, e tomar as devidas ações necessárias para a correção das anomalias.

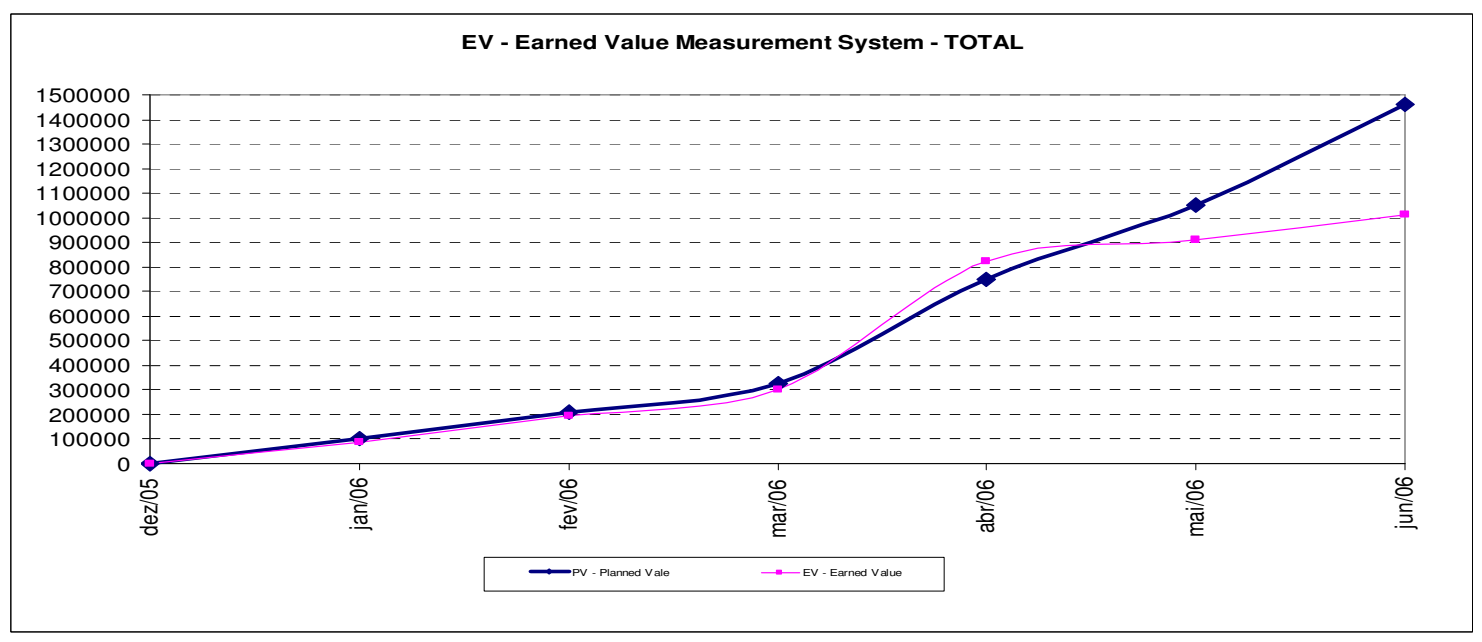

Figura 6.7.2.2.3 - Gráfico do Avanço Físico Total do Projeto (EV) 


\subsubsection{Planilha do cálculo dos custos efetivamente incorridos no projeto (AC)}

$\mathrm{Na}$ tabela 6.7.2.3, as colunas são atualizadas mensalmente com os custos realmente incorridos da mão de obra lançada diariamente no sistema de apontamento de horas, bem como, dos custos efetivamente gastos na aquisição de materiais, equipamentos e na contratação de serviços de terceiros, informações estas extraídas do sistema de administração geral da empresa.

Tabela 6.7.2.3 - Cálculo dos custos incorridos no projeto

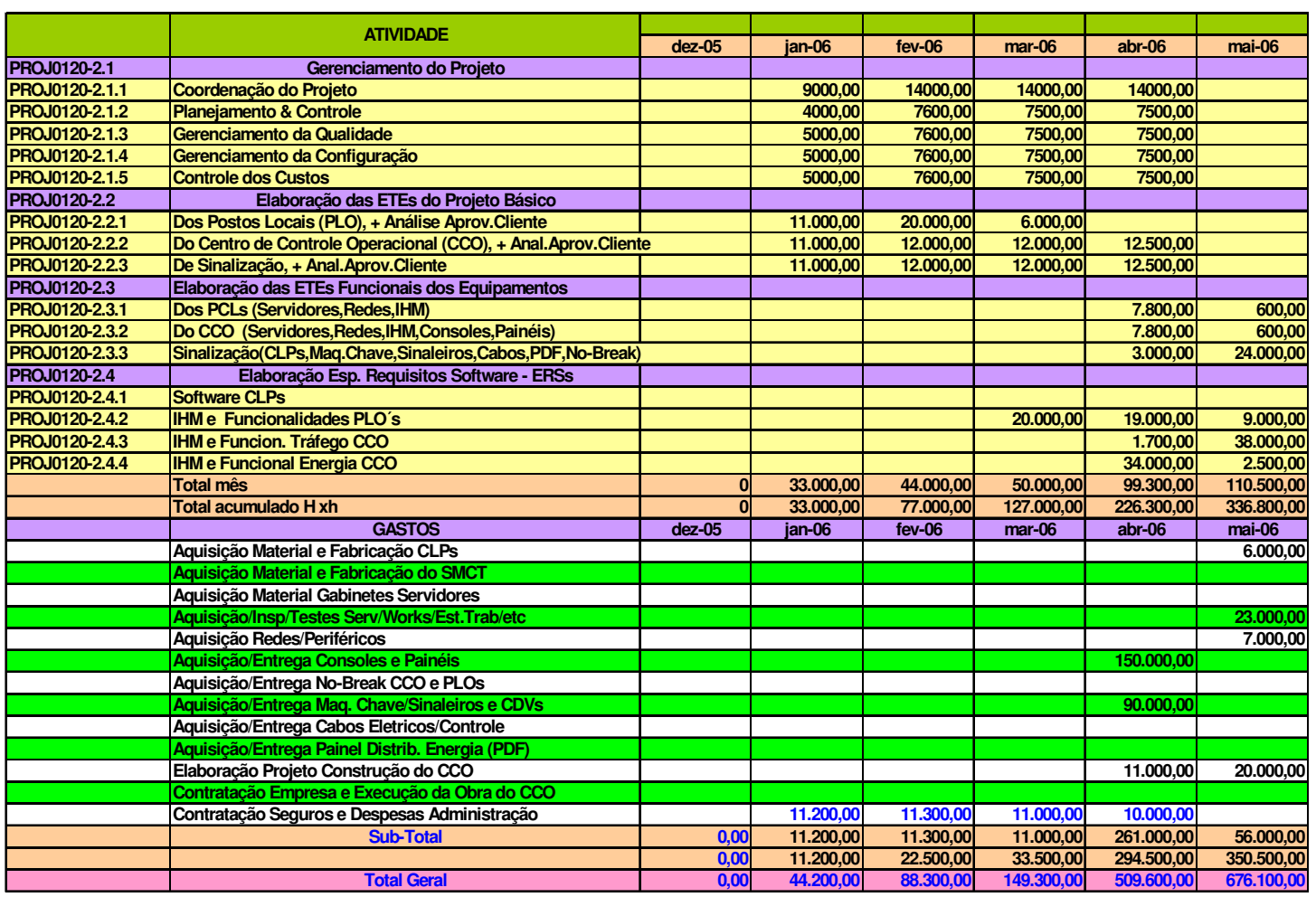

\subsubsection{Curvas dos cálculos dos custos reais incorridos do projeto (AC)}

Nas figuras a seguir, são apresentadas as figuras contendo a representação mensal dos custos efetivamente incorridos em cada uma das atividades previstas no projeto, e das aquisições de materiais, equipamentos e contratação de serviços de terceiros.

\subsection{Custos incorridos da mão de obra realizada no Projeto}

Na figura 6.7.2.4.1 apresenta-se a curva dos custos incorridos referente à mão de obra gasta na realização de cada uma das atividades. 


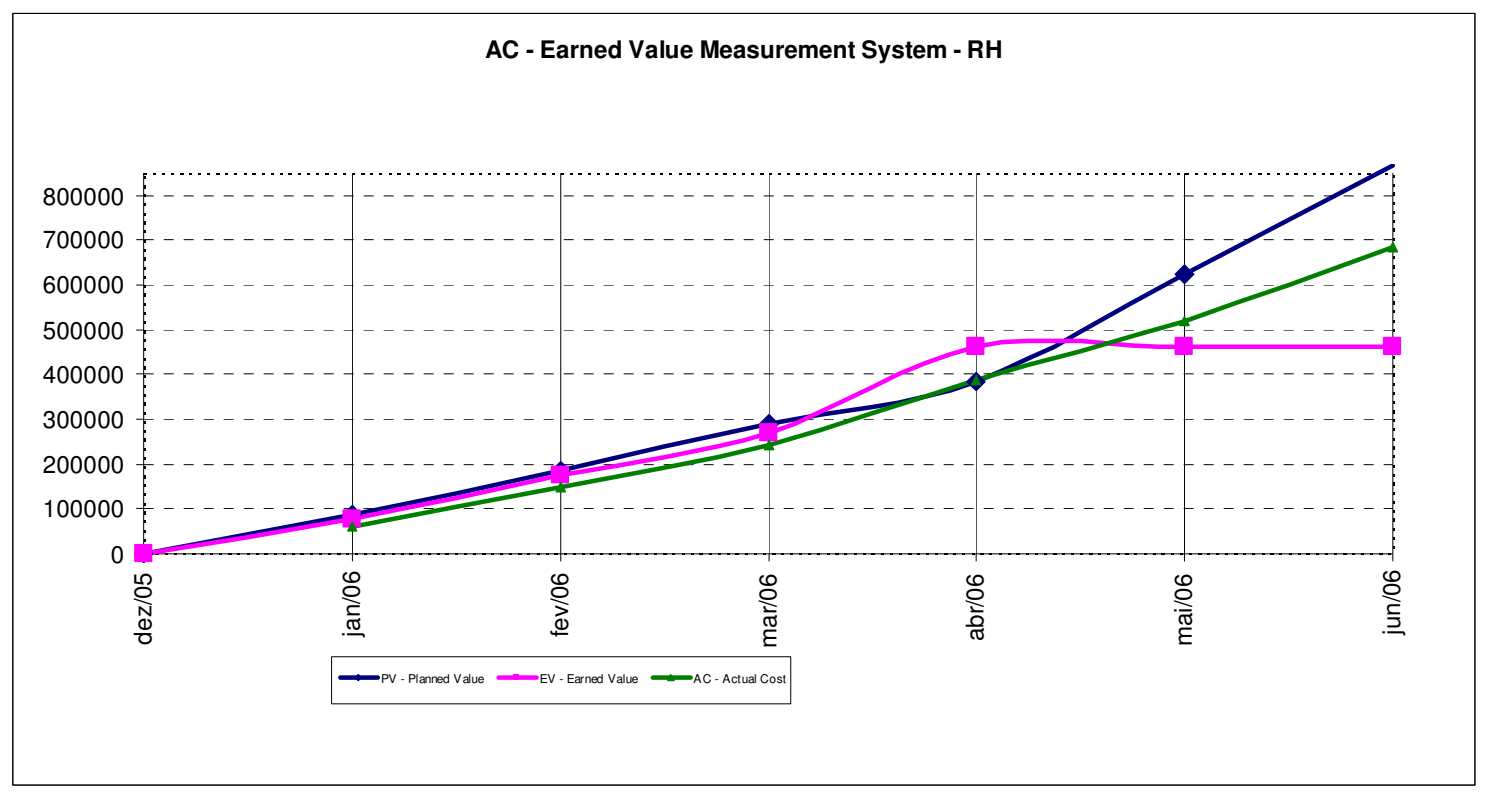

Figura 6.7.2.4.1 - Gráfico dos Custos incorridos da mão de obra realizada

\subsection{Custos incorridos da aquisição de materiais, equipamentos e contratação de serviços externos}

Na figura 6.7.2.4.2 apresenta-se a curva dos custos incorridos referente à aquisição de materiais, equipamentos e contratação de serviços de terceiros.

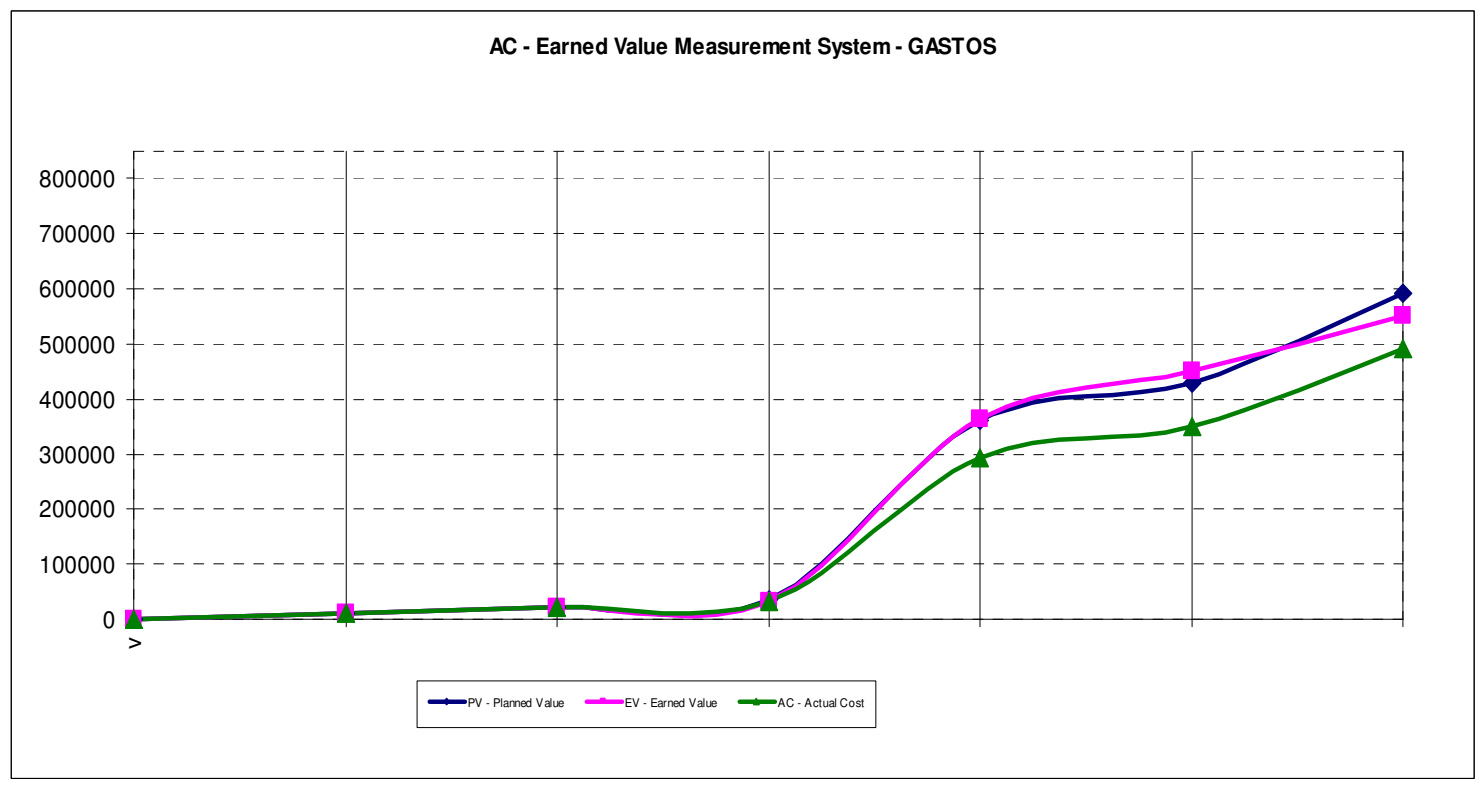

Figura 6.7.2.4.2 - Gráfico dos Custos incorridos da aquisição de materiais, equipamentos e contratação de serviços de terceiros 


\subsection{Curva do Cálculo dos custos incorridos total do Projeto}

$\mathrm{Na}$ figura 6.7.2.4.3, apresenta-se a curva consolidada dos custos realmente incorridos mensalmente, da mão de obra, da aquisição dos materiais e equipamentos e da contração de serviços de terceiros.

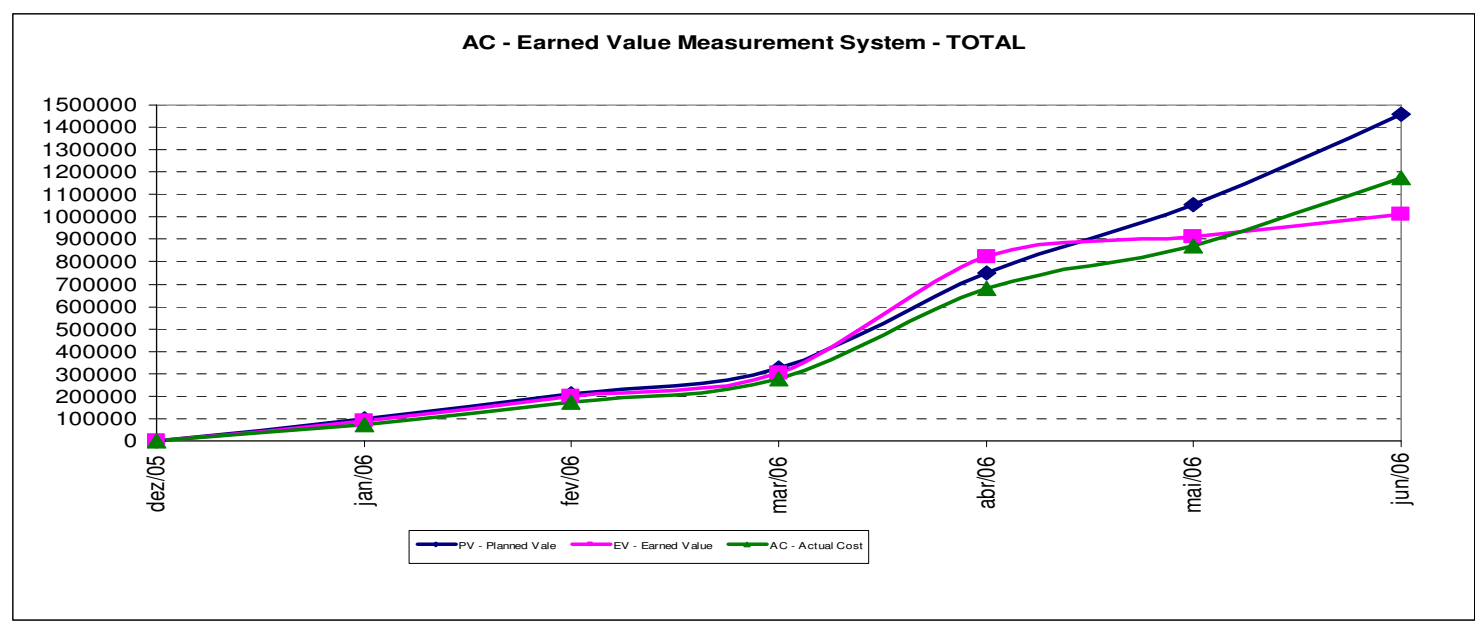

Figura 6.7.2.4.3 - Gráfico dos Custos incorridos total do projeto

\subsubsection{Fluxo de Caixa do Projeto}

No gráfico 6.7.2.5 são apresentadas as seguintes curvas: A curva das receitas, que é gerada através dos eventos de receitas, contidos na Tabela das Receitas previstas no projeto, apresentada no item 6.5.3, os quais depois de cumpridos e aprovados pelo cliente geram as receitas ao projeto; A curva dos Custos Incorridos total do projeto, apresentada na figura 6.7.2.4.3; A terceira curva, Fluxo de Caixa, é a curva resultante da soma da curva das receitas com a curva das despesas, na qual é demonstrado o estado atual do Fluxo de Caixa do projeto.

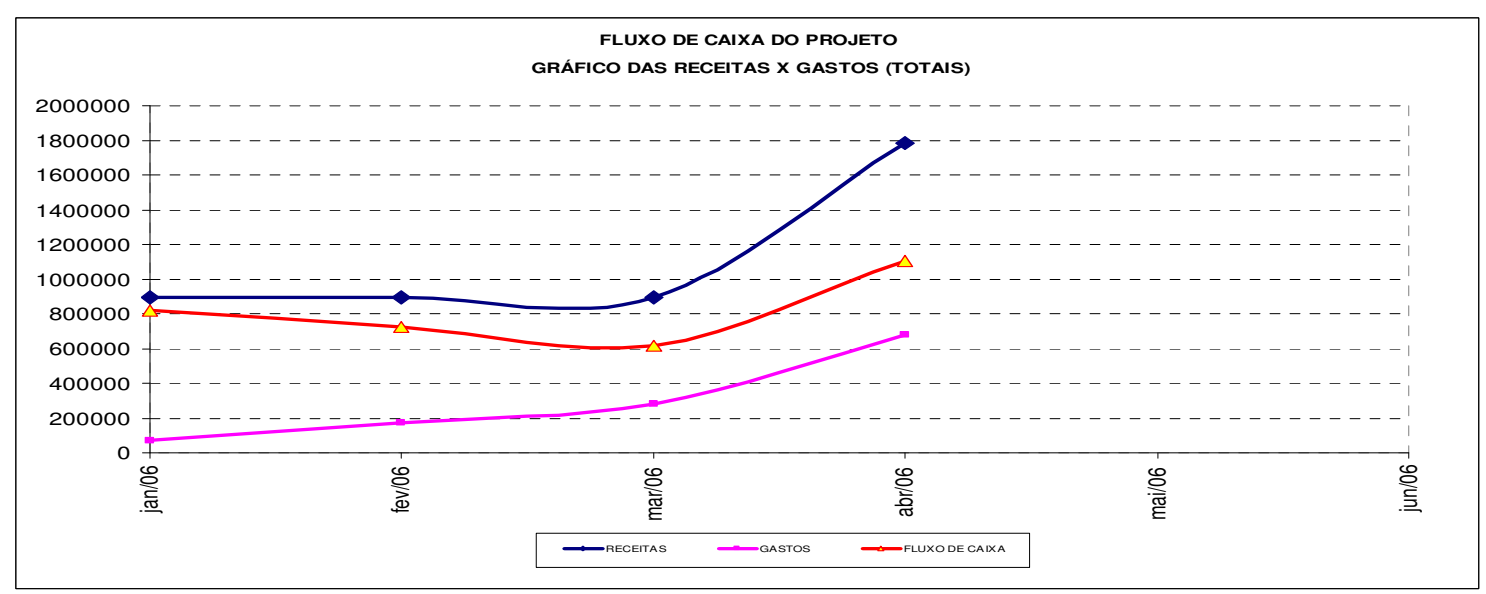

Figura 6.7.2.5 - Gráfico do Fluxo de Caixa do Projeto 


\subsubsection{Resumo Geral do Projeto}

$\mathrm{Na}$ tabela 6.7.2.6 são apresentados todos os indicadores calculados para o projeto da Linha Alfa, com a data de corte em Abril de 2006, para a realização das análises dos indicadores e índices de desempenho do projeto.

Tabela 6.7.2.6 - Resumo dos indicadores do andamento mensal do projeto

\begin{tabular}{|c|c|c|}
\hline \multicolumn{3}{|c|}{ EARNED VALUE MEASUREMENT SYSTEM - EVMS - LINHA ALFA } \\
\hline \multicolumn{3}{|c|}{ GASTOS COM RECURSOS HUMANOS } \\
\hline PV = Planned Value $=$ & $386.210,00$ & Trabalho Orçado \\
\hline EV $=$ Earned Value $=$ & $460.873,34$ & Trabalho realizado é MAIOR que o Orçado \\
\hline$\overline{A C}=$ Actual Cost $=$ & $386.700,00$ & Trabalho Incorrido é MAiOR que o Orçado \\
\hline $\mathrm{CV}=$ Cost Variance $=\mathrm{EV}-\mathrm{AC}=$ & $74.173,34$ & Trabalho Realizado é MAIOR que o Incorrido \\
\hline $\mathrm{SV}=$ Schedule Variance $=\mathrm{EV}-\mathrm{PV}=$ & $74.663,34$ & O Cronograma está ADIANTADO \\
\hline $\mathrm{CV} \%=$ Cost Variance $=\mathrm{CV} / \mathrm{EV}=$ & 16,09 & \\
\hline SV\% = Schedule Variance = SV / PV = & 19,33 & \\
\hline CPI $=$ Cost Performance Index $=E V / A C=$ & 1,19 & \\
\hline SPI = Schedule Performance Index = EV $/$ PV = & 1,19 & \\
\hline CR $=$ Critical Ratio $=$ SPI $\times$ CPI $=$ & 1,42 & Perigo para melhor \\
\hline \multicolumn{3}{|c|}{ GASTOS COM AQUISIÇAO MATERIAIS, EQUIPAMENTOS, SEGUROS } \\
\hline PV = Planned Value $=$ & $362.086,96$ & \\
\hline EV = Earned Value $=$ & $363.310,00$ & Gastos realizados é MAIOR que o Orçadas \\
\hline$\overline{A C}=$ Actual Cost $=$ & $294.500,00$ & Gastos Incorridos é MENOR que o orçadas \\
\hline $\mathrm{CV}=$ Cost Variance $=\mathrm{EV}-\mathrm{AC}=$ & $68.810,00$ & Gastos Incorridos está MENOR que as realizados \\
\hline SV = Schedule Variance $=\mathrm{EV}-\mathrm{PV}=$ & $1.223,04$ & O Cronograma está ADIANTADO \\
\hline $\mathrm{CV} \%=$ Cost Variance $=\mathrm{CV} / \mathrm{EV}=$ & 18,94 & \\
\hline SV\% = Schedule Variance = SV / PV = & 0,34 & \\
\hline $\mathrm{CPI}=$ Cost Performance Index $=\mathrm{EV} / \mathrm{AC}=$ & 1,23 & \\
\hline $\mathrm{SPI}=$ Schedule Performance Index = EV $/ \mathrm{PV}=$ & 1,00 & \\
\hline CR = Critical Ratio $=$ SPI $\times$ CPI = & $\overline{1,24}$ & Alerta para melhor \\
\hline \multicolumn{3}{|c|}{ GASTOS TOTAIS (RH + GASTOS AQUISIÇOES) } \\
\hline PV = Planned Value $=$ & $748.296,96$ & \\
\hline EV $=$ Earned Value $=$ & $824.183,34$ & Trabalho + Despesas realizadas é MAIOR que o Orçado \\
\hline$\overline{A C}=$ Actual Cost $=$ & $681.200,00$ & Trabalho + Despesas Incorridas é MENOR que o orçado \\
\hline $\mathrm{CV}=$ Cost Variance $=\mathrm{EV}-\mathrm{AC}=$ & $142.983,34$ & Trabalho + Despesas realizadas é MAIOR que o Incorrido \\
\hline $\mathrm{SV}=$ Schedule Variance $=\mathrm{EV}-\mathrm{PV}=$ & $75.886,38$ & O Cronograma está ADIANTADO \\
\hline $\mathrm{CV} \%=$ Cost Variance $=\mathrm{CV} / \mathrm{EV}=$ & 17,35 & \\
\hline SV\% = Schedule Variance = SV $/$ PV = & 10,14 & \\
\hline $\mathrm{CPI}=$ Cost Performance Index $=\mathrm{EV} / \mathrm{AC}=$ & 1,21 & \\
\hline SPI = Schedule Performance Index = EV $/ \mathrm{PV}=$ & 1,10 & \\
\hline CR = Critical Ratio = SPI $\times$ CPI = & 1,33 & Perigo para melhor \\
\hline
\end{tabular}

\section{Indicadores de Custos do Projeto:}

PV = Orçamento do Custo Planejado do Projeto. Até o final do mês de abril de 2006, estava planejado que seriam gastos para a realização das atividades o montante de $\mathrm{R} \$ .729 .377,39$.

$\mathrm{EV}=$ Custo do trabalho efetivamente realizado $=$ Avanço Físico do Projeto. Até o final do mês de Abril de 2006 foram realizadas diversas atividades no projeto, perfazendo um total equivalente a $\mathrm{R} \$$. 809.303,33. 
$A C=$ Custo atual incorrido do trabalho realizado. São os custos atuais incorridos lançados na contabilidade da empresa até o final do mês de Abril de 2006, perfazendo um total de $R \$ .681 .200,00$.

\section{Análise dos Custos:}

$C V=$ Variação do custo $=E V-A C=R \$ .128 .103,33$. Este índice mede o desvio entre o custo do trabalho efetivamente realizado (EV) e do custo atual incorrido do trabalho realizado (AC). Analisando este indicador, podemos concluir que até o final de Abril de 2006, o custo do trabalho efetivamente realizado é superior ao custo atual incorrido do trabalho realizado e lançado na contabilidade. Indica que, foram realizadas mais atividades do que as previstas e com um custo ainda menor do que os inicialmente previstos no Orçamento do Custo Planejado do Projeto. Esse resultado demonstra que foram realizadas mais atividades do que o previsto, portanto em termos de custo, o projeto está consumindo menos recursos.

$C V \%=\%$ de Variação do custo $=\mathrm{CV} / \mathrm{EV}=15,83 \%$. Este índice é um complemento ao índice CV citado acima, e indica que a redução dos custos é de $15,83 \%$.

\section{Análise do Planejado x Realizado das atividades do Projeto:}

$S V=$ Variação do Planejado $=E V-P V=R \$ .79 .925,94$. Este índice mede o desvio entre o Orçamento do Custo Planejado do Projeto (PV) e o Custo do trabalho efetivamente realizado $(\mathrm{EV})$. Analisando este indicador, por meio de unidade monetária (custos), podemos concluir que até o final de Abril de 2006, o custo do trabalho efetivamente realizado é superior ao Orçamento do Custo Planejado do Projeto. Esse resultado demonstra que foram realizadas mais atividades do que o previsto, portanto em termos de custo, o projeto está adiantado em relação ao planejamento inicial do projeto.

SV\% $=\%$ de Variação do Planejado $=S V / P V=10,96 \%$. Este índice é um complemento ao índice SV citado acima, e indica que o projeto está adiantado em relação ao planejamento inicial de $10,96 \%$.

\section{Análise dos índices de desempenho do Projeto:}

$\mathrm{CPI}=$ Índice de desempenho do custo $=\mathrm{EV} / \mathrm{AC}=1,19$. Este índice demonstra que a relação dos custos do trabalho efetivamente realizado com o custo atual incorrido do trabalho realizado o lançados na contabilidade, representa uma economia de 
$19 \%$ até o final do mês de abril, indicando que o projeto está realizou mais atividades e gastou menos do que o inicialmente previsto.

$\mathrm{SPI}=$ Índice de desempenho do Planejado $=\mathrm{EV} / \mathrm{PV}=1,11$. Este índice demonstra que foram realizadas mais atividades até Abril de 2006 (Avanço Físico do Projeto) do que as atividades inicialmente planejadas, indicando, portanto, que o projeto está adiantado em relação ao planejamento inicial.

\section{Conclusão das Análises realizadas do Projeto:}

Após a demonstração dos indicadores e índices de medidas do projeto da Linha Alfa, e apresentados na tabela 6.7.2.6, podemos concluir, que o projeto até o final de Abril de 2006, está adiantado e com custos menores do que os inicialmente planejados. Essa tendência, se mantida nos próximos meses, indica que o projeto terminará antes do prazo inicialmente planejado e com os custos menores do que os inicialmente previstos. 


\section{CONCLUSÕES E RECOMENDAÇÕES}

\subsection{Conclusões}

Com a aplicação da metodologia de cálculo do Avanço Físico do Projeto proposta no projeto da Linha Alfa, e apos realizadas todas as demonstrações e análises dos resultados obtidos com a implementação dessa nova metodologia em um projeto, pode-se então concluir que, esta metodologia é mais eficiente do que a atualmente utilizada, porém não se pode garantir que ela é $100 \%$ eficiente, pois ainda depende de certo grau, porém agora menor do que anteriormente, da subjetividade dos envolvidos no processo.

O responsável pelo pacote de trabalho tem maior facilidade em atualizar o Avanço Físico e um controle mais eficaz do andamento das suas atividades, com o controle do Avanço Físico do Projeto realizado nos pacotes de trabalho, pois todas as atividades estão concentradas em uma única planilha de controle.

Verifica-se também, que o tempo gasto pelo responsável pelo pacote de trabalho para atualizar as informações é significativamente menor, e ele não precisa mais pesquisar as suas atividades no planejamento geral, pois já recebe um relatório da área de planejamento do projeto com as atividades do seu pacote de trabalho, o que facilita a sua atualização.

O Gerente do Projeto, recebendo o Avanço Físico de cada pacote de trabalho, tem maior facilidade para analisar e identificar quais dos pacotes de trabalho estão em conformidade com o planejamento inicial do projeto e quais estão atrasados ou com custos acima do planejado. Com estas informações mais detalhadas, o gerente de projeto pode tomar rapidamente as devidas providências, para sanar as anomalias e colocar o projeto dentro do planejamento inicial previsto.

Com a interligação automática das planilhas do Avanço Físico de cada pacote de trabalho com a planilha de Avanço Físico geral do projeto, o gerente de projetos tem uma visão mais precisa do andamento de todo o projeto. Esta informação, juntamente com as informações obtidas anteriormente do estado de cada pacote de trabalho, é incorporada ao relatório mensal de andamento do projeto a ser enviado a alta direção da empresa. Neste relatório, também são descritos os planos de ações 
estabelecidos pelo gerente de projeto com todos os responsáveis pelos pacotes de trabalho, com o objetivo de sanar as não conformidades detectadas no projeto.

Neste trabalho, para o mesmo não se tornar extenso e repetitivo, optou-se por apresentar no item 6.7 apenas as tabelas, as figuras e o resumo geral relacionadas com os cálculos do EVMS do projeto como um todo. Entretanto, é extremamente importante que as tabelas, as figuras e o resumo sejam implementadas para cada um dos Pacotes de Trabalho, pois com a utilização das 3 curvas representadas nas figuras (PV, EV e AC), torna-se mais fácil à interpretação do desempenho do projeto, e a definição do plano de ação a ser elaborado, dependendo dos resultados apresentados.

\subsection{Recomendações}

Recomenda-se que todo o processo de Avanço Físico do Projeto seja aplicado por completo em um projeto, fazendo-se às correções e adaptações necessárias nos sistemas existentes, e depois de consolidado, expandir para os demais projetos da empresa. Devido à falta de conhecimento, aliado a enorme dificuldade constatada pelo autor na sua organização, no entendimento por parte dos profissionais na absorção da metodologia do EVMS, torna-se necessário a realização de um treinamento bem detalhado, de como aplicar e analisar os resultados obtidos nos projetos.

Finalmente, espera-se que o presente trabalho possa contribuir tanto para o meio acadêmico como para o meio profissional, e possa servir de referência para novos estudos, pois neste trabalho, demonstra-se de forma prática, como é calculado o Avanço Físico em um Projeto, pois as literaturas existentes e pesquisadas pelo autor, apenas apresentam o que deve ser feito, ou apenas descrevem os conceitos relacionados ao EVMS. 


\section{REFERÊNCIAS}

BASSO, JOSÉ LUIZ. Engenharia e Análise de Valor - EVA. 1.ed. São Paulo: Instituto IMAM, 1991.

BURKE, RORY. Project Management - Planning \& Control Techniques. $3^{\text {rd }}$ ed.Chichester,England: John Wiley \& Sons LTD, 1999.

CLELAND, I. DAVID \& IRELAND, R. LEWIS. Gerência de Projetos. Reichmann \& Affonso Editores, 2002.

CHRISTENSEN, D. S. Using the Earned Value Cost Management Report to Evaluate the Contractor's Estimate at Completion. Journal of Cost Analysis and Management. P.283-295,1999.

CHRISTENSEN, D.S. The Costs and benefits of earned value management process. Acquisition Review Quarterly, 1998.

DINSMORE, PAUL CAMPBELL, Como se tornar um Profissional em Gerenciamento de Projetos. Qualitymark Editora Ltda, Rio de Janeiro, 2004.

FLEMING, QUENTIN W. KOPPELMAN, JOEL M. Earned Value Body of knowledge. In Annual Project Management Institute / Seminar Symposium, 30, Philadelphia, 1999. Proccedings. Philadelphia: Project Management Institute, 1999.

FLEMING, QUENTIN W. KOPPELMAN, JOEL M. Earned Value Project Management. 2.ed. Newton Square, PA - USA: Project Management Institute, 2000.

FRANK, T. ANBARI. PMI Annual Seminars \& Simposium-Aplications and Extensions of Earned Value Analysis Method.

HARROFF, N.N. Discrete Versus Level of Effort, Milford: NNH Enterprise, 2000.

HELDMAN, KIM. Gerência de Projetos Guia para o exame oficial do PMI. 6.ed. Rio de Janeiro: Elsevier Editora Ltda, 2003.

HUMPHREYS, C. GARY. Earned value management Systems Storyboards - Their Application, Uses, and Benefit. Project Management Institute Annual Seminars \& Symposium, Nashville, Tenn., USA, 2001.

INTERNATIONAL ORGANIZATION FOR STANDARDIZATION. Quality Management Guidelines to quality in project Management. - ISO 10006, 2003. 
KAPLAN, R.S.; ATKINSON, A.A. Advanced management accounting. New Jersey: Prentice Hall, 1989.

KERZNER, HAROLD. Gestão de Projetos. As melhores práticas. 1.ed. Porto Alegre: Bookman Editora, 2002.

MANTINS, ELISEU. Contabilidade e Custos. 9.ed. São Paulo: Editora Atlas, 2003.

MAXIMIANO, ANTONIO CESAR AMARU. Administração de Projetos - Como Transformar idéias em resultados. 2. ed. São Paulo: Editora Atlas, 2002.

MENEZES, LUÍS CÉSAR MOURA. Gestão de Projetos. 2. ed. São Paulo: Editora Atlas, 2003.

MEREDITH, JACK R. \& MANTEL, SAMUEL JR. Project Management: A Managerial Approach. J.Willey and Sons. N. York, 1999.

MERIDITH, JACK R.\& MANTEL, SAMUEL JR. Project Management In Pratice. J.Willey and Sons. N. York, 2001.

MOTTA, REGIS DA ROCHA \& CALÔBA, GUILHERME MARQUES. Análise de Investimentos, Tomada de decisão em Projetos Industriais. 1. ed. São Paulo: Editora Atlas, 2002.

NAKAGAWA, M. ABC. Custeio baseado em atividades. São Paulo: Atlas 1995.

OLIVEIRA, RODRIGO.C.F. Gerenciamento de Projetos e a Aplicação da Análise de Valor Agregado em Grandes Projetos. Dissertação Mestrado. Escola Politécnica da Universidade São Paulo, Depto Engenharia Naval e Oceânica, 2003.

RORY BURKE. Project Management, Planning \& Control Techniques. 4. ed. Burke Publishing, 2003.

SCHULTE, Ruthanne. The Use and Benefits of Earned Value. Welcom. A Welcom White Paper, PA: 2001.

VARGAS, RICARDO VIANA. Valor Agregado em Projetos. 2. ed. Rio de Janeiro: Brasport Livros e Multimídia Ltda, 2003.

WERNKE, RODNEY. Gestão de Custos, Uma abordagem prática. 2. ed. São Paulo: Editora Atlas, 2004.

VERZUH, ERICK. MBA Fast Foreard J.Willey \& Sons. N.York: 1999. 